San Jose State University

SJSU ScholarWorks

Master's Theses

Master's Theses and Graduate Research

Spring 2011

\title{
Academic Writing Development Through Dialogues Between Tutors and Second-language Learners
}

Fabio de Oliveira Coelho

San Jose State University

Follow this and additional works at: https://scholarworks.sjsu.edu/etd_theses

\section{Recommended Citation}

Coelho, Fabio de Oliveira, "Academic Writing Development Through Dialogues Between Tutors and Second-language Learners" (2011). Master's Theses. 3915.

DOI: https://doi.org/10.31979/etd.jndz-j3wp

https://scholarworks.sjsu.edu/etd_theses/3915

This Thesis is brought to you for free and open access by the Master's Theses and Graduate Research at SJSU ScholarWorks. It has been accepted for inclusion in Master's Theses by an authorized administrator of SJSU ScholarWorks. For more information, please contact scholarworks@sjsu.edu. 


\title{
ACADEMIC WRITING DEVELOPMENT \\ THROUGH DIALOGUES BETWEEN TUTORS AND SECOND-LANGUAGE LEARNERS
}

\begin{abstract}
A Thesis
Presented to

The Faculty of the Department of Linguistics and Language Development San José State University

In Partial Fulfillment

of the Requirement for the Degree

Master of Arts
\end{abstract}

by

Fábio de Oliveira Coelho

May 2011 
(C) 2011

Fábio de Oliveira Coelho

ALL RIGHTS RESERVED 
The Designated Thesis Committee Approves the Thesis Titled ACADEMIC WRITING DEVELOPMENT THROUGH DIALOGUES BETWEEN TUTORS AND SECOND-LANGUAGE LEARNERS

by

Fábio de Oliveira Coelho

APPROVED FOR THE DEPARTMENT OF LINGUISTICS \& LANGUAGE DEVELOPMENT

SAN JOSÉ STATE UNIVERSITY

May 2011

Dr. Rosemary Henze Department of Linguistics \& Language Development

Dr. Linda C. Mitchell Department of English \& Comparative Literature

Dr. Soteria Svorou Department of Linguistics \& Language Development 


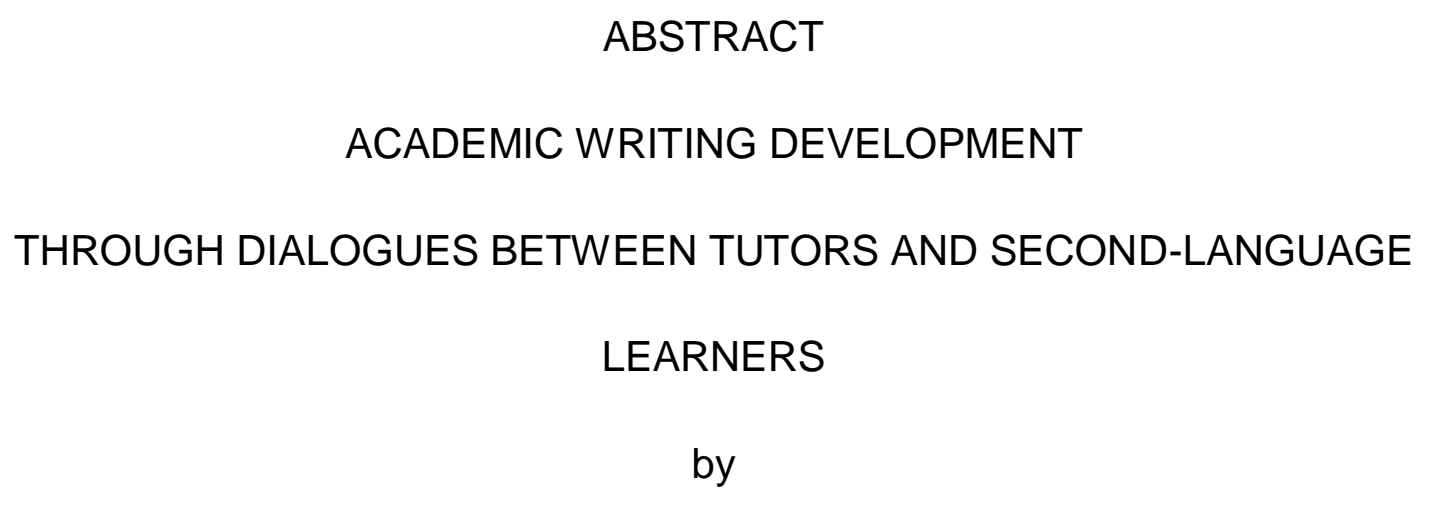

Fábio de Oliveira Coelho

This thesis presents an analysis of dialogues between writing tutors and second-language learners in a writing center setting. The analysis includes a discussion about session appropriation by tutors, the validity of addressing sentence-level mistakes during writing conferences, and strategies that tutors may use to make the sessions beneficial to second-language learners. Among the literature covered throughout the study are studies on Educational Psychology, L1 and L2 Composition, and Cognitive Linguistics (Situated Learning). Collected data include measurements of dialogical patterns in the sessions and qualitative data extracted from session recordings and interviews with interlocutors. Study results suggest that a) sentence-level correction should take place during tutoring sessions involving second-language learners at different stages of the writing process, b) tutors should be explicitly trained in strategies to minimize their session ownership and increase tutee participation time, and c) researchers must look beyond interlocutors' talk time when addressing issues of tutor appropriation. 


\section{ACKNOWLEDGEMENTS}

I would first like to thank all my family: my parents José and Neide, my brother Ricardo, and my sisters Luciana and Fernanda for their never-ending support from far away in Brazil.

I thank my advisor, Dr. Rosemary Henze, for her patience, encouragement, precise comments, and priceless suggestions. My gratitude also goes to thesis committee member Dr. Linda C. Mitchell for being an amazing mentor throughout my graduate degree. I also thank committee member Dr. Roula Svorou for her insights and her never-ending dedication to us students in the Department of Linguistics and Language Development.

I have been fortunate to be surrounded by friends who encourage me to always keep growing. Without their support and advice, I would not have reached this important step. My gratitude goes to all of them. Special thanks to the Puerta San José Team members Rosemary, Linda, Jan, Mayra, and Katie for brightening so many of my days at San José State University.

This thesis is dedicated to all who have worked and continue to work as writing tutors at San José State University. It is also dedicated to all English language learners who have inspired me immensely throughout the time I

worked as a writing tutor. Special thanks to all tutors and tutees that made this study possible through their voluntary participation. 


\section{TABLE OF CONTENTS}

PREFACE

CHAPTER 1 - INTRODUCTION

CHAPTER 2 - REVIEW OF THE LITERATURE

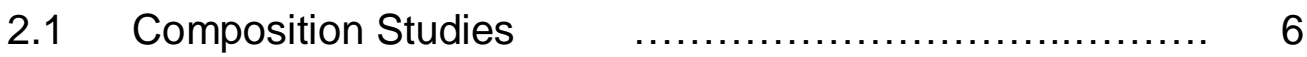

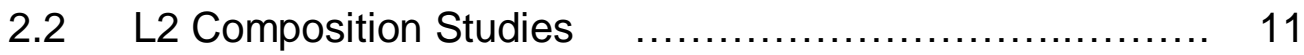

2.3 The Grammar Debate and Alternative Approaches $\quad \ldots . . .15$

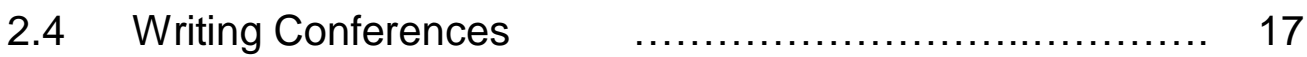

2.5 Benefits of Writing Sessions to L2 Students $\quad \ldots \ldots \ldots \ldots \ldots . . .20$

2.6 Error Correction and the Problem of Transfer $\quad \ldots \ldots \ldots \ldots \ldots .24$

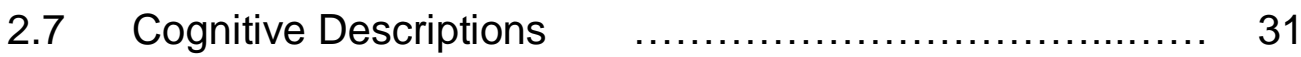

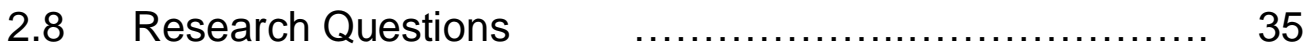

CHAPTER 3 - METHODS

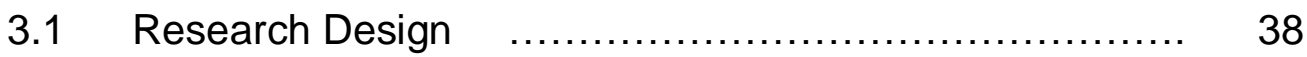

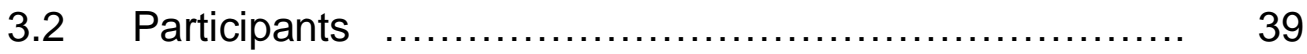

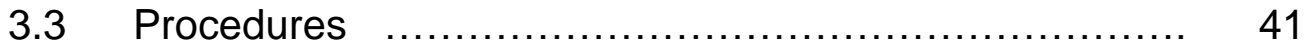

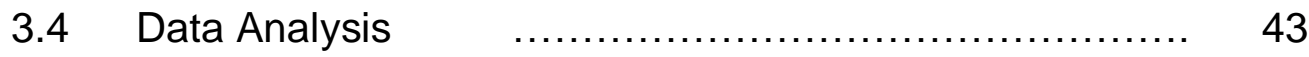

3.5 Overview of Sessions and Participants $\quad . . \ldots \ldots \ldots \ldots \ldots . . . . . . . \quad 44$

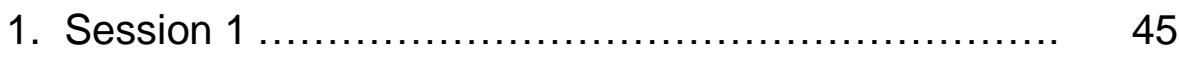

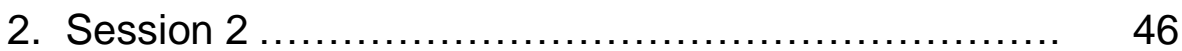

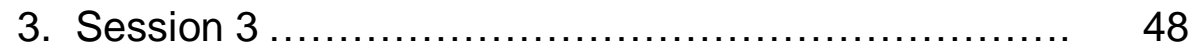

4. Session 4 .......................................... 49 


\section{CHAPTER 4 - RESULTS}

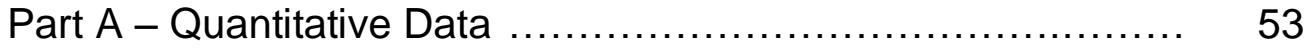

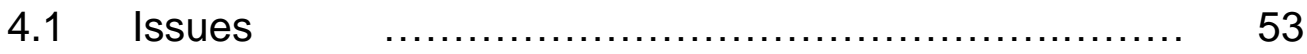

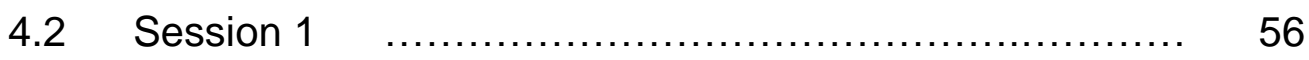

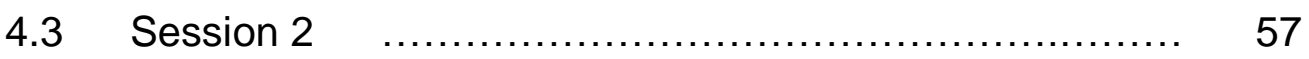

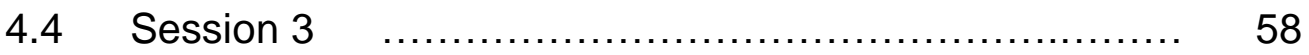

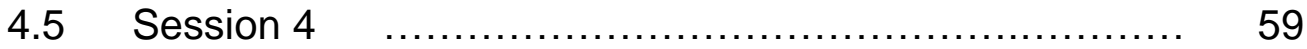

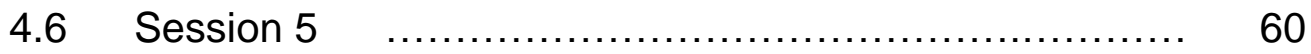

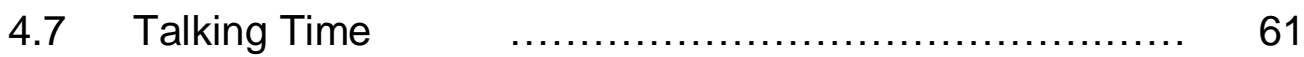

$4.8 \quad$ Use of Deictic Terms $\quad$............................... 64

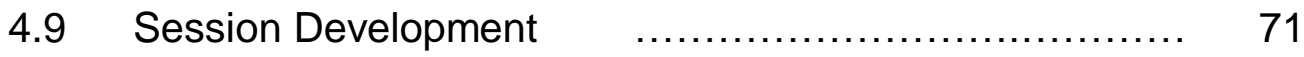

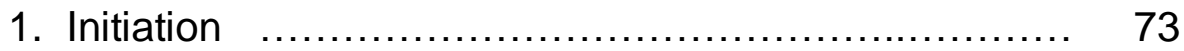

2. Follow-up ............................................. 74

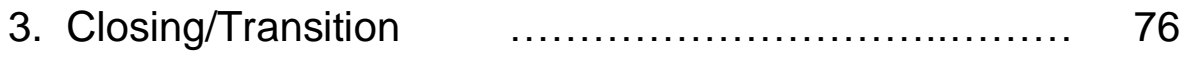

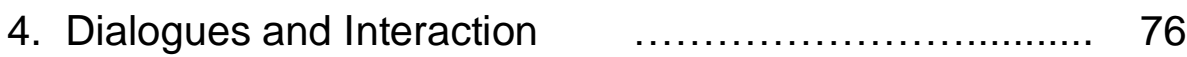

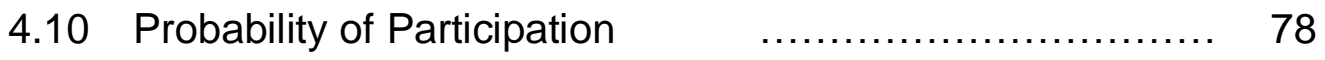

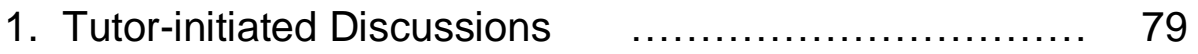

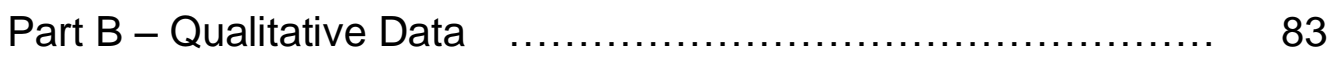

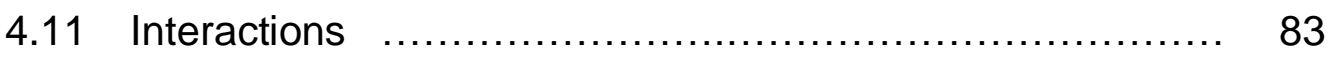

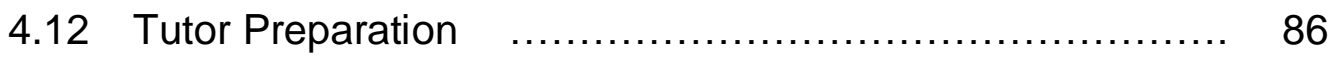

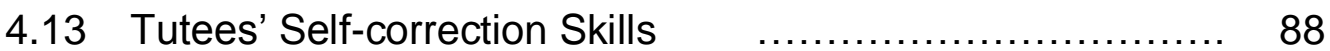

4.14 Session Ownership and Tutee Engagement $\quad \ldots \ldots \ldots \ldots \ldots . . . . \quad 90$

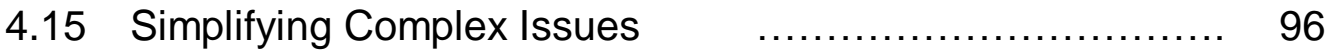




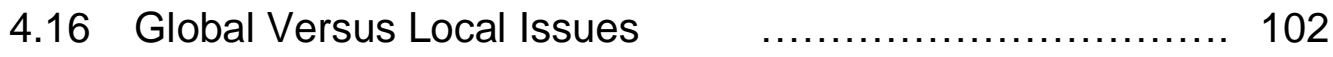

4.17 Grammar Issues as Pathways to Global Issues ............. 110

CHAPTER 5 - DISCUSSION

5.1 Session Ownership and Tutee Engagement $\quad \ldots \ldots \ldots \ldots \ldots . . . .117$

5.2 Addressing Grammar Issues in Tutor-Tutee Conferences 123

5.3 Overall Implications to L2 Writing Development $\quad \ldots \ldots . .126$

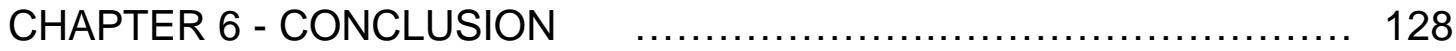

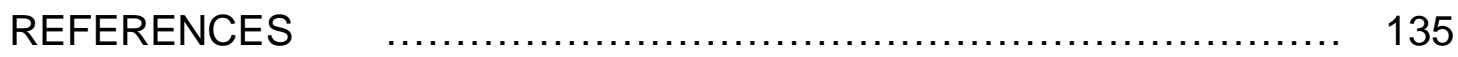

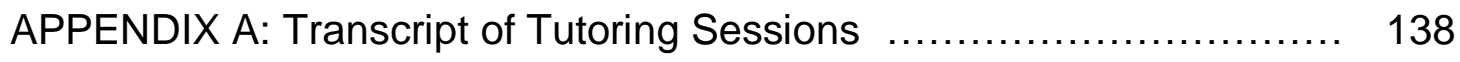

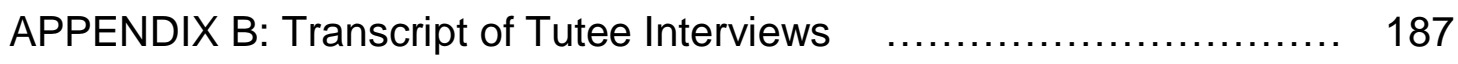

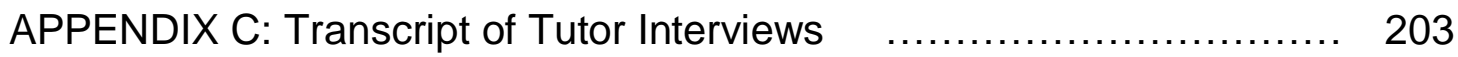

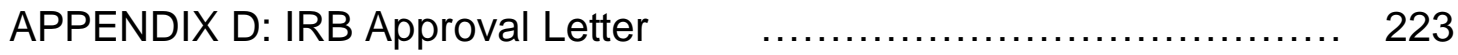




\section{LIST OF FIGURES}

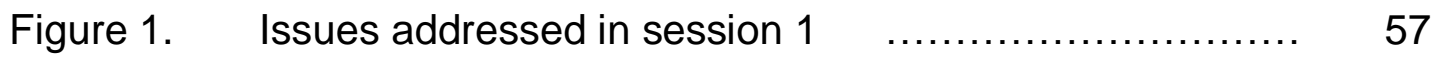

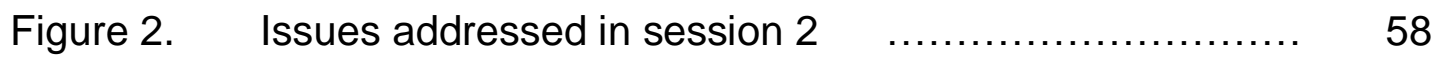

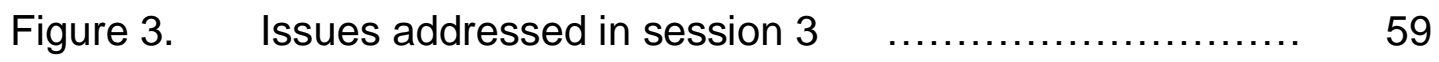

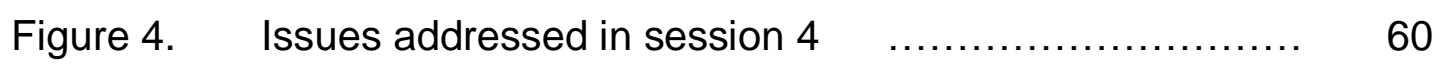

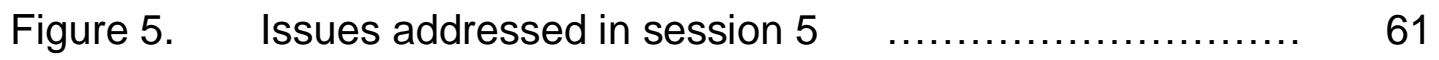

Figure 6. Participants' talk time during sessions $\quad \ldots \ldots \ldots \ldots \ldots \ldots \ldots . \ldots . \ldots . \ldots$

Figure 7. Tutor's use of pronouns and possessives in session $1 \ldots 66$

Figure 8. Tutor's use of pronouns and possessives in session $2 \ldots 66$

Figure 9. Tutor's use of pronouns and possessives in session $3 \ldots 67$

Figure 10. Tutor's use of pronouns and possessives in session $4 \ldots 67$

Figure 11. Tutor's use of pronouns and possessives in session $5 \ldots 68$

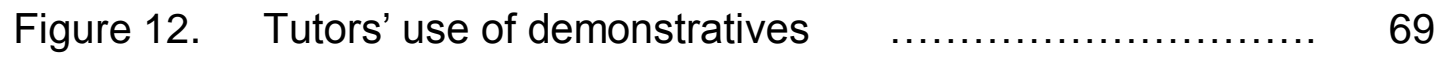

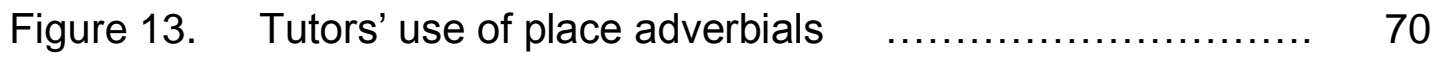

Figure 14. Percentage of initiation types for all sessions $\ldots \ldots \ldots \ldots . . .61$

Figure 15. Interlocutor participation triggered by initiation types $\ldots . \quad 82$ 


\section{LIST OF TABLES}

Table 1. Breakdown of issues addressed in each tutoring session 55

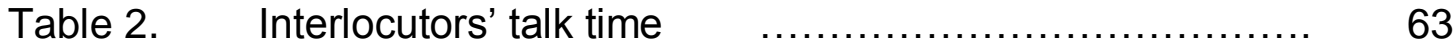

Table 3. Tutors' use of personal pronouns and possessive adjectives 65

Table 4. Number of initiations by interlocutor in each session $\quad \ldots \quad 74$

Table 5. Number of follow-ups by interlocutor in each session $\ldots . \quad 75$

Table 6. Number of closings by interlocutor in each session $\quad \ldots \quad 76$

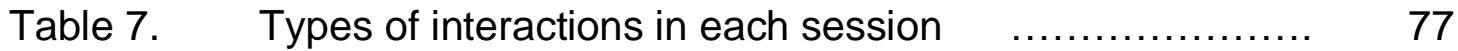

Table 8. Follow-ups to initiation types broken down by interlocutor 79

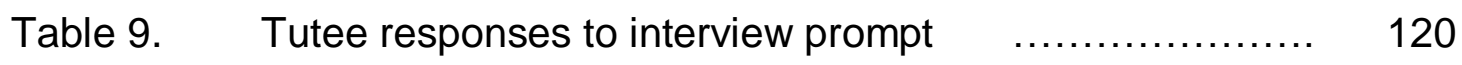

Table 10. Tutee responses to interview prompt $\quad \ldots \ldots \ldots \ldots \ldots \ldots \ldots . . . . \ldots . . .120$ 


\section{Preface}

One year after I joined the MA program in Linguistics at San José State University (SJSU), I started working as an academic writing tutor at the university's Language Development Center (LDC). The LDC serves freshmen who, upon entrance to SJSU, enroll in classes to improve their basic academic writing skills. At the LDC, many freshmen are students who have learned English either as a second language (ESL) or, like myself, as a foreign language (EFL).

I completed both my K-12 and undergraduate studies in Brazil, where the only language of instruction was Portuguese. Later, as a writer in a US university setting, I also faced challenges to become a successful writer. Therefore, I felt that by working as a tutor I could assist the LDC freshmen as they improved their academic English writing skills. My previous experience also empowered me to reflect on the stages of my own development as an English writer and a graduate student. Having walked a similar path as an English learner, I felt I could easily understand the students' frustrations and assist them in becoming better writers.

I worked as a tutor at the LDC for three semesters before I started working at the San José State University (SJSU) Writing Center, where this study was eventually conceived and conducted. At the Writing Center, I began tutoring native speakers of English and English learners attending not only undergraduate, but also graduate courses across the university. As a more 
experienced tutor (Writing Specialist), I became fascinated by the potential of tutor-tutee interactions.

While I felt the SJSU Writing Center training program prepared us tutors to work effectively with English learners, I did not develop as high an opinion about some of the literature on academic writing available to tutors and tutees, mainly scholarly papers and writing guides. These, for the most part, fail to address the needs of non-native English writers, and in general they do not acknowledge the linguistic or cultural importance of the tutor-tutee relationship, particularly that of tutors and English learners. Some writing guides do address issues of English language development by non-native students, but in separated chapters or merely in brief notes across the main units. Some of these papers and guides also opted for a top-down pedagogical approach to the sessions that did not match the work we did at the SJSU Writing Center. Few of them proposed tutoring techniques originated from concerns put forth by the second- and foreign-language learners themselves. ${ }^{1}$

Having encountered a scenario where some of the main linguistic and cultural needs of English learners remain unmet, my experiences as an English learner, a writing tutor, and a graduate student in Linguistics naturally led me to inquire how tutor/tutee conferences can contribute to meeting the academic writing needs English learners more effectively. These reflections led me to questions that guided this study.

${ }^{1}$ For a list of publications that address the needs of English learners, please see the References section. 


\section{Chapter 1 - Introduction}

The relatively small number of studies on EFL and ESL (L2) writing development, compared to English-only (L1) composition studies, makes it difficult for the writing teacher to know what works or not when addressing their

L2 students' writing problems. In fact, most researchers still debate on what the main components of effective writing feedback for English Learners may be. Written commentary, teacher-student conferences, peer conferences, and writing center tutor-tutee conferences are the most common strategies teachers and students resort to, while university writing programs in general opt to use a combination of these.

The student population surveyed or included in the available studies is also far from homogeneous. Earlier studies, and some more recent ones, ignore L2 students altogether, while most recent quantitative studies on the L2 population are either too narrow or have not included a significant number of participants and/or variables, thus giving their suggestions limited applicability. This uncertain scenario leaves a lot of room for ideological biases, as for instance in the case of grammar correction, fiercely opposed by some instructors and strongly defended by others, in the absence of comprehensive studies on the topic.

A growing body of research suggests that L2 students need assistance with writing development in several domains of writing concurrently (Powers and 
Nelson, 1995; Ferris, 2002 and 2003), and the treatment of these domains may need to occur in a different sequence than that of L1 students. However, this differentiation is not yet the practice in many writing courses, mainly because teachers claim research has not been conclusive on any major point when it comes to working with L2 students. This scenario leaves a lot of room for teachers to apply what they know works for L1 students to the L2 student population. The problem is even more aggravated because many studies in the fields of L1 and L2 composition are conducted in isolation, making writing instructors unsure about how the interplay between L1 and L2 may affect the academic writing development of ELs in their classes. In fact, very few articles I surveyed acknowledged or made explicit references to other studies in bilingualism.

In order to understand the current stage of studies on L2 writing development, it is important to trace back the history of L2 composition research, the issues researchers have raised in the past concerning writing development, and the role that these studies play in guiding instructional practice these days. Equally important are L2 students' opinions about what they need as writers, an area not yet thoroughly explored by most research in the field, with a few more recent exceptions (see Ferris 2002, 2003, and 2009).

This thesis is a reflection on the dialogues between writing tutors and their L2 tutees in a public university writing center setting. By using these dialogues as a starting point for my analysis, I was able to highlight several issues 
proposed by the interlocutors themselves - that is, students and tutors - and their implications for L2 writing development. I aimed to use the elements in these dialogues as a starting point for my reflection, and I also contrasted what interlocutors wish with what researchers traditionally recommend.

The study is presented in the following five chapters: Chapter 2 consists of a review of the literature in the field of composition studies, pedagogy, and situated learning. These theoretical approaches helped me select the methods and tools for my analysis, presented in Chapter 3, along with the overall research design. Chapters 4 and 5 present the study results and their discussion, respectively, and they are followed by my conclusions in Chapter 6 .

Since the study focuses on L2 academic English writing, all language learners I refer to, either those who participated in the research or others mentioned in the literature, are learners of English either as a second or a foreign language. Throughout the text, I use the acronyms L1 and $L 2$ to refer to students' first language and second language(s), respectively. I also refer to L2 students as English learners or ELs. 


\section{Chapter 2 - Review of the Literature}

\subsection{Composition Studies}

Among the problems researchers have raised as to how to approach student writing development and teacher feedback in the last three decades, two still remain particularly controversial. The first issue concerns the nature of teacher commentary on student writing, and the second addresses the ways the teacher can engage in a feedback session with the student without appropriating his or her text. These two problems were raised in a 1982 issue of the journal College Composition and Communication, which published the articles "Responding to Student Writing," by Nancy Sommers and "On Student's Rights to Their Own Texts: A Model for Teacher Response," by Lil Brannon and C.H. Knoblauch. The views expressed in these twin articles have shaped much of the discussion in the field since their publication, and they have also affected teacher training and pedagogy very strongly: "For instance, since the mid-1980's, most Composition teachers in the United States have been trained to give feedback on content on first drafts and save responses about grammar, word choice, or mechanics for the penultimate draft (following Sommers) and to avoid "teacherly" responses by asking questions rather than issuing directives (following Brannon and Knoblauch)" (Ferris, 2003, p.7). The type of teacher commentary both articles refer to is written; also, when these articles were published, their authors did not address differences between L1 and L2 students. 
In "Responding to Student writing," Nancy Sommers argues that the main pedagogical role of teacher commentary is to help students take a reader's perspective:

We comment on student writing to dramatize the presence of a reader, to help our students to become that questioning reader themselves, because, ultimately, we believe that becoming such a reader will help them to evaluate what they have written and develop control over their writing. (p. 148)

Nevertheless, the author claims to have found (through her research on the commenting styles of 35 teachers at New York University and The University of Oklahoma) that teachers' comments are mostly framed to take students' attention away from their own texts and that most teachers' comments are too general (Sommers, 1982). She also pointed out that a significant number of comments lacked strategies for students to fix the highlighted problems. Despite her criticism, Sommers did not discredit the value of feedback: "Without comments from readers, students assume that their writing has communicated their meaning and perceive no need for revising the substance of their text" ( $p$. 149). Rather, she questions the type and content of teacher commentary. In "On Student's Rights to Their Own Texts: A Model for Teacher Response," Brannon and Knoblauch claim that the normal connection between a writer and a reader is substantially changed in a teacher-student relationship, to the point that it may harm students. Teacher comments, according to the 
authors, show that the "teachers' agenda is more important than their [the students'] own" (1982, p.158). The authors also state that "the teacher more often than the student determines what the writing will be about, the form it will take and the criteria that will determine its success" (p. 158). As a solution, they believe that the interaction between teachers and students should focus on the relationship between the writer's intention and the effect of what he or she wrote on his or her readers. They also suggest teachers use multiple-draft assignments, a practice widely adopted these days, for it is believed to offer more opportunities for teacher and student to engage in a dialogue about the latter's text. Brannon and Knoblauch's conclusions echo Sommers's belief that the issue is not the feedback itself, which developing writers need, but its content and goal: "In other words, the teacher's proper role is not to tell the student explicitly what to do but rather to serve as a sounding-board enabling the writer to see confusions in the text and encouraging the writer to explore alternatives that he or she may not have considered" (p. 162).

Despite their influential conclusions, these two articles have been criticized for lacking details on the methodologies the researchers used to obtain their results (Ferris, 2003). The articles themselves offer no information on the methods used to reach their conclusions. Also, their concerns originated at a time when the distinction between L1 and L2 writing development was very tenuously made or even ignored in most research, which leaves instructors of L2 students (or of classes in which L1 and L2 students are mixed) unsure of which 
conclusions may or may not apply to their students. Additionally, some of the affirmations in the articles have also been questioned, such as the one by Brannon and Knoblauch that students' intentions override the importance of the finished product. Ferris (2003), for instance, highlights that the authors' philosophical assumption "that student writers in a composition class are primarily motivated by the need to communicate or express their ideas" may be a bit naïve to be accepted by writing instructors, who identify their students' primary motivation as the "will to achieve a good grade and to learn to write successfully for other writing courses" (p. 8).

But again, despite highlighting the apparent inefficacy of teacher commentary, the authors do not advocate for teachers to abolish the practice. What they recommend is that commentaries be of a more engaging nature. Sommers (1982) firmly states:

Instead of finding errors or showing students how to patch up parts of their texts, we need to sabotage our students' conviction that the drafts they have written are complete and coherent. Our comments need to offer students revision tasks of a different order of complexity and sophistication from the ones that they themselves identify, by forcing students back into the chaos, back to the point where they are shaping and reconstructing their meaning. (p. 154)

Brannon and Knoblauch (1982), on the other hand, advise: 
By negotiating those [textual] changes, rather than dictating them, the teacher returns control of the writing to the student. (p. 166)

A later development of the issues proposed by Sommers and Brannon and Knoblauch appeared in Richard Straub's 1997 article "Students' Reactions to Teacher Commentary: An Exploratory Study." Straub surveyed 172 freshmen at a large state university in the United States. Even though he conducted his study at a time when most research already acknowledged differences in writing development between L1 and L2 student populations, Straub chose not to explore this distinction in his study design. In the survey to which his subjects responded, they indicated the types of teacher comments that they preferred. The results, in order of preference, were advisory, praise, open question, closed question, imperative, and criticism. Students also indicated they preferred comments that were clear, specific, and pointed out problems and solutions. Students were particularly "sensitive about comments on the quality of their ideas and resisted comments that deal with matters that go beyond the scope of the ideas they have on the page" (Straub, 1997, p.111). This indicates, according to the author, that students did not welcome instances of teacher appropriation, even though more recent studies have indicated that what constitutes an issue of appropriation to L1 students may not be perceived as such by the L2 student population (Ferris, 2003). One of the great merits of Straub's study is that, unlike most studies at the time, it considered the students' own opinions about the comments teachers left on their papers. 
The articles by Sommers and Brannon and Knoblauch do, in fact, remind teachers to be more conscious of imposing their will on their students' texts through their commentary, and they also engage teachers in thinking about the types of comments they should reserve for each draft. However, if instructors are encouraged to dismiss error correction altogether, students may be prevented from developing control over more complex issues of syntax and style. This approach may be particularly harmful to L2 students, since most instructors who teach L2 students have been trained mostly in L1 writing development and may be applying the authors' suggestions without distinguishing among students and their needs. Also, Sommers does not explain how negotiation can be achieved (and how appropriation can be avoided) if students' main requests and needs are to be "sabotaged" or simply not addressed.

\subsection{L2 Composition Studies}

The late 80 's saw a significant rise in the number of $L 2$ students attending US universities. Concerned that the conclusions from earlier writing development studies did not apply to this growing L2 population, researchers either began to design studies that directly compared L1 and L2 student populations or developed other studies focused solely on L2 students. The results began to show marked differences among the writing needs of native speakers of English and English learners. Silva (1993) compared reports from several studies contrasting L1 and L2 students and/or English as Second 
Language (ESL) students and Native Speakers of English (NES). He summarizes his findings as follows:

Though the composition process patterns are similar in L1 and L2, it is clear that L2 composition is more constrained, more difficult, and less effective. L2 writers did less planning (global and local) and had more difficulty with setting goals and generating and organizing material. Their transcribing was more laborious, less fluent, and less productive perhaps reflecting a lack of lexical resources. They reviewed, reread, and reflected on their written texts less, revised more - but with more difficulty and were less able to revise intuitively (i.e., "by ear"). (p. 668)

Silva also found that fluency, accuracy, and effectiveness were lower in L2 writing overall. However, the author was unable to provide clear information on the subjects' ages and levels of English. The information he provided on the students surveyed in the several studies he collected was broad and generic; for instance, he stated that their educational levels ranged from high school to postgraduate, they possessed fairly advanced levels of English proficiency, and their writing abilities ranged widely (Silva, 1993). Nevertheless, this did not prevent Silva from sending a clear message for instructors that "L2 writing is strategically, rhetorically, and linguistically different in important ways from L1 writing" (p. 669). Silva's conclusions suggest teachers look beyond L1 theories for guidance on how to meet the needs of L2 students. 
Another important study comparing L1 and L2 student populations was conducted by Powers and Nelson (1995), who sent out a survey to writing centers at 75 graduate institutions across the United States. The survey included questions that ranged from how writing centers were staffed to what types of students they served. Results show that writing centers in general struggled to train a constantly changing staff on how to meet the needs of $L 2$ students. Powers and Nelson's study indicates that writing center conferences (or tutoring sessions) tailored to L2 students require that tutors demonstrate a higher ability to adapt tutoring strategies than do L1 conferences. That is because L2 students may bring cultural, rhetorical, and linguistic backgrounds to conferences that tutors may not be familiar with. L2 conferencing also requires that tutors exercise a significantly higher degree of individualized judgment. Powers and Nelson list three aspects of writing center conferencing they consider valuable to L2 students: 1) conferencing is individualized; 2) conferencing can function developmentally; and 3) conferencing staff can function as cultural informants, decoders, and ombudspersons to help students and faculty bridge the gap between L1 and L2 writing contexts (Powers and Nelson, 1995).

Later in the 90's, the design of the research on L2 writing improved overall. Besides asking whether or not teacher commentary was helpful, researchers then also sought to find out what types of teacher approaches to L2 student writing might or not be helpful and why. They also designed studies that gave more importance to students' personal opinions and reactions, a feature 
already highlighted in Straub's (1997) study, as opposed to just looking at teacher's comments on final drafts.

An important body of research on L2 writing development has been produced by Ferris (2002, 2003, and 2009), who not only stressed methodological flaws and sometimes insufficiently supported conclusions from previous studies, but also denounced their rush to judgment (Ferris, 1999). Concerned that teachers and instructors may lack the preparation they need to effectively address issues of academic writing development affecting L2 students, in the last two decades Ferris has conducted and participated in numerous studies (Ferris, 1997; Ferris et al, 2000; Ferris and Roberts, 2001). Ferris's conclusions have served to guide teachers and help them plan activities, design courses, and offer appropriate feedback to students. One issue she urges teachers to consider when providing feedback to students is that of the efficacy/inefficacy of grammar feedback. Ferris co-led a study that included 53 ESL writers who received error feedback. Results show these students were able to self correct about $60-64 \%$ of the errors marked during a 20 -minute editing session (Ferris and Roberts, 2001, as cited in Ferris, 2002). While these studies may not fully answer the question of grammar efficacy, they do highlight that error correction can benefit students when done by well-prepared teachers. 


\subsection{The Grammar Debate and Alternative Approaches}

The issue of whether or not grammar correction is beneficial to L2 students gained momentum in the 1990's. In 1996, John Truscott published "The case against grammar correction in L2 writing classes" in which he stated that error correction is not only ineffective, but harmful to L2 students and therefore should be abolished. Truscott blames the "information transfer view of learning" (or the belief that knowledge can be transferred from teacher to learner) for the pervasiveness of the "dubious intuition that correction must simply be effective" (p.357). He makes this strong statement in a section of his paper titled "There is No Reason to Correct Grammar Errors." Truscott's main self-declared opponent is Ferris, who in 1999 published a response to his 1996 paper. In summary, Ferris claims that "judicious and well-executed teacher feedback" can help students (1999, p.7). In summary, Ferris believes that the grammar error correction can be beneficial if done well and with a clear purpose to students. Another point these two researchers disagree on concerns which direction to pursue after the debate. While Truscott believes we should just abandon the practice altogether, for "no amount of research could ever remove all possible ambiguity about the ineffectiveness of a teaching practice" (1996, p.357), Ferris claims that we do not only need more longitudinal studies, but that these studies also need to be better articulated with existing studies on L1 writing development. The very existence of these two extremes on such an important issue 
demonstrates the lack of a clear direction for instructors, most of whom teach classes where L1 and L2 students are mixed.

While Ferris also acknowledges that we have a long way to go in order to find clearer guidelines for L2 teachers and students (2004), she believes that our knowledge so far about writing development, second language acquisition, and other related fields allows for the following predictions: 1) that adult language acquirers may fossilize errors, if not corrected; 2) that students who receive feedback are more likely to self correct than those who do not; and 3) that students actually appreciate feedback on their grammar errors, thus serving as motivation for their writing development. Despite the lack of consensus, most proponents and opponents of error correction seem to agree on the difficulties of L2 writing, which include students' lexical and syntactic limitations, problems with text organization, limited knowledge about the subject matter due to cultural differences, and lack of prior composition training (Ferris and Hedgcock, 2005).

As L2 instructors started to realize that approaches traditionally applied to L1 writing development could not necessarily be transferred to L2 students, a certain distance emerged between two fields that could benefit from stronger collaboration. One of the main questions regarding L2 writing development relates to the transfer issue (or how much knowledge or information can transfer from one domain to another), since researchers do not know for sure whether certain elements from students' native-language writing skills (when they have developed these) actually transfer to their academic English writing skills. Silva 
(1993) claims to have found some evidence pointing to transfer of rhetorical strategies across languages, but the evidence is far from conclusive. More recent studies on L2 writing development have emphasized strategies to address the needs of English learners specifically. Some of these strategies actually emerged from the increasing disbelief in the efficacy of written teacher commentary from L1 composition studies, which has served to motivate L2 composition researchers to explore alternatives or complements to written feedback. Two such strategies are teacher-student conferences and peer feedback. They have not necessarily replaced written commentary; instead, different types of feedback coexist, and each is used to a different degree across writing courses, depending on the makeup of the class and the experience of the teacher. However, initial results about L2 teacher-student and peer conferencing were far from encouraging.

\subsection{Writing Conferences}

Early literature on L1 teacher-student conferences was quick to conclude that conferencing triggers higher input from students: conferences enable students to set the agenda, make their needs known, express their ideas and opinions, and ask questions to clarify meaning (Carnicelli, 1980 and Zamel, 1985, as cited in Goldstein and Conrad, 1990). However, these results did not hold true for later research on L2 writers (Goldstein and Conrad, 1990). Goldstein and Conrad analyzed teacher-student conferences involving three 
different L2 writers and the same instructors. They also compared the drafts before and after the conferences and tried to identify changes that were negotiated during the conferences and later made to the paper. Whenever negotiation occurred, the authors did find evidence of more successful revisions. However, they found that conferences do not necessarily result in greater student input or participation in dialogue. The authors attribute the difference between their results and those of previous studies to a few factors: their focus on L2 and not L1 students, differences in personality among students, and cultural differences involving the role of teachers and students in dialogues. They also highlight the importance of determining which discourse characteristics actually translate into better revisions and student learning.

With more promising results, Patthey-Chavez and Ferris (1997) also investigated the effects of conferences on student writing and concluded that, to varying degrees, all eight students who participated in their study made changes to their papers that could be traced back to the conferences in which they had participated. The researchers also found that teachers tended to dominate conferences with "weaker" students, while "stronger" students had a more prominent role in the dialogue. Weaker students were those who took little initiative during the sessions, and "they tended instead to play receptive audience to the teacher" (p.61). For the most part, weaker students uttered short sentences and had high levels of back-channel-cues (i.e., uh-hum, yeah, right) in their talk. Stronger students were those who behaved in an opposite fashion: 
they showed initiative and displayed engagement (p. 63). In the authors' view, these conferences are an important "pedagogical tool", and the "qualitative and quantitative" differences they display should be expected and interpreted as evidence that the teacher is adapting to different students. As to the differences between stronger and weaker students, the authors could not conclude whether the more active roles of the former can be explained by their attitudes or by their teachers' approaches. They suggest that looking at the drafts brought by the stronger students may offer some answers to the differences in participation, since the papers frame, to a certain extent, what will be addressed during the session.

In the book Response to Student Writing, Ferris (2003) also reviewed substantial literature on peer response, mostly on studies conducted in the 80's and 90's. These studies seem to agree, with a few exceptions, that peer response is a beneficial pedagogical tool in L2 academic writing development, but that "the odds of peer feedback being beneficial appear to improve even more if students are carefully trained in advance of the peer response task." Overall, students' feelings about giving and receiving feedback were also reported as positive. One such study conducted by Zang (1995, as cited in Ferris, 2003) surveyed 81 students and found that students mostly prefer teacher feedback to non-teacher feedback (94\%) and peer feedback to self-directed feedback (61\%). Peer feedback is defined as feedback from other fellow students and not trained writing tutors. 
As more of these L2 composition studies emerge and give voice to L2 students, we start to understand what these students expect and want from writing courses and their instructors. These studies have also helped gradually change the views of teachers whose practices were informed mostly by L1 writing development theory. For example, the view that error correction does little or nothing to help students has started to be seriously questioned, as well as the notion that it should only be left to the last stages of revision (Ferris, 2003). More research, however, is needed in the areas of peer review and teacherstudent conferences, for these may constitute key moments for L2 students to engage in dialogues either with peers or instructors about their own texts.

\subsection{Benefits of Writing Sessions for L2 Students}

From about the 1930's to the 1970's, writing centers across the country were regarded as centers for remediation and unique spaces, separate from the classroom, for students to work on their writing. As composition theory shifted from product- to process-based, this change also affected the way writing centers operate, causing them to turn from places where papers were merely fixed to resources where collaborative approaches to instruction were tested and used (Williams and Severino, 2004). The benefits of a tutor-tutee relationship have always been widely recognized in the composition literature because this interaction creates a powerful context from which to address writing issues. However, as quick as researchers were to address the advantages of using 
models of writing center peer tutoring, until the mid-90's writing center research ignored L2 learners altogether.

Also drawn into the discussions of teacher appropriation and the nature of teacher-commentary, writing center directors quickly identified the advantages of these centers to help minimize the harmful effects of these problems: in a writing center, work on papers is supposed to be done collaboratively, and the tutor's goal is never to edit or proofread, but to engage the tutee in discussions about his or her text or patterns of mistake. The emergence of $L 2$ writing development studies in the 90's also contributed suggestions as to how writing centers could better help L2 writers: tutors needed to be more flexible, be aware of crosscultural differences, know typical L2 error profiles, and understand contrastive rhetoric and its implications for student writing. However, these and many other suggested approaches to L2 tutoring are yet to be validated by substantial research.

Perhaps the greatest contribution of writing centers has been the development of a format of peer tutoring different from the one used in classroom settings. Although still peers, writing center tutors are usually trained in basic pedagogical skills; they have not only mastered the basics of college composition themselves, but are also able to engage tutees in either a general conversation about a paper's content, in a dialogue about sentence-level issues, or both. Tutors may also play an important role helping tutees make sense of writing requirements and expectations at the college level (Powers and Nelson, 1995). 
In many writing centers across the US, including the SJSU Writing Center, the tutees are the ones who take the initiative to look for help and schedule the sessions. This practice at the very least forces them to think about what it is they want to accomplish during the tutoring session and what kind of help to ask for.

The main theoretical framework cited to support the practice of peertutoring, as it is done in most writing centers, is Vygotsky's concept of Zone of Proximal Development (ZPD). Vygotsky claimed that although learning should be matched in some manner with the learner's developmental level, we must in reality determine at least two of these developmental levels: the actual development level and the level of potential development. Therefore, what the author terms ZPD is "the distance between the actual development level as determined by independent problem solving and the level of potential development as determined through problem solving under adult guidance [in reference to children's learning] or in collaboration with more capable peers" (Vygotsky, 1978, p. 86). To determine a learner's ZPD, Vygotsky suggests giving the learner a task and observing whether she or he will perform it on their own. If so, this may be an indication that certain functions have matured. Reaching that last stage of independently accomplishing the task equals determining the learner's actual developmental level. The zone of proximal development defines the "functions that have not yet matured but are in the process of maturation" (p. 86). These functions, however, would be accomplished with the support of a more experienced guide. 
The dynamics of a writing center conference may play out in a way similar to what has been described above (Patthey-Chavez and Ferris, 1997), although variations from the theoretical framework proposed by Vygotsky should be expected, depending on the players at stake. Vygotsky's concept of ZPD, along with the related concept of scaffolding (the expert's action of progressively engaging the novice to solve a problem), have appeared in studies that investigate the nature of the discourse between tutors and tutees in writing center conferences. For instance, Ewert conducted a study (2009) in which she states that scaffolding has been observed in peer discussions and that one would expect a higher degree of it in L2 writing conferences with less proficient learners. Ewert also claims that the qualitative features of a writing conference emerge when scaffolding is used along with negotiation - conversation management. In her analysis of tutoring sessions involving two ESL teachers and six international students at an intensive language program, the author concluded that "more negotiation around fewer topics may lead to successful revisions and learning" and that "conferences that focus almost entirely on content and rhetorical issues promote more learner participation" (p. 268).

Another reference to ZPD appears in a study by Ferris and PattheyChavez (1997) of sessions among six international students and two native speakers (tutees) and four composition teachers and one graduate student (tutors). As they lay out the theoretical background for their study, the authors (1997) report: 
Conferencing presents a classic example of a teacher-led ZPD:

An expert meets with a novice to address a given task, guiding the novice toward performing the task independently. Knowledge is externalized, mediated through language and action, for both the satisfactory resolution of the immediate task at hand and to give the novice multiple opportunities to acquire that knowledge. (p. 52)

Upon reading the quote above, one would expect the command of the session to slowly transition from tutor to tutee, which is an ideal scenario, but not always the case. Most studies on writing center conferencing indicate a much higher amount of teacher or tutor talk, and this is probably a result of the higher control or power held by the tutor, the expert and the facilitator of the session. But even though talk time plays a major role in describing a productive session, I believe it should not be the only or main variable to be considered. Other variables such as agenda setting power, information held by each interlocutor, and the tutee's goal for the conference should be also taken into account when addressing issues of power between session participants.

\subsection{Error Correction and the Problem of Transfer}

Since studies on teacher feedback have yet to provide strong evidence that grammar correction translates into better papers (or not), some researchers have capitalized on this uncertainty to justify either the adoption or the abandonment of text-level revisions. Those who defend grammar correction 
point to teacher intuitions, student preferences, and studies that show correlation between error correction and better papers. The ones against it believe the lack of evidence itself is enough to persuade teachers to abandon text-level correction altogether.

In this study, even though error correction took place in tutoring sessions and not as written commentary, which is what some of the researchers suggest is ineffective, all participating tutees chose grammar revision as the focus of their sessions. So, if error correction is ineffective in written form, does the mere change of format make it effective? If not, are tutors (and tutees) mistaken? Truscott may suggest they are when he states: "Teachers should not expect grammar correction to work. Teaching practices that rely on transfer of knowledge, without any concern for the processes underlying the development of the language system, are not promising" (1996, p. 343). Therefore, underlying the problem of error correction is the issue of how much transfer is actually possible within a domain of knowledge or across different contexts or domains; that is, if a teacher shows the student how to correct mistakes in a paper, and the student successfully does so throughout the rest of his or her text, does this guarantee that the student will be able to identify similar errors and correct them autonomously in the future? Again, Truscott does not believe so, which raises another question pertinent to this investigation: Since tutors in the sessions recorded engage in error correction with their tutees, does that necessarily imply these tutors are putting all their bets on knowledge transfer? 
Knowledge or information transfer, in addition to being heavily discussed in the cognitive sciences, has been a central concept to developing new approaches to teaching. In the process of defining ZPD, Vygotsky (1978) also addressed the issue:

Learning does not alter our overall ability to focus attention but rather develops various abilities to focus attention on a variety of things. According to this view, special training affects overall development only when its elements, material, and processes are similar across specific domains; habit governs us. This leads to the conclusion that because each activity depends on the material with which it operates, the development of consciousness is the development of a set of particular, independent capabilities or of a set of particular habits. Improvement of one function of consciousness or one aspect of its activity can affect the development of another only to the extent that there are elements common to both functions and activities. (p. 83)

As the quote above suggests, Vygotsky already seemed to recognize the impossibility of full transfer, but he did believe it was possible to some extent. More recently, the issue of how much knowledge can transfer between domains has also been the focus of studies on situated cognition, a theoretical framework that claims that "knowledge is not a thing or set of descriptions or collections of facts and rules" and that "human knowledge should be viewed as a capacity to coordinate and sequence behavior, to adapt dynamically to changing 
circumstances" (Clancey, 1995, p. 49). As we learn, we conceive new activities, which are inherently social. Thus, in this perspective, when we speak of learning, we also have to address issues of identity, membership, and participation in a community.

Part of the emphasis situated cognition places on the setting or social context in which learning occurs comes from classic studies in which learners taught how to solve problems in one context could not apply the same solution to similar problems in similar contexts. Hayes and Simon (as cited in Clancey, 1995) found that participants were unable to solve a second similar problem (puzzle) when they had already solved the first. This and other experiments led the researchers to conclude that it is imperative to teach analogical reasoning skills explicitly. Lave (as cited in Clancey, 1995) also led a study in which participants had to figure out best-buy calculations at a supermarket and then solve a math problem using very similar reasoning skills. She concluded that real-life experience did not transfer to school work.

Clancey criticizes Lave for assuming that theoretical generalizations (descriptions or maps of solving problems) could be useful in multiple settings. He claims that a theory, like any map, must be interpreted for the problems at hand, especially because, from a neuropsychological perspective, the context is never the same. In fact, the term "situated itself means that neural organizations arise in the course of activity, they are always new, they are not retrieved from storage" (Clancey, 1991, p. 110). In order to address the issue of conceptual 
organizers, one needs to also talk about the brain and how it functions:

"conceptual organizers do get reused, but they are always adapted" (p. 110).

Clancey believes transfer takes place more or less, depending on the perceptual similarity and social interaction activity of the new setting.

The mistake Truscott makes in his statement mirrors the one Clancey points out in Lave's study. By correcting errors during a writing session, tutors do not necessarily assume the same errors will automatically disappear in subsequent papers. On the contrary, tutors may address the issue several times because they may be aware mastering the target language requires a certain degree of repetition: revisiting issues and re-explaining concepts. By correcting the same errors on different occasions and contexts, students may eventually reactivate and reuse their conceptual organizers.

In Clancey's words, what remains from each interaction (in this case, a writing session) is a map, and not the whole territory; that is, the experience of finding and fixing errors and not an infallible formula for error correction. These individual experiences, along with other experiences tutees have had or will have, will hopefully get cognitively reactivated and connected to new ones as they continue to evolve as academic writers and find similarities among contexts. This reactivation will depend not only on the similarity or dissimilarity of future writing tasks, but also on issues of timing, social role, place, interaction, power relations, and many others that affect educators or tutors and their students or tutees. 
These reflections are of great importance to the context of $L 2$ academic writing development, especially to writing center conferences. As much as we need to steer away from models of information transfer, we must also refrain from taking the concept of situated cognition (or situated learning) prescriptively; situated cognition does not tell us to deliberately "situate" learning tasks; it is a claim that actions are always at some level improvised through physical coordination, and "this improvisation is situated with respect to perceptual coupling of sensation and motor actions, but also with respect to conceptual coupling of timing, sense of place, role, and choreographies of participation" (Clancey, 1997, p. 344).

Based on this framework, we can make the following theoretical assumptions in regards to the writing conferences: 1) writing center conferences may serve as effective pedagogical tools to $\mathrm{L} 2$ students because they constitute social interactions mediated through dialogue; 2) from a social perspective, the tutor is a writer and reader who can successfully navigate the community the L2 learner wants to gain access to and who can therefore interact according to the expectations of that community; 3 ) the problems discussed and solved during the sessions emerge from the tutee's own text, thus enabling him or her to slowly build meaningful correlations between the processes of writing and revising because he or she is actively participating in both; 4) a writing center conference can be described as the enactment of a live editing session in which writers, to varying degrees, can ask questions or are prompted to verbalize explanations to 
obscure passages in their own texts. This enactment, as all human activity, translates into learning. This view of learning, that is, the "re -coordination of perception, talk, and other actions" (Clancey, 1995, p. 51) is also described by other theoretical concepts and/or terms I have already used in this study, such as expert/novice dyad and ZPD.

This theoretical stance also has implications for the discussion about textlevel revisions present in the composition literature. That students need sentence-level knowledge to improve their sentences is certain. So, does it really help to go over grammar issues during tutoring sessions? The answer may depend not only on the grammatical content itself, but on the student's ability to make sense of the information, the tutor's ability to frame explanations and make them accessible, the tutor and tutee's management of the tension between local or general issues, the tutees' perception of future occasions when the same errors occur, and most importantly on the expectations of the tutees themselves. Tutors and tutees may also need to recognize they may be coming to the table with completely different views and experiences about writing.

In this study, for instance, all participating students indicated they wanted to work on issues of grammar and mechanics prior to the sessions, and they claimed in their post-session interview that they have found such sessions beneficial to their writing over time. Therefore, if students' theoretical conceptions or "cognitive descriptions" of good writing or a good session require attention to issues of grammar and mechanics, it may not make sense 
pedagogically to dismiss that altogether, since this dismissal may jeopardize the tutor-tutee interaction. A skilled tutor will address these issues, as the student may have requested, and also point the tutee towards other issues he or she may not have been able to identify and that may also require attention.

\subsection{Cognitive Descriptions}

Based on the literature on L2 composition so far reviewed, some of the advice given to teachers is to either dismiss grammar issues or address them at later stages of the writing process. This approach is clearly out of synchrony with the expectations of the five L2 students who participated in this study, who specifically requested their sessions focus on issues of grammar and mechanics. This contrast raises the questions of whether or not students are reducing problems to issues of grammar and mechanics and failing to recognize the main issues in their papers, or whether or not the tutor should ignore or dismiss their request and shift the focus of the tutoring session. If tutors are to dismiss these concerns, what implications would this have for the tutor-tutee interaction altogether?

Most writing instructors in favor of addressing sentence-level mistakes in L2 writing tend to agree that grammatical and mechanical issues are hardly the most important ones in academic writing, and that they should either be addressed after global issues or concurrently. If the teacher is to tackle one issue at a time, few teachers would suggest he or she deal with grammar before 
organization, content, or format. Many L2 students, however, do not share this view. Many second and foreign language learners claim they experience difficulties with organization, format, and content precisely because they lack the structural resources to put coherent sentences together. In their own words, "they need more grammar."

This conflict of interests may at first imply that teachers know the students' needs better than the students themselves, or that students are not able to prioritize their own needs. But in reality each party holds on to their views because that is ultimately what they have experienced or continue to experience. Instructors have seen too many texts with perfect sentence structure that lack logic, content, or development, while students experience that it is hard to write coherently or with enough development when they may not have the tools they need to lay the basic blocks - the sentences. In situated learning terms, this means that each participant comes to the interaction with a different description of the writing development task based on their experience. This experience includes their internal cognitive operations and their relationships with other interlocutors in the academic writing environment. These descriptions are not their knowledge, they just point to it, as any map is not the territory it represents (Clancey, 1997). ${ }^{2}$ Descriptions are what allow each interlocutor, in this case the tutor and the tutee, to put forth their needs and engage in an interaction. In order for learning to occur, in this perspective it may be a mistake to try to convince

${ }^{2}$ For an earlier approach to cognitive descriptions, see Maturana and Varela, 1987. 
students that their priorities are wrong or "sabotage their convictions" (Sommers, 1982) that they should not pay so much attention to grammar, when they may feel and experience that grammar is exactly what is preventing them from writing acceptable texts for their professors.

In fact, any attempt to neglect the needs of the student may only satisfy the teacher or tutor, for he or she may feel this is the right action to take, but this behavior may only make sense in his or her own experience. On the other hand, this approach may be perceived by the student as dismissal of his or her most basic needs. In his criticism of written grammar feedback, Truscott (1996) claimed that grammar correction is not only harmful, but it also falls within an outdated view of learning as information transfer. And he has a point in saying so. However, what he proposes - ignoring grammar correction - also falls into the same paradigm of information transfer he criticizes, for he indirectly suggests that when teachers choose not to address the grammar issue and focus on other issues, students will spend more time developing other composition skills. But Truscott forgets that an interaction first begins with acknowledging each participant, their views, and their descriptions. By simply choosing not to address some students' grammar problems, teachers may be rejecting their participation as interlocutors in a writer-reader or student-teacher interaction, thus "trying to impose" their own descriptions on these students and appropriating the session altogether. By doing so, teachers are both limiting students' participation in the session and appropriating it. 
If learning is to involve the students' modification of their views (by new experiences that may lead to different descriptions) through the exploration of new territories during the session, the tutor needs to come in to the negotiation table by first accepting what tutees bring, for that is what students will use as the foundation for learning: "In our speech and writing, descriptions allow us to extend our cognitive activity into our environment, hold active and order alternative conceptions in our mental processing, and thus move beyond reactive, 'unthinking' routines (Clancey, 1997, p. 3). The student needs to be able to enact his or her description of academic writing before he or she can reconsider or modify it. Coming up with ways to encourage students to modify their descriptions themselves through problem-solving is what characterizes good teaching. Teachers and tutors should acknowledge students' descriptions and views first and then use them to guide behavior reformulations. Again, in Clancey's words:

Our names for things and what they mean, our theories, and our conceptions develop in our behavior as we interact with and re-perceive what we and others have previously said and done. This causal interaction is different from the linear 'describing what I perceive' or 'looking for what I conceive.' Instead, the processes of looking, perceiving, understanding, and describing are arising together and shaping each other. $(1997$, p. 3) 
If tutors simply dismiss their tutees' descriptions and impose a new session agenda on them, then they will be cognitively appropriating the sessions. This practice is not conducive to learning from a dialogical perspective, since tutees may interpret it as a denial of their role as interlocutors.

This view also aligns with the interpretative approach chosen for this study: one that privileges "the acts and meanings ascribed to events by the actors [or participants] in a particular social context" (Smith, 1887). Therefore, the research questions I propose are framed not only by the contributions and limitations of the literature on L2 composition reviewed, but mostly by the view of situated learning and the concept of cognitive descriptions just described, for they bring forth the agents in the tutoring process or the interlocutors themselves and not just the problems they face.

\subsection{Research Questions}

Aiming to investigate whether or not dialogues, particularly those involving a tutor and a tutee, benefit L2 students, this study looked into five writing center conferences held between L2 students and peer tutors at San José State University. As I analyzed these sessions, I highlighted linguistic, pedagogical, and cognitive elements that may or may not have benefitted L2 students. After each session, I also interviewed tutors and tutees to collect their impressions about the session. 
When I started to interview SJSU tutors and tutees following the recorded sessions, I hoped to learn whether or not they had agreed on what the main problem in the paper was or which issues needed to be addressed first. At the start of a tutoring appointment, Writing Center tutors always ask the tutees what it is they would like to focus on, and they write the two main issues their tutees raise in the upper corner of the first page of the paper. Nevertheless, the direction of the session may sometimes change as tutors or tutees read the paper out loud and other issues emerge. I was first interested in understanding to what extent tutees' descriptions of their needs would conflict with their tutors' views of what they needed. In order to bring up this information from the start, during the interview I proposed the following questions to tutors: What issues did the student want to focus on during the session? Did you and the student cover these issues? What additional ones were covered and why? I also asked tutees: When you scheduled the session online, what did you want/expect it to focus on? What issues were not covered and why? What additional ones were covered and why?

The other questions below were not asked during the interview, but they guided my investigation as a whole:

1. How do the issues of paper ownership and appropriation play out in these sessions? 
2. In a context where both interlocutors agree that grammar issues need to be addressed, how are they addressed in these sessions, and what strategies proved most effective in addressing them?

3. How much did each participant talk in the session? Which participant initiated, led, and closed discussions?

4. Which strategies used by tutors resulted in increased tutee engagement and participation?

5. Can local (grammar or sentence-level) issues be addressed in a way that benefits the tutees' overall writing development skills? 


\section{Chapter 3 - Methods}

\subsection{Research Design}

This study stresses the quality of the dialogues between tutors and tutees in a university writing center setting; therefore, I have chosen an interpretive qualitative design. As already stated in the Review of the Literature section, this study values the cognitive descriptions that each of the interlocutors brings to the table during the dialogues, the context in which they take place, and the way they evolve throughout the interaction. Therefore, it assumes there may be "multiple constructions and interpretations of reality that are in flux and that change over time" (Merriam, S., 2002). This design also enables me to critique prescriptive stances in relation to L2 writing development (such as the polarized approaches to error correction) and to stress what each tutor and especially each tutee values in the interaction, highlighting how each participant views and experiences the tutoring session.

While the qualitative design offered an insight into participants' views, a few of my research questions led me to also build in quantitative elements or measurements as a way to break down the dialogue between tutors and tutees, find specific roles each participant played, and/or highlight certain variables. The main research questions that justified this hybrid design are questions 3 and 4 , and they refer to how much talk each interlocutor had in the session and how they followed through with each problem raised. The quantitative analysis also 
helped me study the frequency with which certain issues were dealt across sessions. As I interpret these data, I hope to be able to provide suggestions for tutors and/or tutor trainers who work with L2 students based on my findings. In summary, the interpretive qualitative and the quantitative elements complement one another, since the resulting analyses will provide richer material for tutors and researchers.

The data collected consisted of five 30-minute tutoring sessions recorded at the San José State University Writing Center and ten recorded interviews (five tutors and five tutees) conducted no more than 24 hours after the session (see appendices 1, 2, and 3).

\subsection{Participants}

Writing Center tutors are usually graduate students or undergraduate seniors working part-time who pursue degrees mostly in the fields of English Language and Literature, Writing, Communication Studies, and Linguistics. All tutors participating in the study were monolingual and native speakers of English, even though the Writing Center also hires bilingual tutors and non-native English speakers. The Writing Center hires new tutors every semester, but all tutors participating in this research had already worked at least one full semester prior to the one when the study was conducted (the spring semester of 2010). Writing Center tutors were asked to participate in the study voluntarily during one of their 
periodical staff meetings, when I explained the purpose of the research and invited them to join.

Participating tutees were undergraduate and graduate SJSU students who identify themselves as speakers of a language other than English at home and who have learned English as a second language. Four (out of five) of the students in the study are early-arriving students, meaning they have completed at least eight years of their education in the United States. The fifth student, a graduate student at SJSU, concluded all her education prior to graduate school in India, where she claims to have used her native language at home and English at school. To identify potential student participants, I consulted their Writing Center profiles. The students themselves create these profiles when they first sign up to use the SJSU Writing Center services. In their profiles, they may indicate whether or not English is the main language used in their homes, but they are not required to specify which language they use at home. I gathered specific information about their first language during the post-session interviews.

To approach potential student participants, I sent an email message to several students who were registered at the Writing Center and who attended sessions regularly. In this message, I explained what the study was about and invited tutees to participate. In the research description, I emphasized that this was an independent study and that their participation (or not) would not interfere with the services they received from the SJSU Writing Center. I also informed them that they could withdraw from the study at any time. Participants who 
replied to the message and agreed to participate were contacted again, and a date for recording the session was scheduled. Before the session was recorded, both tutor and tutee were asked to sign a form approved by the Institutional Review Board (IRB) stating that they understood the benefits and risks of participation. Each session included a different tutor and tutee. No participant was paid to take part in the study.

\subsection{Procedures}

In order to record the sessions, a small Philips digital voice recorder was used. I was not present while sessions were being recorded. Instead, I taught participating tutors how to operate the recorder before they held their sessions. A short time after the tutoring session (for most, within the following 2 hours, but no more than 24 hours later for any of the participants), I interviewed the tutor and the tutee separately about the session they had just had and about their experiences working and attending sessions at the Writing Center, respectively. I did not listen to any of the recorded tutoring session before interviewing participants.

Writing Center sessions last 30 minutes each, and they are scheduled by the students themselves at their own convenience. To schedule a session, any SJSU-enrolled student can log on to the Writing Center web page and create a username. Along with a password, this username gives them access to the Writing Center schedule. On this schedule, tutees find the names of tutors, a 
brief biography about each, and their available hours. When students click on an available thirty-minute writing session block, they access a page prompting them for information about the writing assignment they are working on. On this page, they are asked to enter the course name for which they are writing the assignment, their instructor's name, the number of visits they have had to the writing center to work on the same assignment, the type of document they are working on, and the stage of the writing process they have reached (planning/prewriting, research, rough draft, revision, editing, or final draft). Students also indicate what aspect of writing they would like to work on (content, organization/format, grammar/mechanics, language difficulty, or other) and whether or not they would like the instructor to send their professor an email notifying them of the session. Tutees can also complete a comments box with additional details about the session or their assignment.

Writing Center tutors receive a daily schedule that summarizes all the information tutees entered prior to the session, but they are also trained to prompt students to tell them, in the first few minutes of the session, what type of assignment they are working on, what it is they want to focus on during the session, and what stage of the writing process they have achieved. Tutors then write down, in the upper right corner of the student's paper, the main objectives of the session, based on what they heard from their tutees. Tutors do not make corrections to the students' papers. They use scratch paper to write down examples or any other information to support their explanations. In addition, 
students are only allowed to work on paper copies of their writing and not on electronic ones during the session. Since the tutees who participated in this study had attended previous Writing Center sessions, they were already familiar with this routine, as the session transcripts show.

\subsection{Data Analysis}

For data analysis, I relied mostly on discourse analysis techniques in order to focus on the dialogues and interaction between tutor and tutee, but I also conducted measurements of certain elements in the sessions, such as the amount of time each participant talked, the time tutors spent reading students' papers, etc. Even though these variables were measured, the goal of my analysis was to assess the breadth and quality of the dialogue and not its direct effect on student papers. For this reason, I did not ask students to submit a copy of the paper used during the session. This study will then offer a descriptive, interpretative, and qualitative account of the sessions aiming to highlight the characteristics of the tutor-tutee interactions and how the participants enact (or construct) and later view them (Smith, 1987; LeCompte, 2000).

I created a coding scheme to highlight patterns of discussion and behavior from tutors and tutees during their interaction. These codes account for issues discussed during the writing session, the time allocated to each of the topics discussed, the time each student talked, the time each tutor talked, the time spent reading the paper, and the types of discussions initiated during the 
session. I also tracked who initiated discussions, how they were dealt with, and how they were closed. I tried to pay attention to how issues were dealt with progressively, meaning whether or not one issue led to another and, if so, whether or not patterns in the progression could be observed. Even though I was familiar with similar studies, their analyses, and coding schemes (see Patthey-Chavez \& Ferris, 1997; Ferris, 2003; Williams, 2004; and Ewert, 2009), I decided on a scheme that "emerged from" and made sense for the data I collected, as is typical in qualitative studies (LeCompte, 2000).

Each tutoring session received a number from 1 to 5 , respectively, as well as their participants. Therefore, tutors and tutees will not be addressed by their real names or by pseudonyms. When referring to the tutee and tutor in session 1, for instance, I will address them as Tutor 1 and Tutee 1 , and the same format will be used for all other participants. Information such as gender, age, academic placement, first language, and number of years in a US educational institution will be provided as needed for contextualization during data analysis. All information leading to tutor and/or tutee identification was omitted from the study.

\subsection{Overview of Sessions and Participants}

Before considering the data and results, I will offer a view of each session, participants, and their expectations. This information was extracted from the interviews and from the session appointment request logs that tutees filled out online prior to their appointments; this contextual information will help make 
sense of the data in the later sections. For a full transcription of all sessions and interviews, see appendices 1, 2, and 3.

\subsubsection{Session 1}

Tutee 1 came to the United States at the age of fourteen and started school in the United States as a high school freshman. Her first language is Japanese. She scheduled a writing appointment to keep working on her case study about an elementary school student, and she has worked together with Tutor 1 several other times. During the interview, when asked what she expected from the session, she answered, "I mainly wanted to focus on grammar because that is something that I can't fix by myself because I am an EL [English Learner]. I can think about content and organize things and ideas and things like that, but when I think of grammar, I need someone to specifically point out (...), because I would not be able to fix them [the errors] myself (...)." In addition to grammatical errors, Tutee 1 also referred to other topics covered in the session: "But at the same time, when I work with [Tutor 1], in addition to grammar she thinks about the content and argument, as well. So, every time I come here I get to learn something new." When asked if the session helped her learn anything new about her own assignment, Tutee 1 claimed she knew about the assignment well before the session. In fact, she provided a clear description of her assignment both at the start of the tutoring session and during the interview. 
Session 1 shows Tutee 1 was aware of her role in the session, and both she and her tutor acknowledged she came to her appointments well prepared. During her interview, Tutor 1 confirmed that Tutee 1 normally takes an active role in the sessions. She also reported the tutee wanted to focus on verb tenses, but the sentence-level work she wanted required they address more than just verb tenses: "She analyzed her response [paper] needed all three kinds of verbs present, past, and future - but she was not sure if she was using them correctly. (...) So we went through looking at it, "so what's the content of this sentence we are talking about and what are we going to use?" In the interview, Tutor 1 also reported her student knew what her professor's expectations for the assignment were. For instance, in the beginning of the session, Tutor 1 asked the tutee whether the reflection they were working on was a formal or a more informal document, and the tutee was able to answer promptly. According to Tutor 1, she and the tutee have already developed a certain synergy, which contributes to a positive interaction during the session: "we have worked together to the point that 'we work together' (...), and it is more like a discussion."

\subsubsection{Session 2}

Tutee 2 is an international student pursuing a graduate degree in the United States, and she completed her education, including her undergraduate degree, in India. She had classes in Hindi and in English throughout her school years, especially at college. She described herself as a bilingual student, but she 
stated that "the kind of English used over there [in India] and the kind of English used over here [in the United States] are very different. So, through the tutoring sessions I learn a lot instead of taking any other [English] classes over here: the grammar, the punctuation, everything." Tutee 2's session reservation log indicates she wanted to focus on grammar and mechanics, which she confirmed during her interview. She brought the final draft of her assignment, and it was the first time she worked on it during a writing conference with Tutor 2, even though they had already worked together on different assignments. When asked if the session had helped her better understand her assignment, she replied, "it was already clear to me, and I had already given a presentation [about it] in the class. After presenting in the class, I did a write-up."

In his interview following the session, Tutor 2 confirmed that the focus of the session had been grammatical and mechanical issues, but he also acknowledged these issues led to others, "There were a few things that were not strictly grammar. It might be hard to figure out when you are listening to them, but they were more clarity, you know, they were more based on the clarity of the content or clarity of the ideas than strictly grammatical. In most cases, it was something that I noticed. Most of the issues I [was the one who] noticed." In Tutor 2's opinion, mechanical issues end up being the focus of most of his tutoring sessions mainly because students ultimately see these sessions as opportunities to improve their papers and boost their grades. Nevertheless, he also seemed aware of ways to prevent the focus on errors from turning the 
session into a one-way correction event: "For most cases, it's just, you know, a compromise. They want their papers corrected to get a good grade. In order for us to correct their papers, they are going to have to learn first, you know. 'We are going to teach you, and you're going to get a good grade.' So, it's the case in most sessions." In his view, even though the recorded session was not necessarily a good sample of a back-and-forth interaction, the student still participated when prompted to: "She was engaged. I would ask her, 'What would be the best way to rewrite this?' and she would give a suggestion. And often times it was the right suggestion. You don't necessarily have to tell her."

\subsubsection{Session 3}

Tutee 3 came to the United States from Vietnam when he was eight years old. In an informal conversation before the interview, he voluntarily shared that he has always struggled with academic English at school. He also believes he has not developed his academic English well enough, yet. His appointment log indicates this was the first session he scheduled to work on this document, that he had reached the editing phase of the writing process, and that he wanted to work on issues of grammar and mechanics. Tutee 3 and Tutor 3 had worked together in previous sessions, and Tutee 3 explained why he chose to schedule a session with a familiar tutor: "So far, I have been trying to keep the same tutor; she knows how you write, and she is able to teach you better next time. So, if I switch around a lot, every time I have a new tutor it will be difficult for the person 
because the person might not be familiar with it [the way I write] and give me difficult opinions." Despite his intention to focus on grammar issues during the session, during the interview he also admitted to working on content. He remembered he explicitly asked his tutor a question about whether or not he should keep certain pieces of information on his paper.

Tutor 3 reported that she has been working with Tutee 3 for a long time and that most of their sessions deal with grammar issues. She describes, "So, we just sit down and he tells me what it is that we are looking at, and if he has anything special like, 'this one actually I am worried about content,' he will let me know. But otherwise we just sit down and read through it. In most of our sessions we focus on grammar. (...) This one specifically, it was grammar and idiom, a lot of idiom." Tutor 3 also credited the tutee with his share of participation in the session: "Working with [Tutee 3] is really nice because he always has questions prepared." In Tutor 3's view, Tutee 3 clearly understood what his assignment entailed.

\subsubsection{Session 4}

Compared to the other sessions, session 4 was clearly an outlier. Tutee 4 did not bring a paper to the session, as did the tutees in all other sessions. He booked a 30-minute appointment to go over language issues he normally struggles with, such as verbs and idiomatic uses of sentence constructions. However, I decided to keep data from session 4 as part of the analysis because it 
contributes contrasting elements to the discussion. Session 4 may not have the same format as the others, but it helps to highlight the differences between two types of sessions that can take place at the SJSU Writing Center, even though sessions such as session 4 do not occur as frequently as the others.

Tutee 4 came from Vietnam to the United States 15 years ago to attend high school. He completed all his high school and undergraduate studies in the United States. On his English skills, he commented, "I talk to a lot of foreigners who have been here for a year, and their English is so good compared to my English. I have been here longer. I don't know. I think they [had] better foundations when they came here." When asked about his desired focus for the session, he stated, "I brought up the idea of using the 'be' verb. Like, active, main verb, passive voice, [and] then we talked about singular and plural. I didn't bring a paper this time. I just wanted to talk about these issues." Tutee 4 also reported he appreciates having developed a connection with his tutor and having someone or a place to just go and ask questions about the English language.

Tutor 4 reported that Tutee 4 schedules sessions with him periodically. To these sessions, he either brings a paper or an issue they both explore. With regard to this particular conference, Tutor 4 shared that the main topic the student chose to discuss - verb to be - was a topic they had started discussing in their previous session the week before. When asked if the issues the student brought were covered during the session, Tutor 4 replied, "yes and no, because sometimes his issues are broad. (...) One thing I suggested him during the 
session was (...) '[if] you come to sentences you are confused about (...), just cut and paste them , and put them in a document, and bring the document the next time you come and we can talk about [the sentences] specifically'." Tutor 4 believes Tutee 4 left the session with better understanding of passive voice, one of the topics they discussed, but not necessarily article usage, another topic addressed in the session. Tutor 4 also stated he and Tutee 4 have been able to work together well and proactively: "He is the kind of student who will come back, and there will be some stars in his handout, and he will say like 'I get everything up to here.' He's done it in the past with other [topics]."

\subsubsection{Session 5}

Tutee 5 came from Mexico to the United States six years ago, and she completed the last two years of high school in the United States. Her session log indicated this was her first session working on the document she brought and that she wanted to revise her final draft for grammatical and mechanical errors. When I asked her about her expectations about the session in the postconference interview, she stated, "Most of the times when I come here, I focus on grammar and spelling because I am always done with my paper, like I don't need help with structure [organization and content] or anything. So, I just want to make sure the spelling is correct [and that] I don't get grammar errors." Tutee 5 expressed that she is aware of her role as a student during the tutoring sessions. 
When asked about what her role was in the session, she stated, "Asking questions and letting the tutor know what I want to focus on."

Tutor 5 confirmed that the session focused on grammar and mechanics, and that the student was precise in choosing so, "She had her paper organized in a fashion such that she answered questions pretty directly. She knew what she had to do. She told me she seemed pretty confident about her content. She didn't want to focus on content, so we didn't. If anything did come up with her, I would address it." Tutor 5 also stated she believes the tutee was engaged during the session mainly because she asked questions. 


\section{Chapter 4 - Results}

This section is divided into two parts: Part A contains all quantitative data that is relevant to the study; Part B includes all qualitative data or data extracted directly from session dialogues and post-session interviews.

\section{Part A - Quantitative Data}

\subsection{Issues}

To determine the problems that were most often addressed during the sessions, I created codes and assigned them to the different issues that emerged. The codes used were adapted from an error-coding system for written commentary proposed by Ferris (2005). Additional error codes were also included based on the oral nature of the exchange and on the reports that SJSU Writing Center tutors completed after each session. In these reports, tutors listed all issues addressed during the appointments. Following is each code with detailed explanations, when needed:

- Verb: errors with verb tense or verb form;

- Noun: errors with plural, possessives, and noun endings in general ${ }^{3}$;

- Determiner: errors with articles and/or determiners;

- Word: vocabulary issues;

\footnotetext{
${ }^{3}$ Errors with noun endings are of the inflectional type. Derivational errors belong to the category Word.
} 
- Sentence structure: word order, missing words, unnecessary words, runons, fragments, comma splices;

- Audience: issues related to the audience being addressed; clarity

- Content

- Organization

- Format

As I present the results in this section, I will refer to the issues of verb, noun, determiner, word, and sentence structure as local issues. Audience, content, organization, and format, on the other hand, will be referred to as global issues.

According to the appointment $\log s^{4}$ (records of what the students request when they schedule an appointment), all tutees requested their session address issues of grammar and mechanics. They also indicated that they were working either in the editing phase or final drafts of their writing pieces. In their interviews, they reiterated their requests and stated that they had come to the session with a clear idea of what they should write and how (content, organization, and format). Nevertheless, they claimed that they still needed help with mechanical issues in their text. Tutors also expressed that they felt tutees had understood their assignments clearly, and no tutor reported finding serious issues of content, organization, and format in the tutees' papers.

${ }^{4}$ I did not include copies of these records in an appendix in order to protect participants' identities. 
Table 1 - Breakdown of issues addressed in each tutoring session.

\begin{tabular}{|c|c|c|c|c|c|c|c|c|c|c|}
\hline \multirow[t]{2}{*}{ Issues } & \multicolumn{2}{|c|}{ Session 1} & \multicolumn{2}{|c|}{ Session 2} & \multicolumn{2}{|c|}{ Session 3} & \multicolumn{2}{|c|}{ Session 4} & \multicolumn{2}{|c|}{ Session 5} \\
\hline & $\begin{array}{l}\text { \# of } \\
\text { Issues }\end{array}$ & $\%$ & $\begin{array}{l}\text { \# of } \\
\text { Issues }\end{array}$ & $\%$ & $\begin{array}{c}\text { \# of } \\
\text { Issue } \\
\text { s }\end{array}$ & $\%$ & $\begin{array}{l}\text { \# of } \\
\text { Issue } \\
\text { s }\end{array}$ & $\%$ & $\begin{array}{l}\text { \# of } \\
\text { Issue } \\
\text { s }\end{array}$ & $\%$ \\
\hline Verb & 9 & $38 \%$ & 5 & $12 \%$ & 9 & $24 \%$ & 7 & $64 \%$ & 11 & $24 \%$ \\
\hline Noun & 1 & $4 \%$ & 5 & $12 \%$ & 6 & $16 \%$ & 1 & $9 \%$ & 3 & $7 \%$ \\
\hline Determiner & 2 & $8 \%$ & 2 & $5 \%$ & 4 & $11 \%$ & 2 & $18 \%$ & 1 & $2 \%$ \\
\hline Word & & & 3 & $8 \%$ & 5 & $14 \%$ & & & 12 & $27 \%$ \\
\hline $\begin{array}{l}\text { Sentence } \\
\text { Structure }\end{array}$ & 5 & $21 \%$ & 24 & $60 \%$ & 10 & $27 \%$ & 1 & $9 \%$ & 16 & $36 \%$ \\
\hline Audience & & & & & 1 & $3 \%$ & & & & \\
\hline Content & 1 & $4 \%$ & & & 2 & $5 \%$ & & & & \\
\hline Organization & 5 & $21 \%$ & & & & & & & 1 & $2 \%$ \\
\hline Format & 1 & $4 \%$ & 1 & $3 \%$ & & & & & 1 & $2 \%$ \\
\hline Total & 24 & $100 \%$ & 40 & $100 \%$ & 37 & $100 \%$ & 11 & $100 \%$ & 45 & $100 \%$ \\
\hline
\end{tabular}

Data from Table 1 above confirms that sessions mostly focused on issues of grammar and mechanics. Percentages reflect the number of issues discussed under each type, compared to the total number of issues addressed in the session. Issues were computed anytime one of the interlocutors brought it up. Each issue was computed once, regardless of the time interlocutors spent on it. For instance, the table indicates that nine of the issues covered in session 1 pertained to verb tenses. This means that nine different issues of verb tenses were brought up and discussed by interlocutors. Altogether, the issues of verb, noun, determiner, word, and sentence structure account for over $70 \%$ of all 
problems addressed in session 1; over $90 \%$ of the issues addressed in sessions 2, 3, and 5; and $100 \%$ of the issues addressed in session 4 . Global issues were not as frequent as sentence level issues in the sessions, except for session 1 in which $21 \%$ of all discussions were dedicated to organization. Following is a breakdown of issues by session. The information taken from Table 1 above has been reproduced in graphs for better visualization.

\subsection{Session 1}

Most of session 1 discussions revolved around verb tense issues (38\%). The second most discussed topics were sentence structure (21\%) and organization (21\%). Issues with articles and other determiners ranked third $(8 \%)$, and the three other issues discussed were noun (4\%), format (1\%), and content $(4 \%)$.

The data reflect that the tutee accurately identified the type of help she needed. At the beginning of her session, after describing the assignment she brought, she added, "I want to work on tense." Among all sessions, session 1 was also the session with the largest number of issues outside the realm of grammar and mechanics (seven of the issues dealt with global topics such as organization, format, and content), and they amounted to $29 \%$ of the topics addressed during the session.

Many of the global issues the tutor and tutee covered in this session in fact emerged from local issues. For instance, some of the decisions the tutor 
and tutee made regarding text organization started as discussions about verb tenses, a connection that will be further explored in the analysis section.

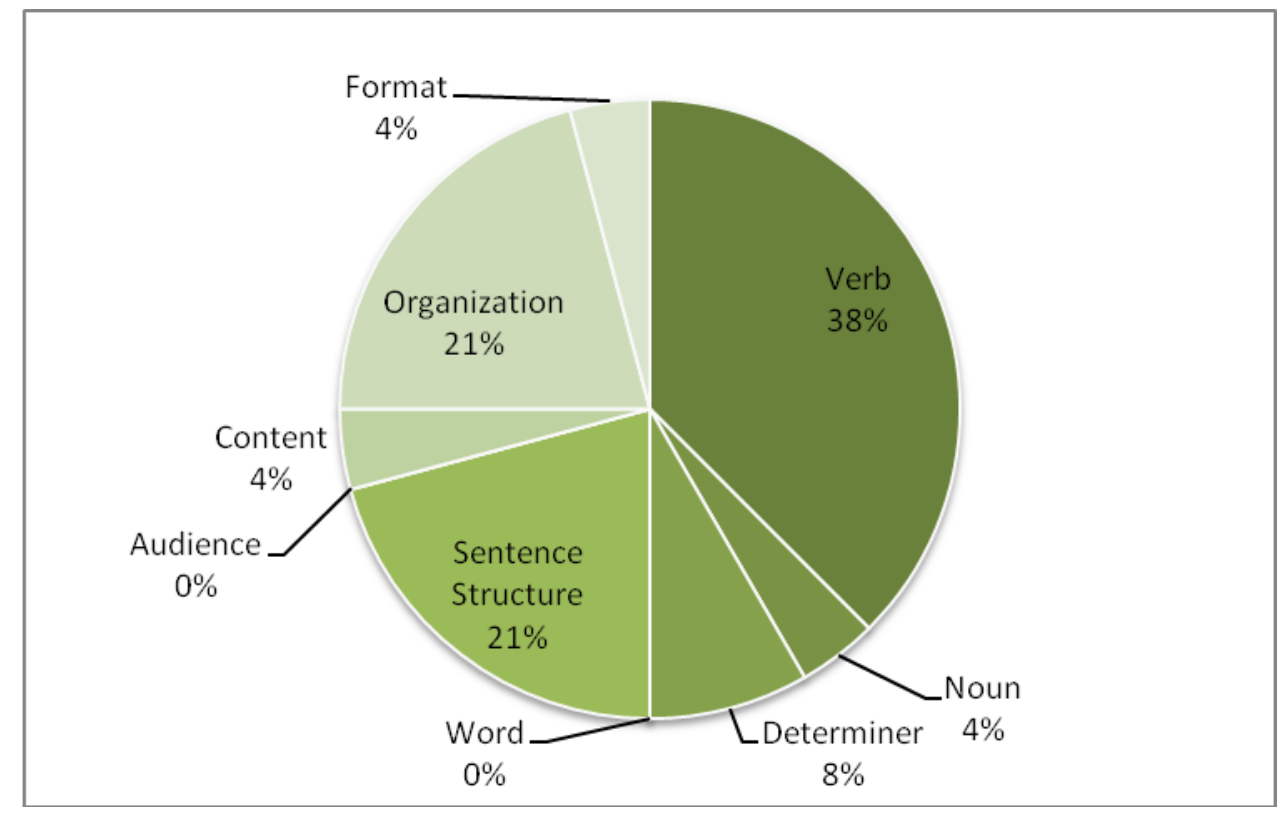

Figure 1 - Issues addressed in session 1

\subsection{Session 2}

The topic that was most addressed in session 2 was sentence structure, amounting to $24(60 \%)$ out of the 40 issues discussed during the appointment. Noun (12\%) and verb (12\%) were in second place. Other grammar topics covered were word ( $8 \%)$ and determiner $(5 \%)$. Format $(3 \%)$ was the only global issue covered during the session.

Nevertheless, as the session transcript shows (see appendix 1, Session 2, turns 44 to 46), there were moments in the session when the tutor suggested 
sentence-level changes to the text based on what would be clearer for readers, establishing a connection between a local problem and its global repercussions within the text, a topic that will be explored further in Chapter 5 .

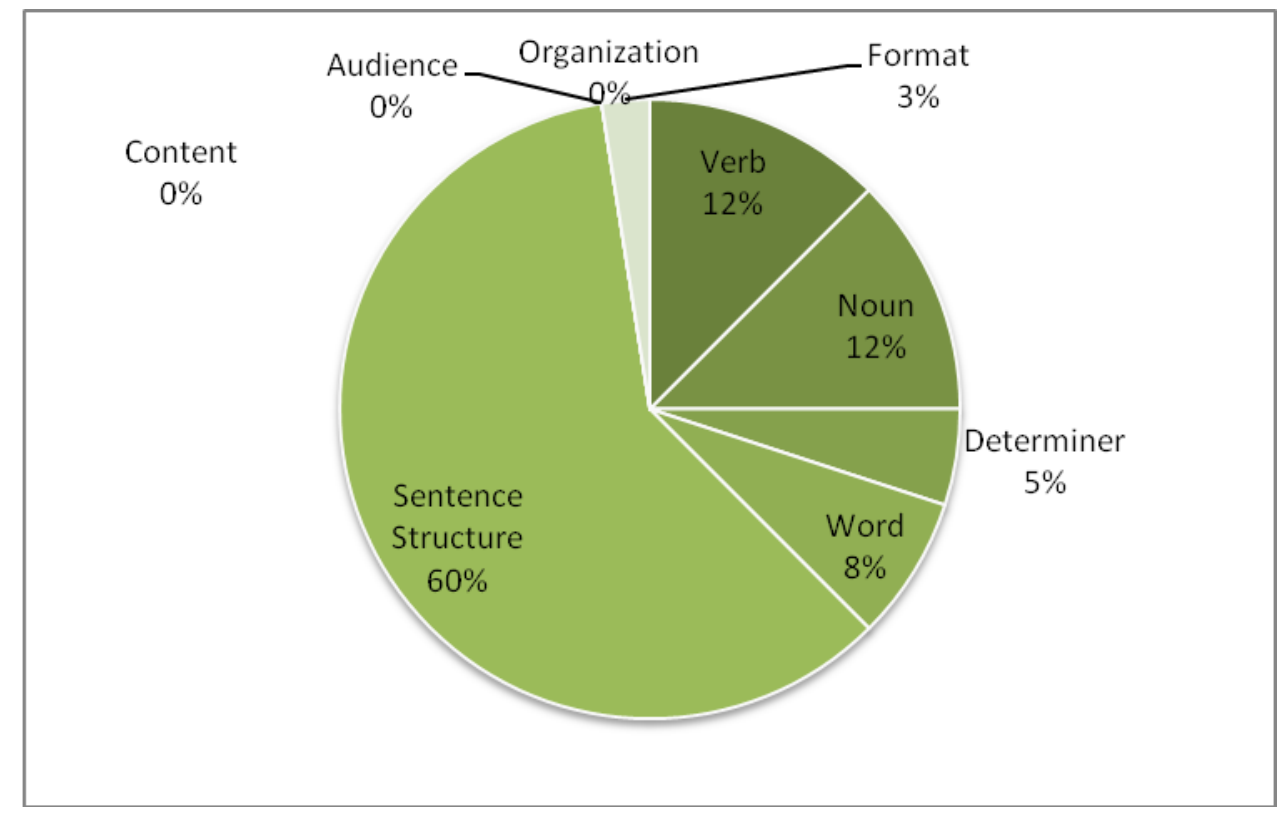

Figure 2 - Issues addressed in session 2

\subsection{Session 3}

Even though $92 \%$ the issues covered in this session were problems of grammar and mechanics (the sum of all issues, except audience, content, organization, and format), session 3 had the most balanced breakdown of local topics covered. Issues of sentence structure (27\%) were the most addressed in the session, followed by verb issues (24\%). Following these are noun (16\%), 
word (14\%), determiner (11\%), and the global issues of content $(5 \%)$ and audience (3\%).

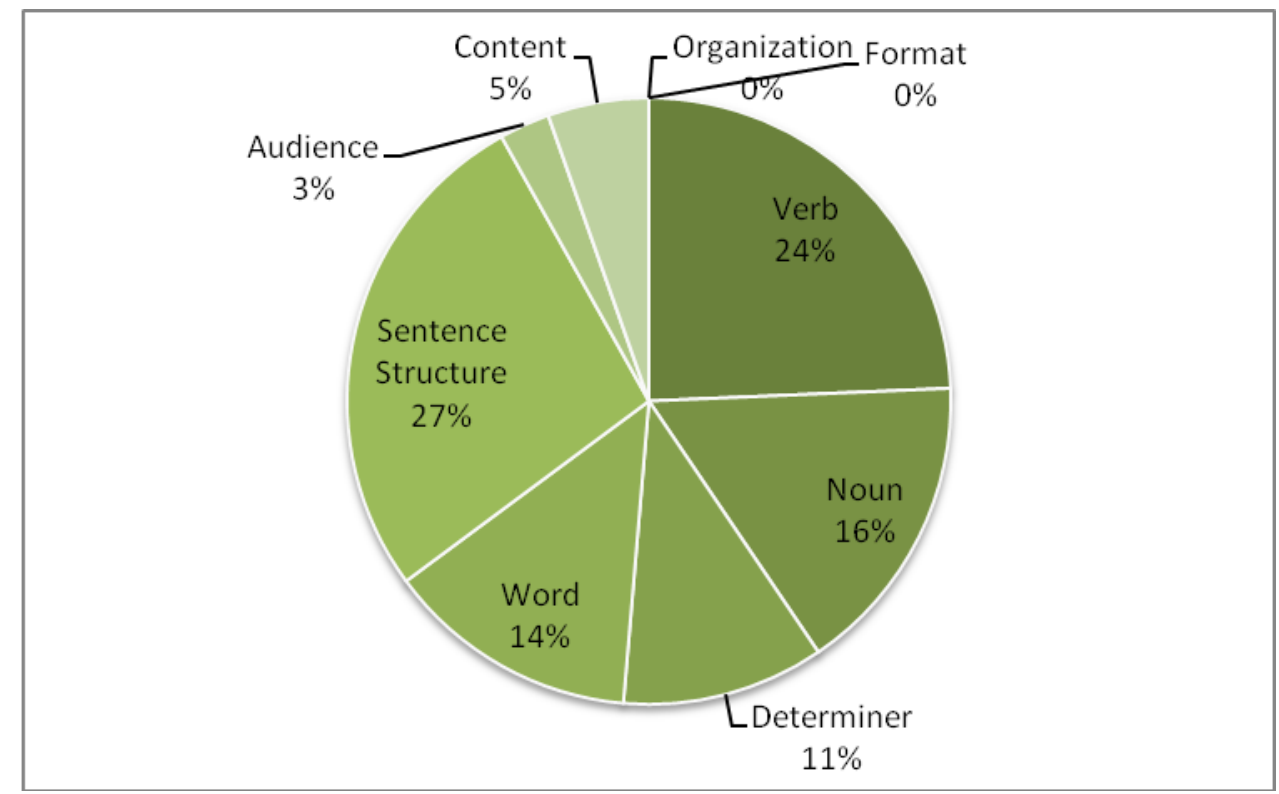

Figure 3 - Issues addressed in session 3

\subsection{Session 4}

Tutee 4 did not bring a paper to the session and chose to use his appointment as an opportunity to explore answers to some of the grammar topics about which he had questions; therefore, the session addressed local issues exclusively. Verb issues dominated most interactions (64\%), and they were followed by questions and comments about determiners (18\%), nouns (9\%), and sentence structure (9\%).

Both tutor 4 and tutee 4 acknowledged they had held similar sessions before, even though these sessions were not as frequent as those dedicated to 
revising the tutee's writing work. Participants also shared that this session was in some ways a continuation of a previous discussion they had held the previous week (see tutor 4's and tutee 4's post-session interviews).

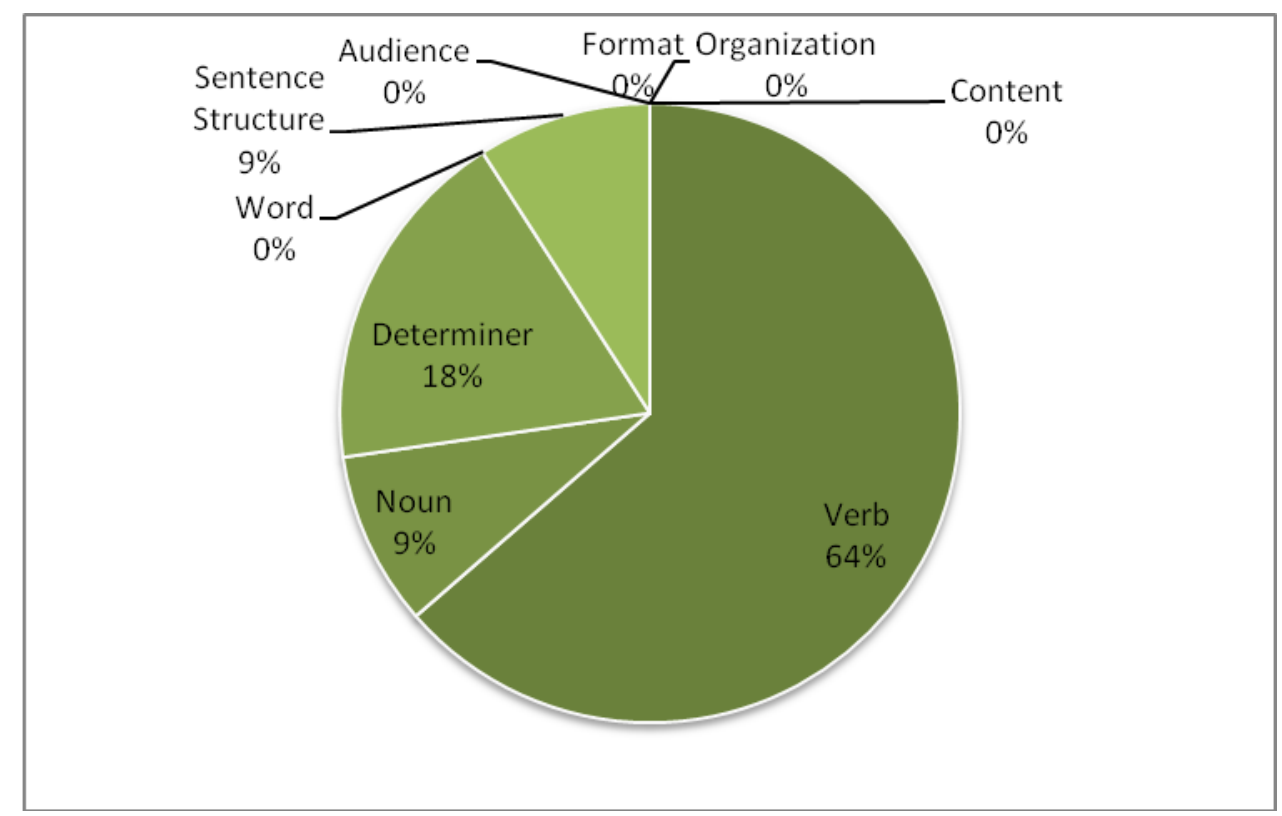

Figure 4 - Issues addressed in session 4

\subsection{Session 5}

As requested by the tutee at the start of the appointment, grammar issues dominated session 5, with global issues accounting for 2 out of the 45 issues in the whole session: organization (2\%) and format (2\%). The three most discussed topics were sentence structure (36\%), word (27\%), and verb (24\%). Three noun issues (7\%) were also addressed, as well as a problem with determiners (2\%). 
In her interview, Tutor 5 reported that the student was precise in choosing the focus of the session. She also credited the student with having a good grasp of her assignment prior to the session. Following is a breakdown of the topics covered in session 5 :

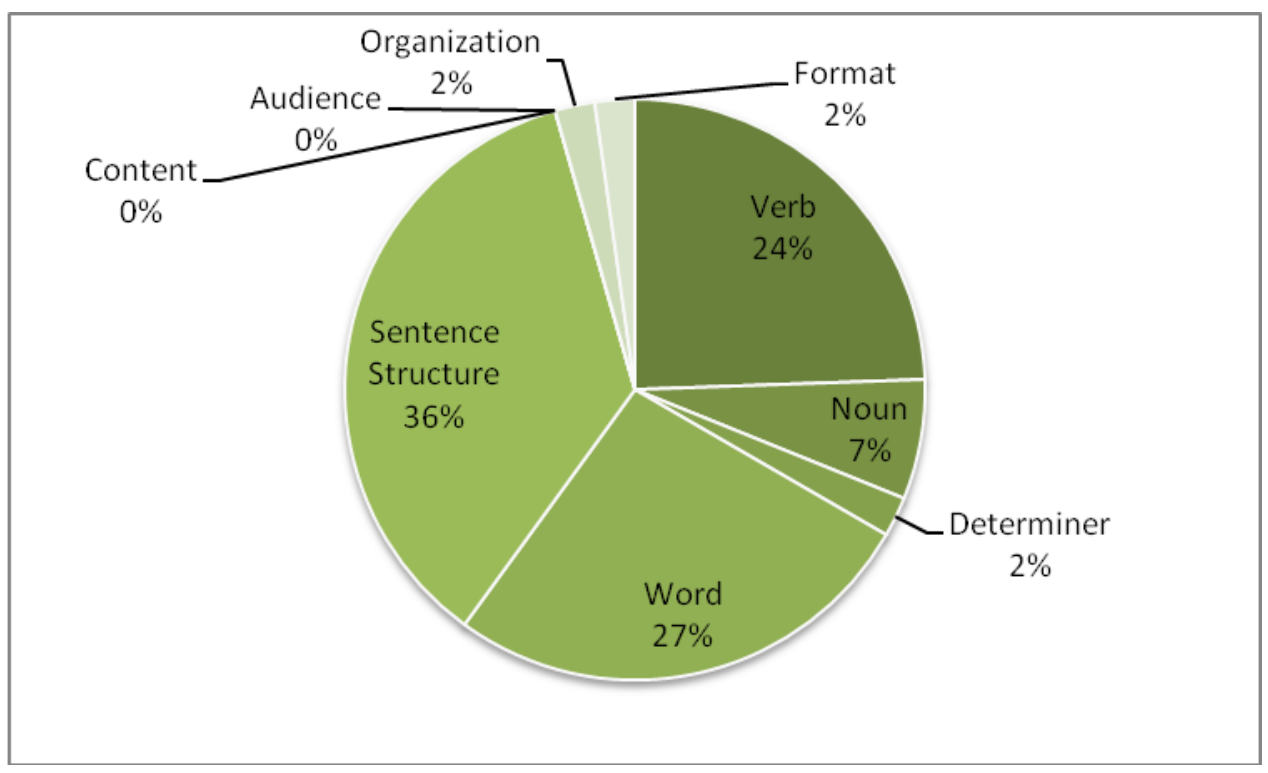

Figure 5 - Issues addressed in session 5

\subsection{Talking Time}

Some studies (Goldstein and Conrad, 1990; Patthey-Chavez and Ferris, 1997; Ewert, 2009) point to tutor and tutee participation or talk time as key indicators of engagement in the session. Reduced tutee talk time (or increased tutor talk time) has been previously identified with sessions involving a "weak" tutee. I have chosen to add qualitative variables to the measurements of talk time in an effort to also show how meaningful some of the dialogues were, even 
some shorter exchanges. These measurements of talk time will generate valuable data to compare with the qualitative results. To measure talk time by participants meant basically to track the minutes that each participant talked during the sessions. Throughout this process, I decided to include the tutee's text as a separate interlocutor, since the time spent reading was time devoted to the text itself. Additionally, while in all the cases it was the tutor who read the paper, the time they spent reading was not used to explain or comment on their tutees' writing. Therefore, it did not seem accurate to claim that time as tutor time. On the other hand, it was also hard to attribute this time to tutees, even though they wrote the assignments, because they were not the ones reading the text. I then concluded the best approach was to compute the text itself as a different interlocutor in the process ${ }^{5}$.

Results (Table 3) indicate that tutors spoke the most in all sessions. Overall, tutors used about 30 to $60 \%$ of session time for their comments, explanations, and observations, depending on the session. Reading aloud took from about 20 to $60 \%$ of the time, and tutees spoke during about 10 to $25 \%$ of the sessions.

\footnotetext{
${ }^{5}$ I have not come across any previous literature on writing center tutoring sessions that has treated the text as a separate interlocutor. Once again, I chose this approach because the tutoring sessions I recorded had specific time dedicated to reading the paper aloud.
} 
Table 2 - Interlocutors' talk time.

\begin{tabular}{|c|c|c|c|c|c|c|c|c|c|c|c|}
\hline \multirow{2}{*}{\multicolumn{2}{|c|}{ Interlocutor }} & \multicolumn{2}{|c|}{ Session 1} & \multicolumn{2}{|c|}{ Session 2} & \multicolumn{2}{|c|}{ Session 3} & \multicolumn{2}{|c|}{ Session 4} & \multicolumn{2}{|c|}{ Session 5} \\
\hline & & Time & $\%$ & Time & $\%$ & Time & $\%$ & Time & $\%$ & Time & $\%$ \\
\hline $\bar{A}$ & Tutee & $5{ }^{\prime} 26^{\prime \prime}$ & $24 \%$ & 4'20" & $15 \%$ & 5'59"' & $21 \%$ & 7'33" & $25 \%$ & 2'58" & $12 \%$ \\
\hline$B$ & Tutor & 10'31" & $45 \%$ & 17'14" & $62 \%$ & $16^{\prime} 27^{\prime \prime}$ & $57 \%$ & 22'11" & $75 \%$ & 7’06" & $31 \%$ \\
\hline C & Writing & 7'13"' & $31 \%$ & 6'17" & $23 \%$ & 6'15" & $22 \%$ & $\mathrm{~N} / \mathrm{A}$ & $\mathrm{N} / \mathrm{A}$ & $13^{\prime} 10^{\prime \prime}$ & $57 \%$ \\
\hline$A+C$ & $\begin{array}{l}\text { Tutee + } \\
\text { Writing }\end{array}$ & 12'39" & $55 \%$ & 10'37" & $38 \%$ & 12'14" & $43 \%$ & $\mathrm{~N} / \mathrm{A}$ & $\mathrm{N} / \mathrm{A}$ & 10'04" & $43 \%$ \\
\hline$A+B$ & $\begin{array}{l}\text { Tutor + } \\
\text { Writing }\end{array}$ & $17{ }^{\prime \prime \prime \prime}$ & $76 \%$ & 23’31" & $85 \%$ & $22 ' 42^{\prime \prime}$ & $79 \%$ & N/A & $\mathrm{N} / \mathrm{A}$ & $20 ' 16 "$ & $57 \%$ \\
\hline \multicolumn{2}{|c|}{ Total } & $22^{\prime} 10^{\prime \prime}$ & $100 \%$ & $27^{\prime} 51^{\prime \prime}$ & $100 \%$ & $281^{\prime \prime}$ & $100 \%$ & $29 ' 44 "$ & $100 \%$ & 23 '14" & $100 \%$ \\
\hline
\end{tabular}

In three of the sessions (1, 3, and 4), tutees had $24 \%, 21 \%$, and $25 \%$ of talk time, respectively. In sessions 2 and 4 , tutees spoke less - $15 \%$ and $12 \%$ of talk time, respectively. Tutor talk time also varied: $31 \%$ in session $5 ; 45 \%$ in session $1 ; 57 \%$ in session $3 ; 62 \%$ in session 2 ; and $75 \%$ in session 4 (during which no paper was read). Session 5 was the only one in which the read-aloud took more time than other interlocutors. In all other sessions during which a paper was read, the reading time was higher than the tutee talk time. In all but one session (session 5), tutor talk time was higher than reading time. 


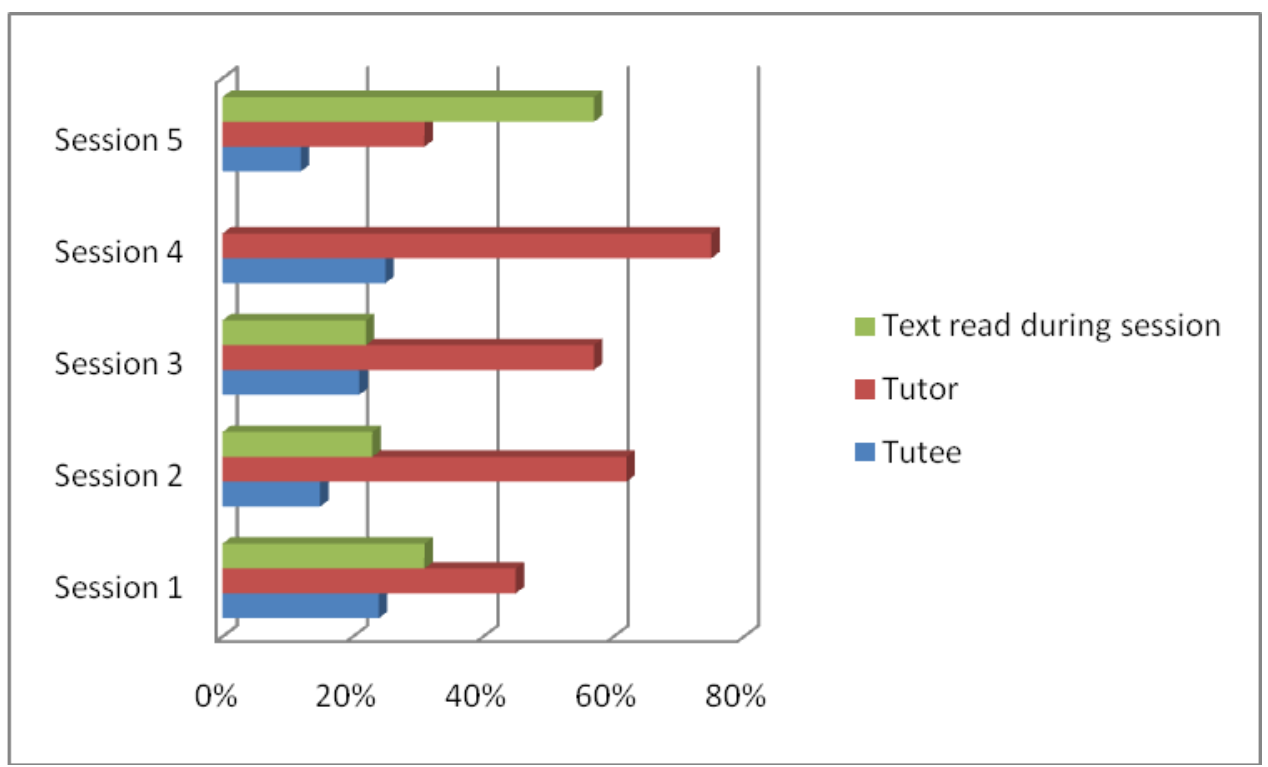

Figure 6 - Participants' talk time during sessions

\subsection{Use of Deictic Terms}

Tutors' use of deictic terms was also computed during the sessions, for they can indicate the effort a tutor makes to alleviate his or her authority role, as well as convey a collaborative approach to text ownership. The deictic terms I analyzed include personal pronouns, possessives, demonstratives, and time adverbs. They point to the perspective of each participant in the discourse, and therefore may provide information as to how much ownership each participant claims over the text and the discussion. For the data that follow, I only computed instances of tutor talk, that is, when the tutor was making comments, answering questions, explaining, or making suggestions based on the tutee's text or an example provided. Tutee statements were not considered because tutees were always referring to their own texts. 
Table 3 - Tutors' use of personal pronouns and possessive adjectives

\begin{tabular}{|c|c|c|c|c|c|c|c|c|c|c|}
\hline Pronoun or & \multicolumn{2}{|c|}{ Session 1} & \multicolumn{2}{|c|}{ Session 2} & \multicolumn{2}{|c|}{ Session 3} & \multicolumn{2}{|c|}{ Session 4} & \multicolumn{2}{|c|}{ Session 5} \\
\hline $\mathrm{l} / \mathrm{me} / \mathrm{my}$ & 16 & $19 \%$ & 4 & $3 \%$ & 19 & $20 \%$ & 16 & $12 \%$ & 11 & $24 \%$ \\
\hline You/your & 42 & $51 \%$ & 35 & $22 \%$ & 35 & $36 \%$ & 99 & $72 \%$ & 20 & $43 \%$ \\
\hline We/our & 25 & $30 \%$ & 120 & $75 \%$ & 43 & $44 \%$ & 22 & $16 \%$ & 15 & $33 \%$ \\
\hline Total & 83 & $100 \%$ & 159 & $100 \%$ & 97 & $100 \%$ & 137 & $100 \%$ & 46 & $100 \%$ \\
\hline
\end{tabular}

One pattern seen across all sessions was the relatively small number of references to the tutor's own person when making comments or suggestions. The highest percentage found was $24 \%$ (session 5 ). The other types of pronominal and possessive references $\left(2^{\text {nd }}\right.$ person singular and $1^{\text {st }}$ person plural $)$ varied according to the session. In sessions 1,4 , and $5,2^{\text {nd }}$ person singular references outnumbered $1^{\text {st }}$ person plural references. They were particularly high in session 4 , which did not include a paper. As to $1^{\text {st }}$ person plural references, they were the highest in session 2 (120 references or $75 \%$ ) - the session with the most pronominal and possessive references altogether, followed by session $3(44 \%)$. In general, when tutors wanted to make a personal reference, they used we/our instead of $I / m e / m y$. This overall preference to plural personal pronouns may have reinforced the sense of a collaborative session among participants. Differences in their use among sessions (see Figures 7 to 11) may be attributed to tutors' personal styles and/or their awareness of the impact of pronoun choice on tutee's attitudes. 


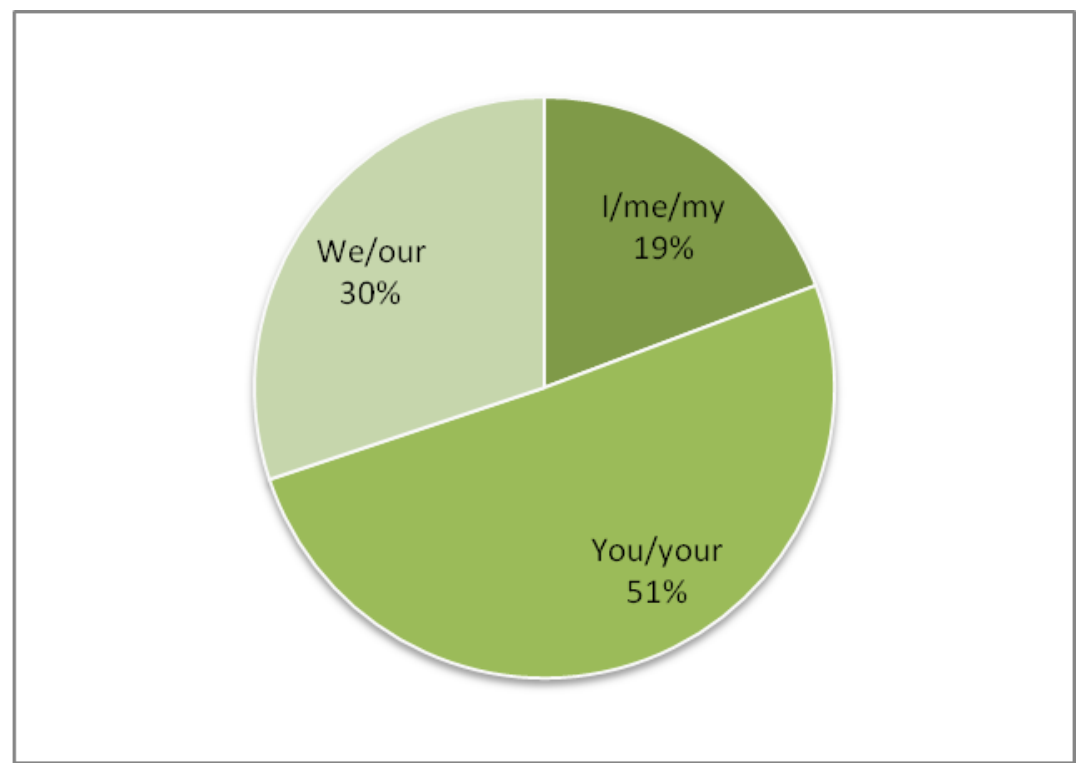

Figure 7 - Tutor's use of pronouns and possessives in session 1

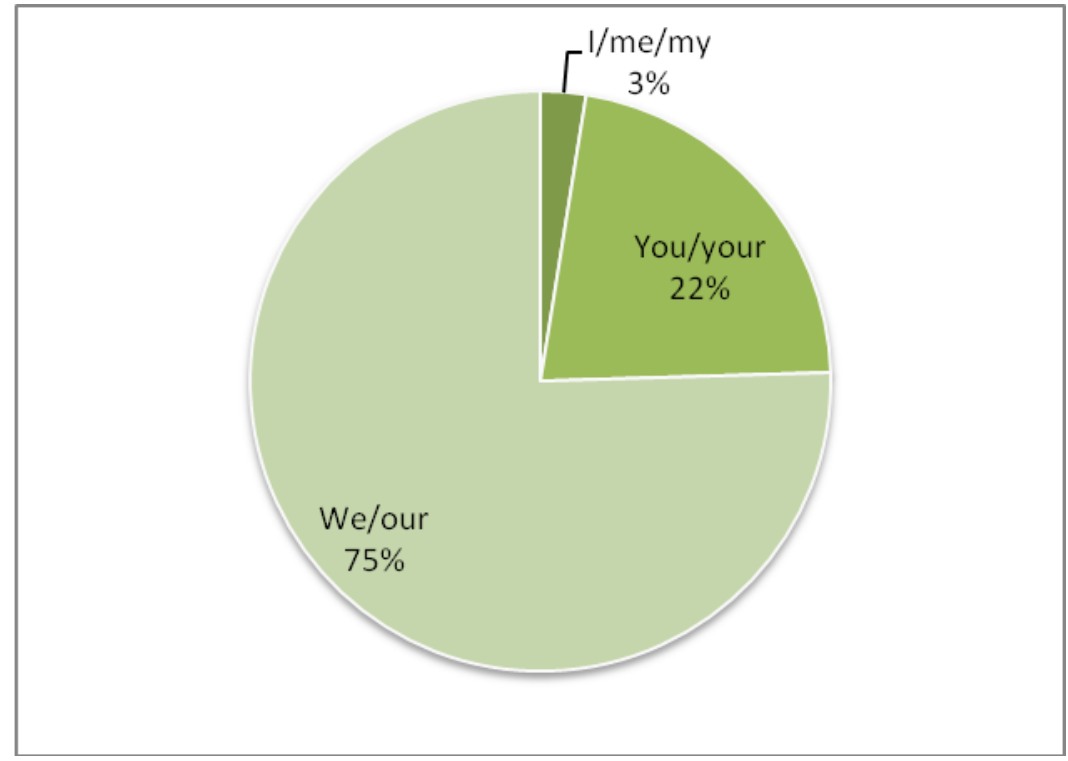

Figure 8 - Tutor's use of pronouns and possessives in session 2 


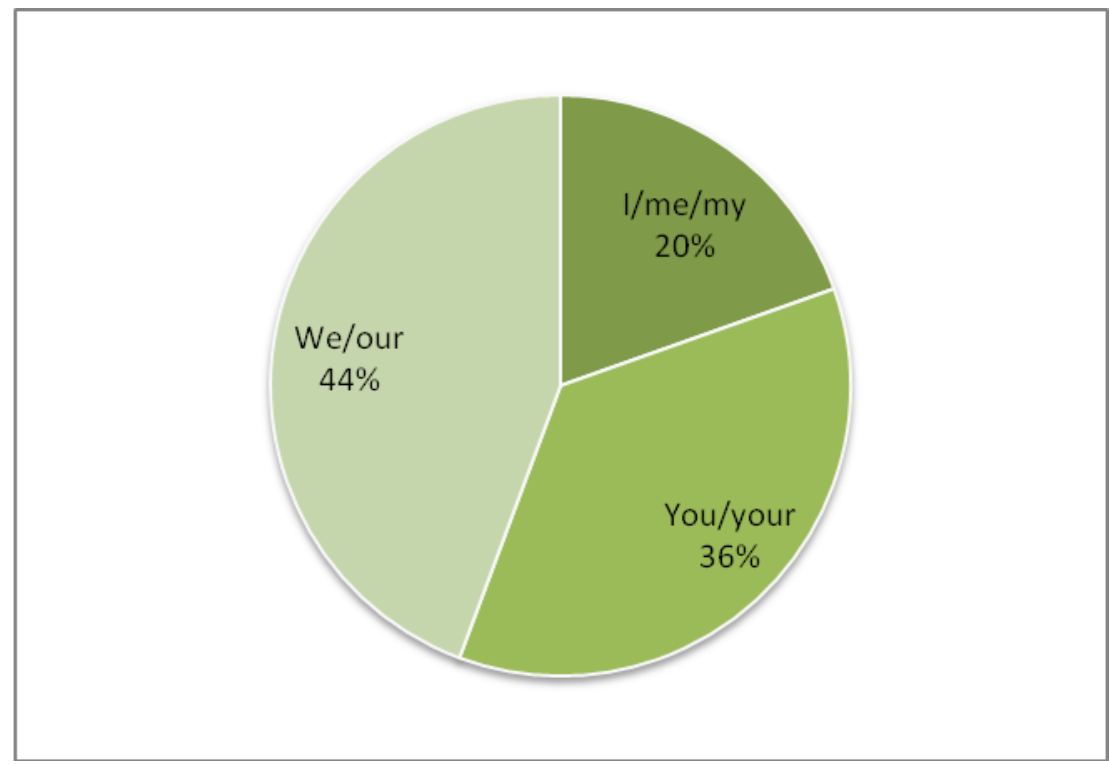

Figure 9 - Tutor's use of pronouns and possessives in session 3

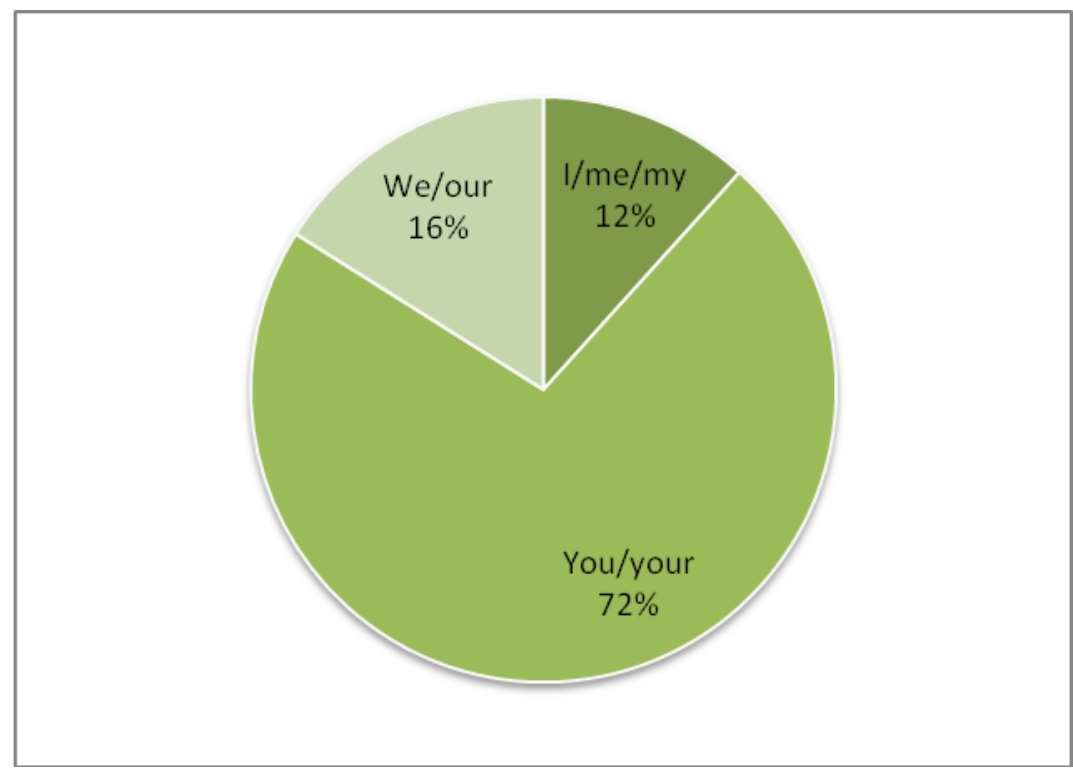

Figure 10 - Tutor's use of pronouns and possessives in session 4 


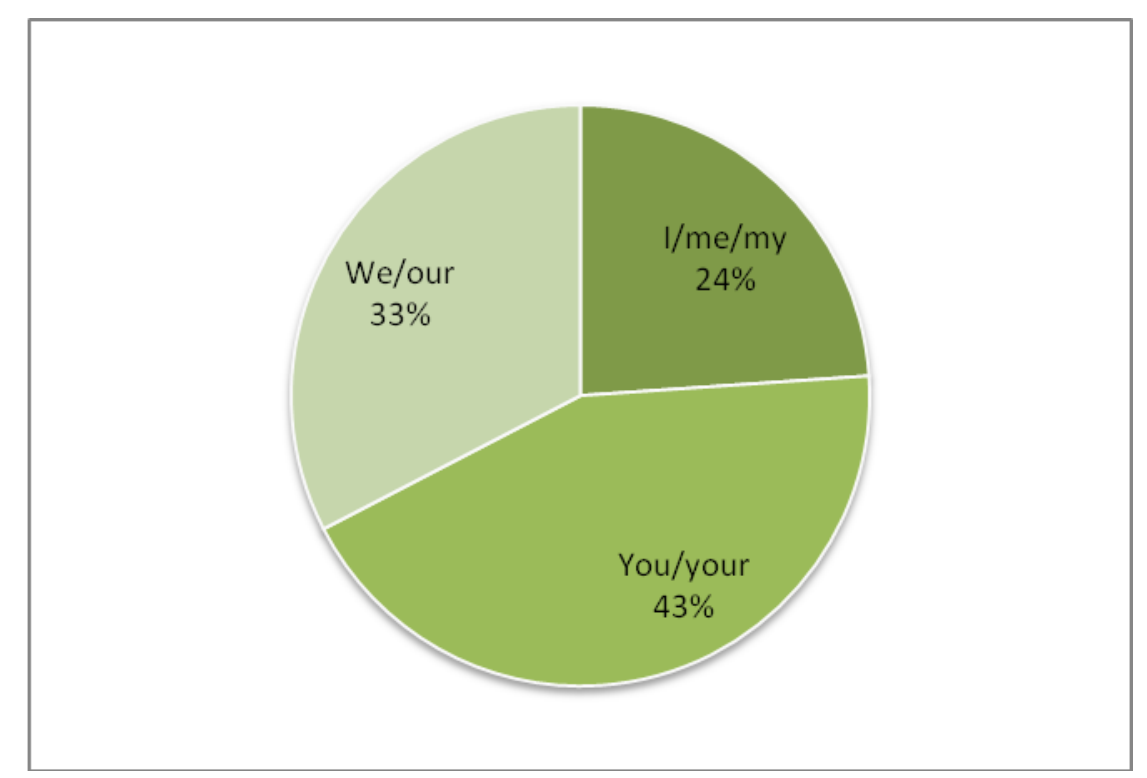

Figure 11 - Tutor's use of pronouns and possessives in session 5

Results for demonstratives and place adverbials may seem obvious at first, since one may already expect tutors to refer to a paper near them mostly by using the demonstratives this and these. However, from a pragmatics perspective, this practice may also be interpreted as a way to ground the session through language, thus reminding tutees indirectly that the session is being enacted based on their own papers. Terms that indicate proximal deixis (this, these, and here) may also allude to the level of emotional proximity and trust between tutors and tutees. If tutors overused terms indicating distal deixis such as that, those, and there - these might signal a degree of emotional distance that could potentially affect tutees' receptiveness to suggestions, comments, or corrections. The most striking revelation by the figure below is that session 1 contains over twice as many uses of this/these than any other 
session, or the same number of references, 23 , of all other sessions combined, except for session 4, which did not include a paper. This revelation illustrates the tutor's enactment (and possibly description) of the session as a collaborative event. That and those were used twice in sessions 1 and 3 and once in session 5. Besides the obvious reference to the paper sitting in front of both interlocutors, this and these may also contribute to creating a sense of closeness between participants.

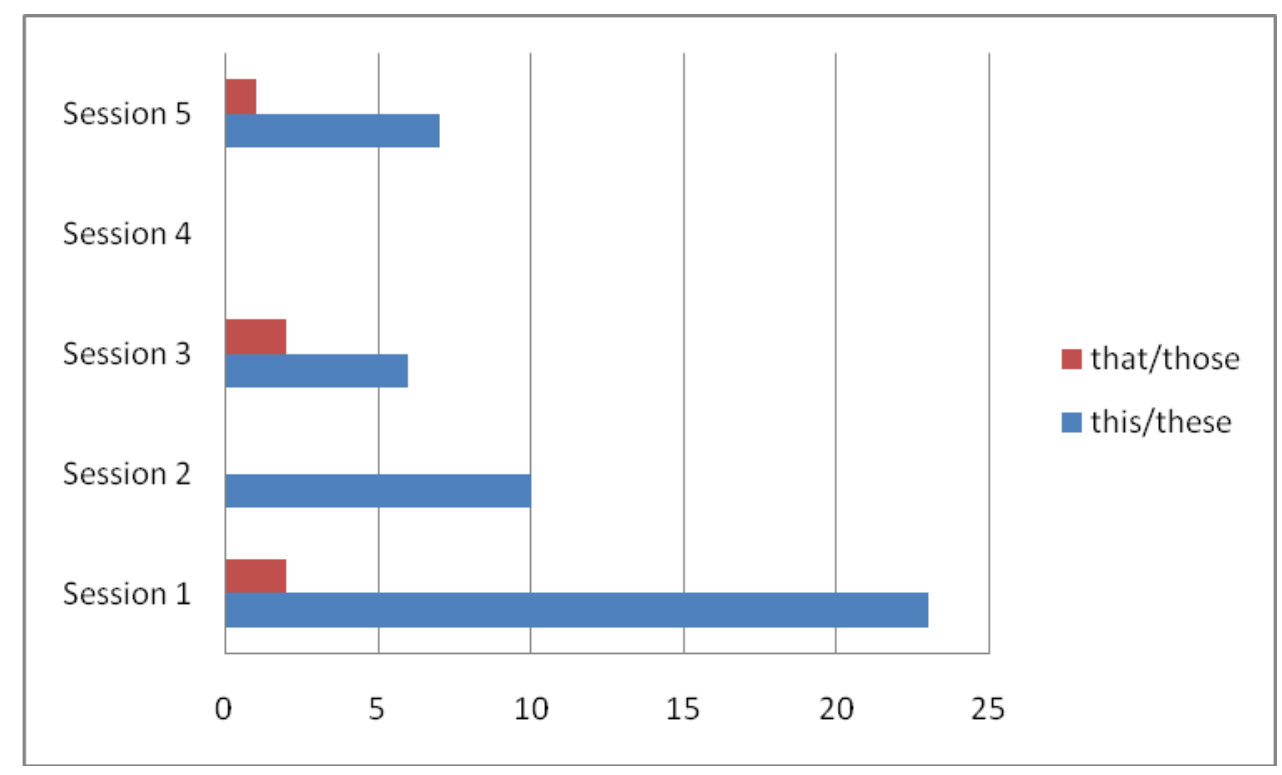

Figure 12 - Tutors' use of demonstratives

Place adverbials (here, there) were frequent in session 2 (29 cases), but they were infrequent in sessions 1 and 3 (7 cases) and rare in session 5 (1 case). As with demonstratives, they hold linguistic importance in that they are tools that tutors may use to draw tutees' attention to the session as one devoted 
to their own writing. Once again, one session (2) stands out with more uses of a term indicating proximal deixis (here) than all other sessions combined. The almost exclusive use of the term suggests an effort by tutors to create emotional proximity.

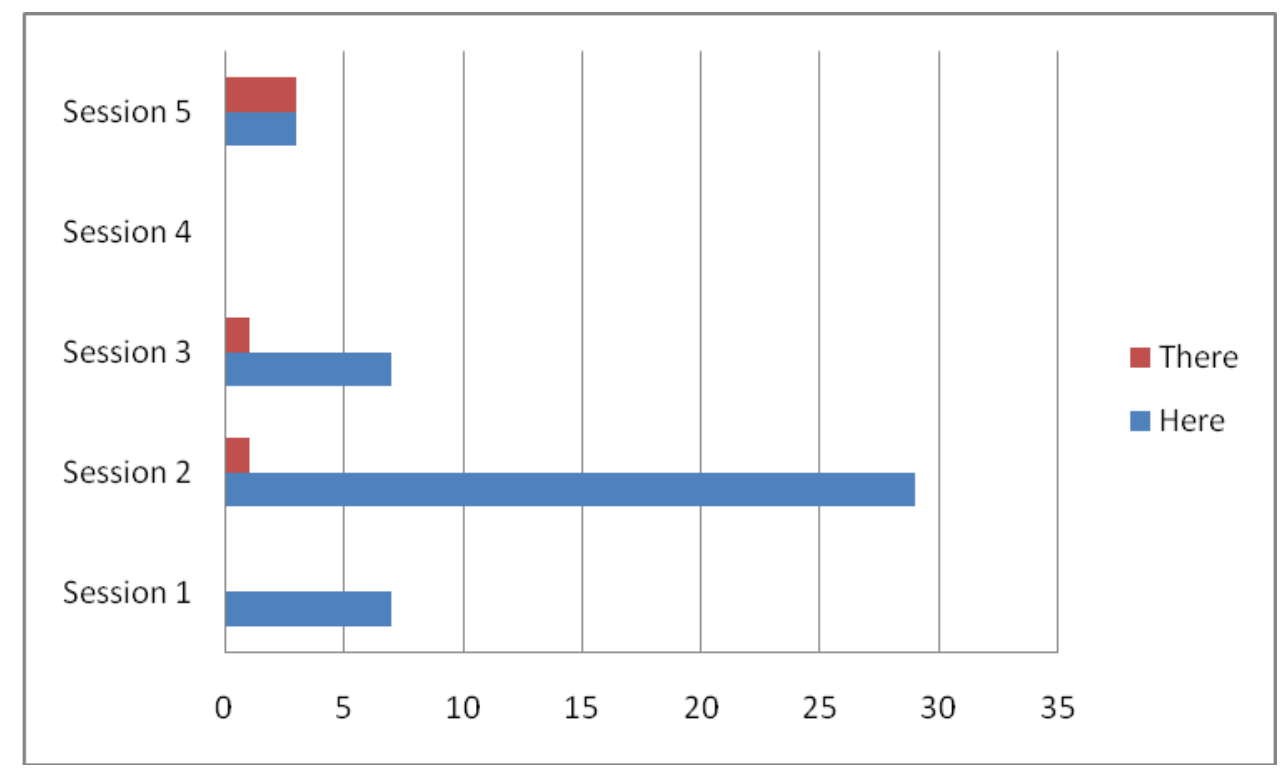

Figure 13 - Tutors' use of place adverbials

Even though deictic terms may serve to help the tutor ground the session and create emotional closeness, some variations in their numbers could be attributed to the tutors' own individual registers or manners of addressing their tutees during the session. They may also be attributed to differences in their personal descriptions and experiences of enacting sessions as collaborative events. No direct correlation was found between their use and specific variables considered in each session. More generally, however, tutors did use them as 
important dialogical tools to help set a positive, grounded, and collaborative tone for the session. This effort may contribute to making the writing session a time when tutees may feel safe and open to ask questions and receive feedback.

\subsection{Session Development}

In order to understand the role of each interlocutor during the writing conferences, I broke down the issues discussed in each session into three of their constitutive parts: initiation, follow-up, and closing/transition. My goal was to determine which interlocutor participated in each of the parts, how his or her participation played out, and in which instances his or her participation either turned into a dialogue about the issue or was dominated by one of the interlocutors. For this analysis, only questions or statements by tutors and tutees were considered, meaning that the parts when the tutee's paper was simply being read were excluded from the coding and calculation processes. The only exceptions were tutor pauses during his or her reading of the text. These pauses served as triggers of tutor participation, so it was crucial to include them.

To understand how each issue in the paper was dealt with, I first coded its constitutive parts: initiation, follow-up, and closing/transition. I created codes to highlight not only the participant (tutor or tutee), but also the type of participation (comment, question, suggestion, etc.) ${ }^{6}$ Codes are composed of two letters each, and the only exception is the code that indicates when the tutor ends the

\footnotetext{
${ }^{6}$ In some of the literature, particularly in the field of Pragmatics, these are identified as speech acts (see Austin, 1962, as cited in Cummings, 2005).
} 
session (T-END). In all codes, the first letter identifies the participant: $\mathrm{T}$ is the first letter in all tutor codes, and $\mathrm{S}$ is the first one in all tutee codes. The second letter in the code reflects the participant's intervention type (comment, question, etc.). Following is each code and its definition:

1. Initiation codes
a. TC - tutor comments on the issue
b. TQ - tutor questions
c. SC - tutee comments on the issue
d. $S Q$ - tutee questions
e. TP - tutor pauses

2. Follow-up codes
a. TQ - tutor questions
b. TS - tutor suggests
c. TE - tutor explains
d. TA - tutor answers
e. SQ - tutee questions
f. SA - tutee answers
g. SS - tutee suggests
h. SE - tutee explains
i. SC - tutee comments on the issue

3. Closing/Transition codes

a. TR - tutor continues to read 

b. TN - tutor asks new question
c. TX - tutor expands on issue
d. SN - tutee asks new question
e. T-END - tutor ends session

\subsubsection{Initiation}

Most initiation strategies used were the same for tutors and tutees; TC, TQ; ST, SQ, with the exception of TP (tutor pauses), which appeared only when tutors paused their reading. Tutors were also the participants who most often initiated discussions, as the data below show. They brought up issues by pausing their reading to either reread or try to understand what the tutee had written. Other times they paused to ask direct questions or make comments and then hear their tutee's reaction. On some occasions, both interlocutors participated in initiating discussions. In these cases, multiple codes were used. For instance, I used the combinations "TP, SQ" (tutor pauses, tutee asks) to indicate that a tutor's pause led to a question by the tutee, "TQ, SQ" (tutor asks, tutee asks) to show that a tutor's question triggered another question by the student, and "TC, TQ" (tutor talks, tutor asks) to indicate that a tutor's comment led to a subsequent question by the tutor himself or herself. The table below shows the total number of initiations and the number in which each interlocutor participated. 
Table 4 - Number of initiations by interlocutor in each session

\begin{tabular}{|c|c|c|c|c|c|}
\hline Interlocutor & Session 1 & Session 2 & Session 3 & Session 4 & Session 5 \\
\hline Tutor & 20 & 34 & 30 & 3 & 38 \\
\hline Tutee & 4 & 3 & 5 & 8 & 6 \\
\hline Both & 0 & 3 & 2 & 0 & 1 \\
\hline Total initiations & 24 & 40 & 37 & 11 & 45 \\
\hline
\end{tabular}

As the data illustrate, tutors were the main initiators in all sessions when a paper was read aloud. The only session in which the tutee was the main initiator of issues was session 4. Interlocutors shared initiations only in a few topics during the sessions. In general, tutees initiated fewer topics than tutors.

\subsubsection{Follow-up}

Follow-up refers to how a topic continues to be addressed after it is initiated or brought up in the dialogue. Follow-up codes were either used individually or in combination, and many discussions were conducted in such a way that tutor and tutee took turns making comments, asking questions, or making suggestions. For instance, a follow-up instance coded as "SA, TE, SQ, TS" indicated that the tutee answered a question (asked during initiation) that led to an explanation by the tutor; this explanation led to another question by the tutee that triggered a suggestion by his or her tutor, and so forth. Like initiations, follow-ups included questions, but they also contained the tutor's or tutee's answer (TA or SA), suggestion (TS or SS), and explanation (TE or SE). The 
table below shows the total number of follow-ups and the participation of each interlocutor in them.

Table 5 - Number of follow-ups by interlocutor in each session

\begin{tabular}{|c|c|c|c|c|c|}
\hline Interlocutor & Session 1 & Session 2 & Session 3 & Session 4 & Session 5 \\
\hline Tutor & 8 & 21 & 19 & 1 & 27 \\
\hline Tutee & 4 & 5 & 4 & 0 & 14 \\
\hline Both & 12 & 14 & 14 & 10 & 4 \\
\hline Total Follow-ups & 24 & 40 & 37 & 11 & 45 \\
\hline
\end{tabular}

Follow-up data shows increased joint participation, as compared to initiation data. In all sessions, except for session 5, joint follow-ups exceeded tutee-only follow-ups, but for the most part they did not exceed tutor-only followups, except for session 4. Despite the small number of joint follow-ups in session 5, tutee-only follow-ups outnumbered joint follow-ups. In session 1, the number of joint follow-ups is the same as the added number of tutor- and tutee-only follow-ups.

This pattern shows that once a topic was brought up, participants were in general at ease to participate and discuss. Tutors are trained to look for issues and point them out, and this explains their higher number of follow-ups altogether. Tutees, on the other hand, may not have conducted discussions as actively as tutors, but the data in the table illustrate that they were comfortable either leading some of the discussions themselves or participating in them with tutors. 


\subsubsection{Closing/Transition}

Tutors were in charge of closing discussions on most topics as they continued to read the students' papers during the sessions (TR), thus moving on to different issues. Tutors also closed a few topics by asking a new question (TN) or by expanding on the topic that was being discussed (TX). Students also asked new questions and closed discussions (SN), although few. The last issues addressed in the sessions were coded with a T-END, indicating that the tutors ended them.

Table 6- Number of closings by interlocutor in each session

\begin{tabular}{|c|c|c|c|c|c|}
\hline Interlocutor & Session 1 & Session 2 & Session 3 & Session 4 & Session 5 \\
\hline Tutor & 23 & 39 & 35 & 5 & 44 \\
\hline Tutee & 1 & 1 & 2 & 6 & 1 \\
\hline Total Closing & 24 & 40 & 37 & 11 & 45 \\
\hline
\end{tabular}

The only session whose closings were not tutor-dominated was session 4 , also the only one during which no paper was read. Throughout this session, participants discussed topics brought up mostly by the tutee.

\subsubsection{Dialogues and Interaction}

When analyzing the sessions and the participation of interlocutors in each of the topics discussed, any back-and-forth interaction from initiation to follow-up in which the participation of one interlocutor triggered the participation of the 
other was considered a dialogue, that is, for the purposes of our analysis, a dialogue was any interaction in which the participation of an interlocutor was triggered by the other either through a question, a comment, or a pause. These interactions may have happened either within the same part of a discussed topic (i.e., during initiation) or across different parts (i.e., from initiation to conduction). Tutor- or tutee-dominated participations were not regarded as dialogues.

Table 7 - Types of interactions in each session

\begin{tabular}{|c|c|c|c|c|c|}
\hline Type of Interaction & Session 1 & Session 2 & Session 3 & Session 4 & Session 5 \\
\hline Tutor- dominated & 4 & 17 & 16 & 0 & 20 \\
\hline Dialogue & 20 & 23 & 21 & 11 & 25 \\
\hline Total issues & 24 & 40 & 37 & 11 & 45 \\
\hline
\end{tabular}

Even though tutors performed most initiations and closings, when we look at transitions across the different instances of a discussed topic, which includes follow-ups, we obtain more evidence of dialogues that took place during the sessions. There were no tutee-dominated issues, and the tutor-dominated ones, which were relatively high in some sessions, are defined as those in which the tutor both initiated the issue and conducted it by explaining or suggesting a solution without explicit tutee participation. However, dialogues outnumbered tutor-dominated interactions in all sessions, and this shows tutees participated in most issues discussed during their tutoring appointments. 


\subsection{Probability of Participation}

Breaking down issues within sessions made it possible to analyze what types of tutor or tutee initiations were most likely to trigger the participation of the other interlocutor while a particular issue was being dealt with. The table below shows, for instance, how often initiations of the TC (tutor's comments on a topic) and TP (tutor's pauses) types triggered tutee participation.

Some of these results were indeed expected; for instance, it makes sense that all SQs (student's questions) initiations immediately triggered a response by the tutor and that all TQs (tutor's questions) were followed by a tutee's response. However, the data (see table 9) also show that TC (tutor's comments) interventions dominated the sessions overall, and they were not necessarily effective ways to encourage tutee participation. Of the $81 \mathrm{TCs}, 60$ resulted in discussion follow-ups by the tutors themselves. On the other hand, TPs (tutor's pauses) were mostly followed by student comments. By analyzing the data, it is possible to anticipate which intervention strategies will most probably draw the other interlocutor into the dialogue. For example, in these sessions TCs (tutor's comments) did not seem as effective to draw tutee participation as were TP (tutor's pauses) or TQs (tutor's questions). The data allows tutors to raise awareness of the repercussions of their interventions during the sessions. This finding is discussed in greater detail in chapter 6 (Conclusion). 
Table 8 - Follow-ups to initiation types broken down by interlocutor.

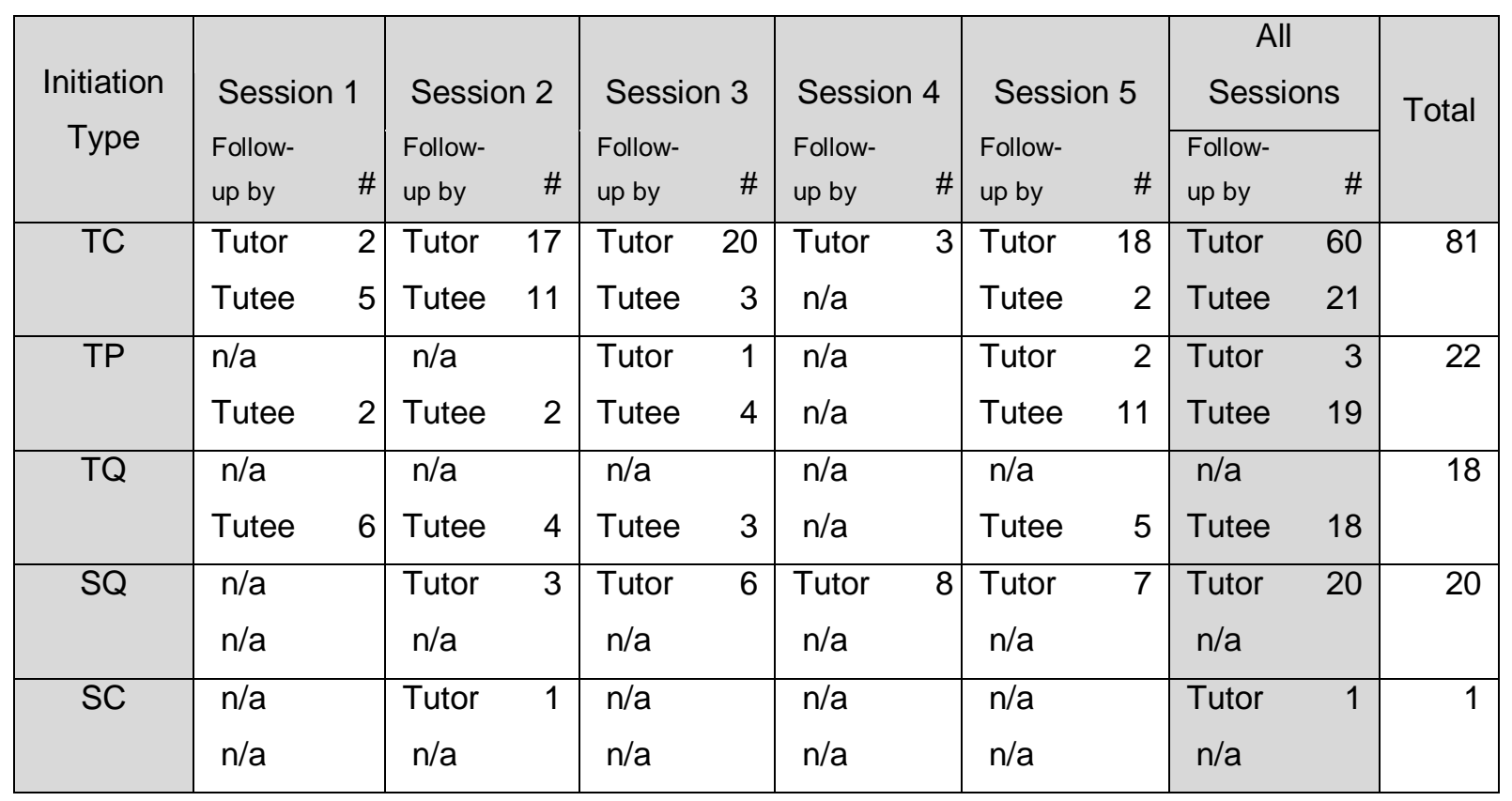

\subsubsection{Tutor-initiated Discussions}

Most discussions initiated by tutor comments (TCs) were tutor-dominated, except during session 1. Therefore, TC-initiated discussions showed an overall tendency by the tutor to monopolize talk throughout the whole issue, and they responded for most of the tutor-dominated discussions, as if the tutor was merely prompting (during initiation) his or her own subsequent explanation of the issue (during follow-up).

Tutor pauses (TPs) were instances when the tutor stopped reading to make sense of the text or to think about how he or she would frame a comment. Interestingly, these interactions most often triggered a tutee-response, as if the tutee felt responsible for explaining an issue or a point that caused the tutor to pause. Tutees may have interpreted these pauses as moments that prevented 
the tutor from understanding a certain section of their text. This behavior and the most frequent response to it have interesting pedagogical implications that will also be explored in the analysis of the results.

As one would expect, all TQ-initiated interactions (issues brought up in a question by the tutor) resulted in tutee-led follow-ups, whereas SQ initiations (issues brought up in questions by tutees) resulted in tutor-led conductions. The data above also include the few instances when the question was preceded by a comment. As obvious as this conclusion may seem at first glance, the data can also be interpreted as an indication that tutors will most often increase tutee participation by framing text issues directly into questions, or make sure their comments are immediately followed by questions.

Among all sessions (Table 9), there was only one case of ST (student making a comment on the reading); it accounted for $1 \%$ of all initiation types and resulted in a tutor-led follow-up. The sum of initiation types from all sessions also reveals that the strategy most tutors resorted to was making comments $(\mathrm{TC}=81$ or $57 \%$ ), even though this strategy did not necessarily prove to be the most effective to trigger tutee participation. The second most used initiation types were tutor pauses ( $\mathrm{TP}=22$ or $15 \%$ ), followed closely by tutee questions ( $\mathrm{SQ}=20$ or $14 \%)$ and tutor questions ( $\mathrm{TQ}=18$ or $13 \%)$. 


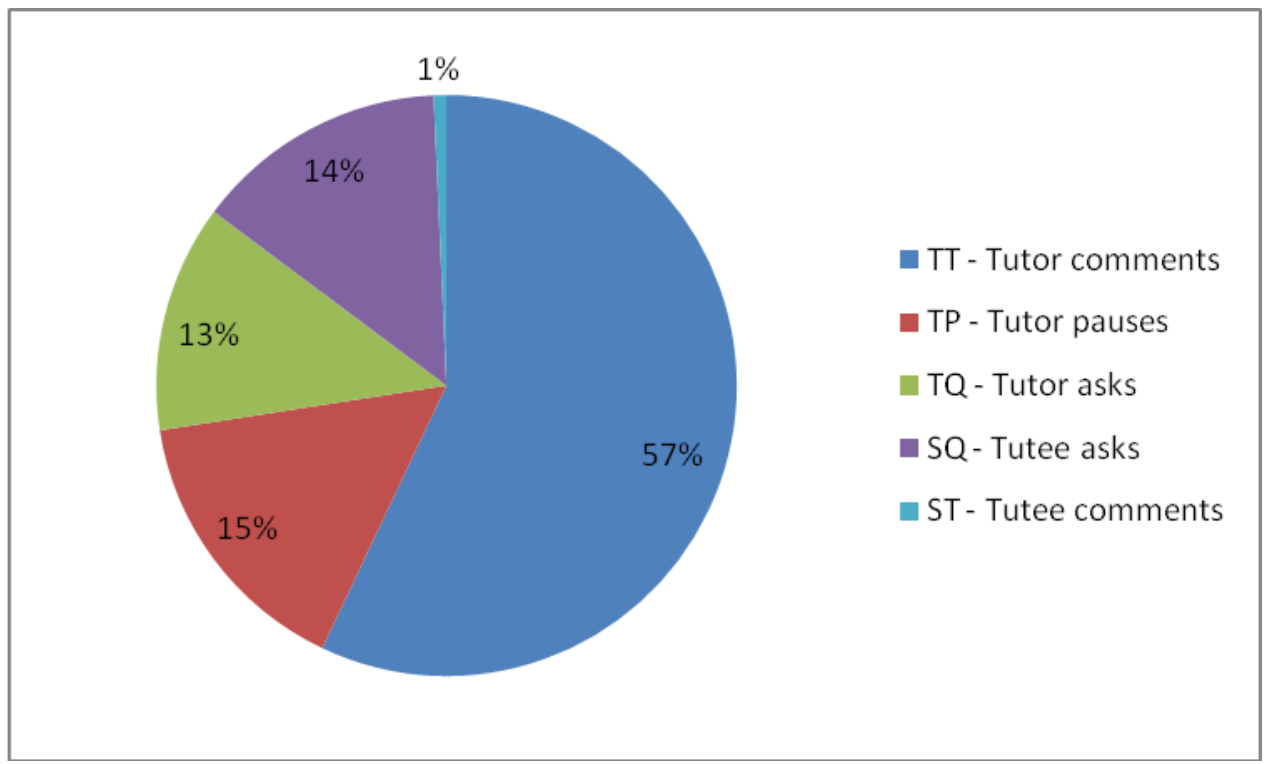

Figure 14 - Percentage of initiation types for all sessions

The graph below (Figure 15) highlights how much interlocutor participation each initiation strategy triggered, and it may serve as a tool for tutors to strategically plan issue initiation types based on the response they expect or want from tutees. The codes used in the figure are:

- $\mathrm{TC}$ - tutor talks or comments

- TP - tutor pauses

- $\mathrm{TQ}-$ tutor asks

- $\mathrm{SQ}$ - student asks

- $\mathrm{SC}$ - student talks or comments 


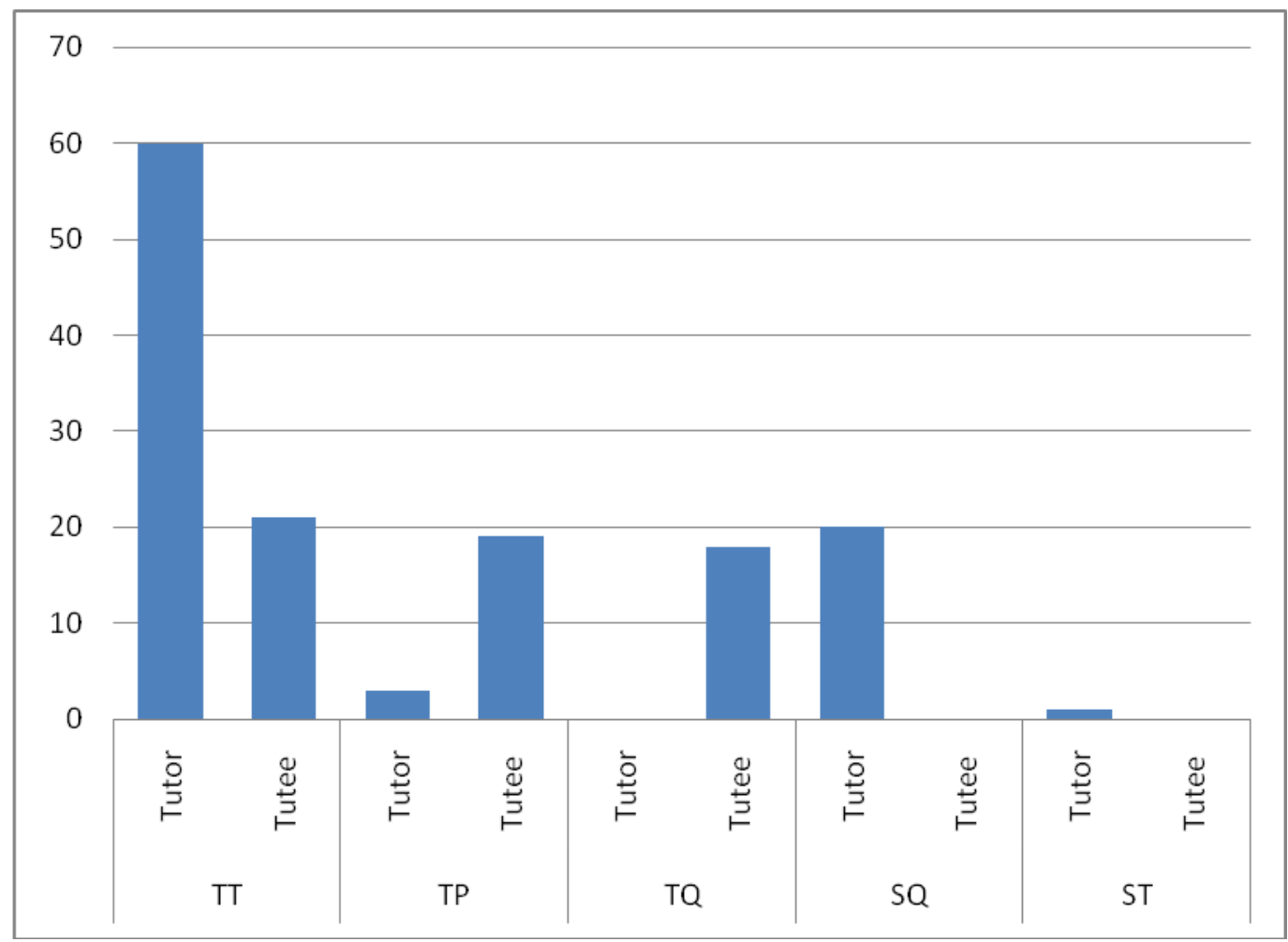

Figure 15 - Interlocutor participation triggered by initiation types

As figure 10 shows, the initiation strategies TQ and SQ only triggered a response in the other interlocutor who was prompted to answer the question. However, whereas many tutors followed up on many of the comments they had originally made (TC), student comments (SC) were only followed up by tutors. This may indicate that tutor comments (TC) may be interpreted as prompts for discussions, while tutee comments (SC) may be treated as questions. 


\section{Part B - Qualitative Data}

\subsection{Interactions}

Session recordings illustrate that writing conferences were indeed dialogical interactions between peers: one seeking help and the other "more capable," as Vygotsky defined. The sessions also contain examples of problemsolving initiated by either tutors or tutees, which allowed them to engage in conversations that in many cases transcended the initial problem and, according to participants, involved other issues (see Appendices B and C for post-session interviews). Recordings and interviews show that the main elements that contributed to the success of the sessions to interlocutors were a) tutors' awareness of the pedagogical benefits of the tutoring session and the linguistic needs of their tutees, b) tutees' understanding of how much autonomy they gain as writers by participating in the tutoring sessions, and c) the shared history between both parties at the SJSU Writing Center. These elements are illustrated in the session and interview excerpts below.

In the interview immediately following his recorded tutoring session, when asked to reflect on the kind of help students get at the SJSU Writing Center, Tutor 2 stated:

You know, in a classroom information is going one-way, usually, in most cases, but there is a very conversational aspect to a tutoring session. You are getting instant feedback from your tutee, whether they are getting it or not, whether they are engaged or not. And I think that really helps them 
learn, and it helps us to focus our tutoring or pedagogical style to them, and I think it is something you can't do in a classroom. (Tutor 2, postsession interview)

As tutors and tutees participating in this study had also worked together on previous papers, tutors showed they had a good sense of how much of the writing and revising process their tutees had already mastered or not. They seemed to have a strong sense of their tutees' ZPDs. Tutors also portrayed their tutees as active participants and attempted to minimize their authority role, especially during the interviews. Speaking of their interactions, tutors reported:

We have worked together to the point that we work together. I don't really like the whole I have the authority or listen to me kind of situation. So, there's that, and it is more like a discussion. (Tutor 1, post-session interview)

She was engaged. I would ask her, 'what would be the best way to rewrite this?' and she would give a suggestion. And often times it is the right suggestion. You don't necessarily have to tell her. (Tutor 2, postsession interview)

It's actually kind of funny because he is one of the first students I started working with, so with him I don't even ask anymore, like generally it's always going to be grammar. Traditionally with him I go over article use, 
prepositions and idioms, that's really..., and actually verb tense. He used to have problems with verb tense, but I think he has really fixed that. So, we just sit down and he tells me what it is that we are looking at. If he has anything special like, 'this one actually I am really worried about content,' he will let me know. (Tutor 3, post-session interview)

It's interesting to me in sessions that challenge me like that, it sheds light on what I don't know and need to work on, and he is one the students I work with when that happens quite a lot. After the session I go like, Man, I feel like I need to go out and understand the pedagogy behind how to teach something like 'to be' or 'to have'. I feel like that's good because it sheds light on your own weaknesses, and you see your strengths as a tutor, and you feel good about that, but you also try to see where you have your shortcomings." (Tutor 4, post-session interview)

She had her paper organized in a fashion such that she answered questions pretty directly. She knew what she had to do. She told me she seemed pretty confident about her content. She didn't want to focus on content, so we didn't. If anything [other than grammar and mechanics] did come up with her, I would address it. (Tutor 5, post-session interview) The examples above by no means suggest that every peer tutoring session will automatically involve problem solving or become an exemplary 
dialogical session. If the sessions analyzed in this study achieved this goal to some degree, it can be attributed to the tutor's pedagogical approach (by facilitating the session to encourage tutee participation) and to the tutees' claim of their space in the sessions. Both seemed aware of their roles in the interaction, most likely because tutors and students in this study had worked together previously and could enact a high-level interactive exchange in which their needs were addressed more quickly and effectively. In other words, participants were aware of these needs, and their shared history at the Writing Center enabled them to address them in the session. Therefore, participants, as well as the context they operate in, deserve the credit for facilitating their sessions in a highly interactive format.

In addition, the appointment system adopted by the SJSU Writing Center as well as other writing centers across the United States places key responsibilities in the tutees' hands before the session. By the time they come to their appointments, they will have already indicated what they are working on, what they need help with, and how far in the writing process they are. This system prompts tutees to share the information they hold and to think about their needs before the session (see subsection 4.14).

\subsection{Tutor Preparation}

Prior to working at the SJSU Writing Center, tutor candidates are required to take grammar and style tests, shadow or observe at least three sessions by 
other experienced tutors, and lead 2-3 mock tutoring sessions themselves in which senior tutors play the role of students. After these mock tutoring sessions, senior tutors give trainees feedback and advice for future sessions. This apprenticeship-style training format allows new tutors to practice and fine-tune their teaching skills on the job, and it may contribute to the dissemination and recycling of good tutoring practices among the staff.

The training tutors receive at the Writing Center, added to their experience working with a significant bilingual and multilingual population on campus, also seems to have increased their awareness of the linguistic needs of L2 students, as the following statements reveal:

One big thing aside from help from tutors and teachers is just to try to immerse yourself in the language, basically read a whole lot. Not so much just watch the news, but read, read, and read. It's the only way you can really pick up, especially as a writer, pick up all those little things that you have to do when writing, like avoiding repetition, redundancy, and all these things, and all these conventions that are in written language that are not in spoken language. (Tutor 2, post-session interview)

I know I read a lot of LLD [Linguistics and Language Development] papers in the Writing Center, and I know for a lot of people there's the cultural issue, so you don't want to just read English magazines because of cultural issues, but they have to do some of it. To really understand 
English idiom and speech and be able to articulate ideas at the college level, you have to do some of that, even if you don't want to. And a lot of them ask what they should do, and I tell them to watch something like the news and put on English subtitles, and they go like that sounds boring, and I go well, it's the only way you are going to learn (Tutor 1, postsession interview)

The excerpts above illustrate tutors' intent to engage in dialogues and create opportunities for their tutees to participate. They also highlight their awareness that second language development issues require taking time and overcoming specific difficulties, tasks that may be expedited by the work accomplished during the tutoring sessions.

\subsection{Tutees' Self-correction Skills}

Tutees also reported knowing to what extent their tutors are able to help them and how their help may translate into learning. In the tutee interviews following the sessions, some stated that attending writing center sessions over time had helped them learn to catch some of their own errors. Tutee 3, for instance, said he now revises the paper before each Writing Center session in an attempt to catch his own mistakes and reduce the session time spent on simple mistakes he is now able to correct alone. About his ability to self-correct, he stated: 
I am learning a lot from her [tutor 3] when I come here. Sometimes I make the same mistake, but I am able to catch the majority of my mistakes now. I will have less error on the paper. As I am reading along with her, I am able to catch it and fix it right away, without her telling me, Oh, what's this? If I miss it, she would say, Oh, what are we missing right here? Then, I would be able to catch it. The first semester I was here, which was like a year and a half ago [laughs], I was not able to do any of this, and now I am able to pretty much like edit my whole paper. The first meeting actually took like half an hour to spend on two pages. Now I can go through four or five pages with her without asking questions. Sometimes I ask questions because I want to know like why this is an "s" or something like that. (Tutee 3, post-session interview) In addition to clearly alluding to an increased ability to self-edit his papers, Tutee 3 characterizes a productive appointment as one in which he and the tutor could to go through four to five pages in a session without asking questions. This may suggest that while he may see session dialogues as invitations to engage in problem-solving tasks, they may not necessarily be the most relevant aspect in a productive and useful appointment for him. In this case, the tutee identified the tutor's and his ability to move through sections of the paper without asking too many questions as evidence that some of his needs did not have to be extensively discussed or even discussed at all. The tutee also suggests that his 
increased ability to self-correct before the session has contributed to faster revisions.

\subsection{Session Ownership and Tutee Engagement}

In tutor-tutee conference sessions, tutors, as teachers, are likely to be deferred to as the experts by L2 students, for they are in charge of facilitating the session, and they function as the experts in the dyad. In the five sessions I recorded, this dynamic was evident. Tutor 2 acknowledged it by stating in his post-session interview:

In most sessions, I, as the writing specialist, lead the session. In most cases, when I give them the option of, you know, do you want to read it out loud, or do you want me to read it out loud? They'll be like, you read, because maybe they think I'll pick up more errors that way. Clearly most tutees defer to me as the expert. (Tutor 2, post session interview)

Despite tutees' deference to tutors, there were also moments when it was clear the former played a significant role in directing the session, especially when they held information that was crucial to starting and maintaining the dialogue. Excerpts from all sessions, as can be seen below, show how tutees used information that only they possessed to set the initial tone and direction of the session. All excerpts are from the first few minutes of each session:

(1) Session 1: 
1- S: This is my writing, and first of all what it needs to do is to assess the student. You know, last week I showed you one of my students' writing about how she had her eye surgery. So, basically this is about her assessment prior to the case study, and then what I taught her.

2- T: OK.

3- S: And also, I want to work on the tense.

4- $\mathrm{T}:$ The tense?

5- S: Sometimes when talking about the test, I want to use the past tense, but like when I am analyzing what I am doing, I kind of feel like I am going in to present tense, too.

(2) Session 2:

1- T: OK. What would you like to work on today?

2- S: I have a presentation [inaudible] for which I have to do a write-up, so this is to go through the grammar.

3- T: Yeah.

4- S: So, 15 points was the presentation, the project is 50 points, and 35 points is for the write-up.

(3) Session 3:

1- T: OK, that looks like it [the recorder] is going. 
2- S: So, today I am working on my journal again about the two last class meetings. I started on my project for developing recreational activity for one of the client based on a case study.

3- T: So, the journal entry scripts? OK [starts reading student's paper].

(4) Session 4 (no paper was read)

1- S: I actually have a question for you.

2- T: Yeah.

3- S: When should I use the "be" verb compared to or versus the main verb or whatever, like "get" or "want?" When is it a good idea to use that [verb "be"]? It is kind of confusing. You know that I tend to use "be" like "I am," "he is," a lot compared to like "he get." I am using... like "if he get hungry," I would say like "if he is hungry." I tend to use that [construction] way more. Is there a reason? Would you recommend a situation when I should use the "be" verb?

(5) Session 5

1- T: Ok. So, what are we working on today?

2- S: I have to write a paper about...well, I am doing my internship, and I have to like find out a problem that my community has, and I have to like provide some ways to solve it.

3- T: OK. 
4- S: And I would like to focus on grammar.

5- T: [Scribbles] OK. So, mostly grammar...

6- S: Yeah.

Not only at the beginning, but also throughout the sessions tutors had to rely on tutees to obtain certain answers before making suggestions or corrections; other times tutees themselves intervened to make sure that what they had written did not get modified. Once again, such examples show that tutees did play an active role (to varying degrees) in determining the direction of the session. Session 2 is one that included a few of those instances: In passage 6 below, the tutor asks the tutee which person number $\left(1^{\text {st }}\right.$ or $3^{\text {rd }}$ person singular $)$ she is allowed to use in her writing before making a suggestion. The tutee then informs him that her text does not have to follow APA format and that she can write it in first person, which she then chooses to do after considering the two options Tutor 2 gave her. Passage 7 illustrates Tutee 2's decision not to go over a section of her paper she had quoted from a document, even after hearing from tutor 2 that it contained grammatical mistakes, a decision she might not have maintained in front of her own instructor. Italicized sections indicate that the paper is being read aloud:

(6) Session 2

44- S: In the training session... [Pauses], no...

45- T: So, who's discussing it? Can we say who's discussing it? Because this is actually not clear either who's... 
46- S: I am discussing it.

47- T: You're discussing it. OK. I guess you're forbidden from using "l" here. You think...?

48- S: It's not in APA because, in the conclusion, I have written "I."

49- T: Well, and you could also...one way to get around it is that you could just say "the author," you know. You are talking about yourself, but you can use "the author."

50- S: Or "the trainer?"

51- T: The trainer? Hmm, well, I don't know if it is clear that the trainer is the same person as...

52- S: I can use "I."

53- T: Yeah, either "I" or "the author." And then we can use that as our subject: "I will discuss..." or "the author will discuss..." hmm...

54- S: [Scribbles and mumbles]. "I will discuss..."

55- T: "I will discuss..." OK. You are discussing during the training session.

56- S: "During this training session, I will discuss...."

57- T: Exactly.

(7) Session 2 
124- T: ... handles food, exactly. Would you want to eat at or buy food from their business? Train food service employees on using the procedures in this SOP. Report to work and good health...

125- S: This is like I just copied from the SOP procedures, so I don't think we need to go through this.

126- T: OK.

127- S: OK, because there is a handout which I will be attaching to this. It's a standard handout.

128- T: Well, it's standard, but it has grammatical errors [laughs].

129- S: [laughs]. That's OK.

130- $\mathrm{T}$ : Then, conclusion?

Session 1 contains a similar passage (8), but in this case the tutee decides not to follow her tutor's advice based on her knowledge of the overall goal and content of her paper:

(8) Session 1

69- S: We are analyzing what she was doing prior to the case study. 70- T: This seems out of place [laughs].

71- S: [Laughs]. I think I can take it out because I talked about her conventions earlier, about capitals and... [Laughs]

72- $\mathrm{T}$ : You can make the point about catching her [a student the tutee was writing about] own grammatical errors maybe when you introduce the idea of editing before, if it's an important point that you bring up later. 
73- S: Not really, because I didn't talk of the conventions. We didn't get to that.

74- T: Because the whole...Up until this point the whole point of your paper seems to be on revision and not editing, and then you end it with a note that she doesn't know how to edit, either, which seems to not be what you want to talk about, right [laughs]?

75- S: We didn't get to editing either during the case study.

These excerpts also emphasize the need to look beyond participants' talk time in order to discuss how much ownership each interlocutor had, particularly tutees. The appointment system used by the SJSU Writing Center, the pedagogical approaches used by the tutors during the conferences, and the tutee's sense of session ownership contribute to placing the responsibility of establishing the session objectives on the tutees' shoulders. For those students already familiarized with this process, as is the case of all tutees participating in this study, this format may translate into more decision power and participation in their hands.

\subsection{Simplifying Complex Issues}

The data in this study also show that, during the sessions, grammar explanations were either prompted by tutees' questions or offered by tutors whenever the latter felt clarification was needed. These explanations were in general delivered in a simple, concise, and informal fashion. The recorded 
sessions contain interesting examples of how potentially complex issues were dealt with in a quick and accessible format to students, as some proponents of grammar feedback to L2 students recommend (see Ferris, 2003). The short format also prevented these grammar mini-lessons from taking time away from other discussions. In Tutor 2's post-session interview, when asked to complete the half-sentence "During a tutoring session, I help students mostly by..." about his views on writing center pedagogy, he responded in a way that summarizes the overall tone of the grammar explanations present in the appointments:

During a tutoring session, I help students mostly by... making complex ideas, whether they be grammatical, organizational, thesis statements, by making complex ideas easier to understand or explain, which I guess is the job of most teachers, you know. That goes in terms of complex grammatical rules, but that's also trying to get them to explain their own writing, to simplify their own ideas. Or maybe not simplify them, but to make them more understandable for the reader, which, I think, is a similar process, you know what I am doing in terms of the complex grammatical organizational ideas and what they're doing, or what they want to do with their own writing. (Tutor 2, post-session interview) In the following excerpt, extracted from session 2, Tutor 2 comes upon an issue of clarity caused by a case of passive voice in the tutee's text. Turn 41 of the session transcript shows the section of Tutee 2's text the tutor was reading when he came upon the issue. The subsequent lines describe how Tutor 2 
broke down the issue for the student. First he talked about how passive voice may affect sentence clarity and reader comprehension, and then he asked the tutee a direct question to guide her toward fixing the sentence. Throughout the whole explanation, Tutor 2 used elements from the tutee's own writing to ground his explanation. Italicized sentences refer to parts of the paper that the tutor read aloud:

(9) Session 2:

41- T: [T]rain food service employees in the restaurant in using the HAWCP-based SOP for personal hygiene. During the training session, all aspects of personal hygiene the trainees... [Pauses] the trainees are required to follow while handling and preparing food will be discussed. 42- S: It's [Should there be] a comma here...?

43- T: No, the main problem here...it's just an awkward sentence. Nothing you could really fix with just a comma or something. And the main problem is we have passive voice here. What passive voice [does] is it sticks the verb at the end or towards the end of the sentence, or... [Pauses] Yeah, what it is doing here is sticking the verb at the end of the sentence. We have all this stuff [before the verb] here. And in most sentences the reader is expecting the verb somewhere closer to the beginning of the sentence. So, when it's at the end of all this stuff, the reader is not going to know where to place all this information in context. So... 
44- S: "In the training session, [Pauses] no..."

45- T: So, who's discussing it? Can we say who's discussing it? Because this is actually not clear either who's...

46- S: I am discussing it.

Session 3 also contains a mini-explanation about the use of the noun "time" as a count or non-count word. This time the tutor looks for examples beyond the tutee's writing to illustrate her explanations, and she then immediately goes back to the tutee's text. Tutor 3 first provides examples, and then she offers a more abstract rule. Italicized sentences were those that were read aloud by the tutor, and the underlined words were those stressed in speech:

(10) Session 3:

54- T: Yeah, "crave alcohol." And then when we say "most of the time," it's actually "time" singular.

55- S: Singular because even though [we may say] "many times," actually when you talk about most of the time you...

56- $\mathrm{T}$ : Yeah, generally when you have "times" with the "s" at the end, it's the more idiomatic phrase. It's either very literal like "I am free at these times" or "the times are changing." But then "most of the time" is used without the "s" because it is more thought of as a non-count noun. 57- S: Oh, OK. Unless you talk about... like you gave me in your examples like, "how many times...?" 
58- $\mathrm{T}$ : Yeah. Because time as we measure it is non-count, whereas time as in terms of when something happens, like exact time, that's count. 59- S: Oh.

60- T: Become irritated if he does not get a drink at the regular time... maybe "at a regular time"?

61- S: "a regular time."

Session 4, whose discussions did not revolve around a paper, also contains a particularly interesting grammar explanation requested by the student. The question the tutee asked shows his knowledge of grammatical terminology, thus licensing the tutor to freely use it in his answer:

(11) Session 4:

59- S: There is something I want to kind of understand too while I am here. When you change it [be] to "have." "Have" tends to be followed by a noun. It can be a noun or a verb, right? But to describe something, a noun, right?

60- T: I have?

61- S: I don't know. I was trying to... I don't want to confuse myself. So I try to look for a pattern. "Have" tends to be followed by a verb or a noun, not an adjective.

62- T: Well, you could say like "I have white teeth." White is an adjective describing teeth. Yeah, you are going to have a noun or a verb... 
63- S: and the adjective to describe the noun...

64- T: Yeah, the adjective would describe the noun...

65- S: But you would not have just the adjective: "I have white..."

66- T: No.

67- S: At least the object has to be a noun...

67- T: Yeah, I mean this [the example that follows] is a bad [negative] example, but you could say, "I have stupid friends," you know, "my friends are silly," or "I have silly friends." It's [This last example is] better than the other one [laughs]. But you would not just say "I have silly" and period. 68- S: Yeah, yeah.

69- T: That does not work. Because "to have..." inherently in the form of the verb if you have something, you have to tell us what that something is, and a noun is a person, a place, or a thing. So, if it is falling under that heading, it's probably going to be a noun. [In] "I have to go," it is followed by an infinitive. [Provides another example:] "I have to find my silly friends." But a lot of times you have "I have" and the infinitive form. That might be a helpful pattern to think about. It might not always work that way, but off the top of my head, anyway, you could almost say it is partially a rule.

Other times, these mini-lessons also functioned as connections among grammar errors and other types of errors in the essay that had broader 
repercussions to the text and its accessibility to readers, as the two following subsections show.

\subsection{Global Versus Local Issues}

Also evident in the recorded sessions were instances when tutors explained grammar rules in a way that not only highlighted the correct form, but also made it clear that the issue may have had repercussions throughout a larger portion or the paper. Tutors, in these cases, sought to connect grammar issues to broader issues that could potentially jeopardize text clarity and readability.

As seen in previous examples from session 1, the main goal of the appointment (as requested by the student) was to check the tutee's use of verb tenses. In the following excerpt, Tutor 1 stresses that a change be made so that the verb tense in the particular example be consistent with other uses throughout the paper. The tutor makes a clear connection between a verb tense issue and its potential relationship to the paper as a whole. Italicized sections indicate that the text is being read aloud:

(12) Session 1:

51- T: ... This indicates [pauses] that she understands that she needs to edit her piece and that she would immediately start to edit without revision. I looked at her writing, and it is evident that she takes the time to edit her writing by checking her capitals and punctuations, as she uses these correctly for the most part. However, by looking at her paragraphs, she 
did not edit or delete any ideas. This again serves as evidence that she omitted revision [pauses]. OK. So, this indicates...Then you have a shift here because you are analyzing what these things mean, right? So, this is fine [rereads and mumbles]. However, by looking at her paragraphs, she $\operatorname{did} . .$.

52- S: Tense, right?

53- $\mathrm{T}$ : Yeah, so we need to make these consistent with the rest of them [verb tenses] [Reads same text section again]. OK. When Valerie wrote, she retold what she did in chronological order. She simply listed what she did, instead of explaining why each statement was meaningful to her. [Pauses and rereads] ...or focusing on a particular part. For example, in a personal narrative, she wrote "they had to do three surgeries. They said my eye would do much better, and my eyes healed."

54- S: I changed her tense to make it fit. Is it working? She said "they had to do three surgeries. They said my eye will feel better and that my eye will heal." Like that kind of didn't make sense in the context, so I changed it [the verb tense]. Did I fix it correctly?

55- T: Yeah! It works in here.

All other sessions contain examples and explanations that explore this same tension between local and global effects of grammatical and mechanical mistakes. In the following excerpt, Tutee 2 evokes the readers' understanding to justify his suggested change to the tutee's paper: 
(13) Session 2:

27- T: ...So, in this case we are actually going to have to use "that" instead of "which." When we use "that," what that means, as opposed to "which," is that we're saying this entire... um... clause or group of words is going back in describing points.

28- S: Uh-uh.

29- T: Both "that" and "which" mean "that." What "that" means is that this group of words is telling the reader which points you are talking about or what kinds of points you are talking about. Because the reader so far doesn't know what points you are talking about. If, on the other hand, you have already described the points like earlier, like the reader already knows what points you are talking about, and you just want to give more information about those points, then we use a comma and "which." What "which" means is that it's basically non-essential information; information that is not essential for understanding what points you are talking about, and you use "that" for what we call essential information. Does that make sense?

30- S: Uh-uh.

In the following first example (14) from Session 3, the student first identifies an issue of repetition in his text, and then the tutor makes a suggestion based on her perception that a statement written by the tutee was unclear. When Tutee 3 informs her that the statement shows he is anticipating some of 
his patient's problems, she then suggests he frame his predictions as conditions, as opposed to using firm statements that may confuse readers. In the second example (15) from the same session, she responds to a question by the tutee, and they delve into a sequence of issues that start with verbs and then move through sentence structure to generalizations. Italicized sentences were those read aloud by the tutor, and underlined words were emphasized in speech:

(14) Session 3:

115- S: [Mumbles sentences as he makes corrections]. I have a lot of "believe" here.

116- T: Actually, you could keep [the verb] "think" for this one, I would say. Yeah... um... because he is feeling sad... Did you get this from the case study itself, like you know he feels these things, or...?

117- S: I am anticipating some of the problems he [pauses] has.

118- T: Oh, because of his...

119- S: Yeah, because of his diagnosis.

120- $\mathrm{T}:$ In that case, I might actually put this in the subjunctive [conditional], and say, you know, "if he feels these, Frank might not want to go anywhere or interact with anybody," because we don't know. 121- S: So, I am concluding that he is feeling this... 122- T: Yeah, if he didn't tell you, you don't know for sure... Generally we don't want to assume. And then here you could say, "If he is feeling guilty...." OK 
(15) Session3:

135- S: I have some questions... about this.

136- T: Sure.

137- S: I wrote this earlier: "symptoms of mania are, symptoms are." Like are [emphasizes verb "are" multiple times]. If I use "are" right here, instead of "may include", "are high or irritable mood..." would I be able to keep this, or do I have to use "decreasing", "are decreasing...?"

138- T: Actually, you would not need to change anything in your list. The main difference between "are" and "may include" is basically like... if you say "are," it might imply to a reader that to be manic one has to have all these symptoms, whereas [with] "may include" we are dealing with the realm of possibility, so like... maybe if you have one of these symptoms, it could still be mania. So this [verb "are"] is more absolute as for this is kind of like... think of...

139- S: Is it more specific, or like a...?

140- T: [Reads]. If you were to use "are," you would not need to change any of these because they are still adjectives. It's almost like... I think...Did we ever discuss like subject and subject complement before? 141- S: Subject complement?

142- T: Yeah. It's kind of like... if I say "you are smart", "you" is the subject, "are" is the verb, and "smart" is the subject complement, which is going to be an adjective. 
143- S: Oh, no. Not yet. So, if you say...

144- T: It's one of the most basic constructions where it's like, "you are..." let me start with subject [pause], verb [pause], and then whatever comes after is the subject complement.

145- S: Which is describing "you."

146- T: Yeah. So, "you are an occupational therapist." "Occupational therapist" is your subject complement. "You are a writer;" that would be it. Generally this is going to be an adjective, and it can also be a noun. And here these are all functioning as subject complements: Symptoms of mania are...so they can be nouns, which means we would not need "decreasing" because that would...

147- S: Would not describe...

148- $\mathrm{T}$ : Yeah, that would be the present participle to modify need for sleep, whereas "decreased need" is more of a noun phrase in itself. 149- S: When I was rewriting this, I did not know how to use it, so I just changed it back to...

150- T: I would actually go with "may include" because I think "are," I mean, it would not necessarily [apply] to all readers, but to some it might mean all of this very literally, whereas like maybe someone who is manic only has high mood something.

While going over a handout about the uses of passive voice with his tutee, Tutor 4 concludes his explanation on the topic by clearly stating how passive 
constructions affect the type of information that will be available to readers:

Passive voice causes writers to either demote or hide actors, and therefore may affect text clarity on certain occasions:

(16) Session 4:

38- T: Yeah. So, this [the handout] will talk more about clarity in meaning. They often have to guess what you mean. The metropolis was scorched by the dragon's fiery breath. Ok. That makes sense, but when her house was invaded... well, if you read that, you go, "well, wait a second. Who invaded her house? I don't get it." And a lot of times a student might think that this covers... "Well, I told you that her house was invaded," and the comment in the margin from the professor might be like, "well, who is committing this action? Who did that? You need to tell me that." When you leave things like that out, the clarity suffers a little bit.

39- S: Huh.

40- $\mathrm{T}$ : That's what they say. Sometimes the confusion is minor. 41- S: Yeah, but sometimes it makes a difference.

42- T: Right. It lacks explicit reference to the actor. If there is one thing you can take away... This is how you can identify the passive voice [by asking]: "does it lack explicit reference to the actor?" We don't know exactly what the acting force is, who what is invading her house. Let me see... What other questions do you think you have regarding...? 
In the following example from session 5 , the tutee asks whether she should use "or" or "nor" in her sentence, and the tutor framed her suggestion based on how each would affect text formality. By doing so, Tutor 5 models that the issue of correctness is a broad issue whose decision depends on the overall tone of the text:

(17) Session 5:

71- T: Uh-uh. ...they need to be respectful toward students as well. They should not yell or use any type of abuse when trying to solve the problem. 72- S: Is it "or" or "nor?"

73- T: Let's say "or." Now you could say, "They should neither yell nor use any type of abuse," but that sounds almost too formal. So, I think it is better the way that you have it.

74- S: OK.

While the examples in this session revealed that participants identified and explored the existing tension between local and global issues of academic writing, others exist in which local issues served as entry points to global issues in the text the tutee had not perceived. In all of these cases, explored in the following sub-section, an apparent sentence-level issue was deconstructed by the tutor, revealing that the mistake involved other aspects of the tutee's text. 


\subsection{Grammar Issues as Pathways to Global Issues}

Perhaps the most interesting cases the data provided were those when interlocutors were able to break apart an apparent grammar issue and find a textwide issue to which it pointed. In these cases, tutors were not simply exploring the possible repercussions of tutees' writing errors; they deliberately highlighted the global face of local issues in the text, or rather modeled that local issues in reality might be serving as leads to related and broader issues. These cases illustrate that the grammar issues tutees were concerned about actually served as gateways to issues of format, content, and organization.

Session 1 illustrates such local to global transition. In the first example, as soon as Tutor 1 starts reading the paper, Tutee 1 asks a question about one of the sentences in her text. The tutor quickly reframes the question as one about the whole organization and logic of the writing piece:

(18) Session 1:

7- S: This is like her example [reads], second I open the presents, and she moved on to the next point [reads again]; third, I... do something. 8- T: OK. But she doesn't elaborate on...

9- S: Should I explain that? Like "in her writing, she wrote this... This indicates that she doesn't elaborate on her point."

10- T: You could do that. You could open up instead of putting these in parentheses and explain the example a little bit more. What's the thesis of 
what you are writing about? Is this supposed to be like an intro with a thesis or kind of like a reflection?

11- S: Kind of like a reflection.

12- T: OK. I would explain that a little bit more still just to give it an idea...What details do you think you should add in-between these two sentences?

13- S: OK.

14- T: Because I see from the example you gave that she goes "second; says something; third, says something," but you are not indicating what you think she needed to add in-between the ideas.

15- S: Uh-uh.

In another excerpt from the same session, the tutor again addresses the inconsistent use of verb tenses and turns it into an overall discussion about the organization and logic of the paper:

(19) Session 1:

34- T: ....in order to be able to choose a particular genre herself to convey meaning or fulfill a certain purpose. OK. So, there's a couple... like, "she chose to..."[rereads]. So, this one is fine, cause we're talking about when she is like in the process of writing it in the past. But I think when we are referring to the actual writing, like [reads], the "needed..." She still needs more instruction? Because you are making a point that she still needs it now since we are reflecting on her, even though in the past she has done 
this, the fact that she still does it, and you are writing a reflection on how she needs to improve these things.

35- S: Right. And this is what I found out, and then the next section is based on this. Like this information... I taught these things. So, partially, she is still doing this. Even if I taught her these skills, she is still... stuck to that...

36- $\mathrm{T}$ : I would just frame it as she is still doing it too because then if you are doing this kind of organization where you have a problem and then a fix, you want to frame the language in that it is still a problem. So, if you put it in past tense, it makes it sound like she's not doing it anymore. And then the next section is going to be like, "and this is how I fix this problem." You want language that shows it's a problem. Does that make sense? 37- S: Yeah.

In this last example from session 1, the tutor continues on the same issue of organization, and this time she connects this third issue to the first one they had addressed based on the tutee's question:

(20) Session 1:

42- T: She never shared her piece with her classmates or people outside of the class. Clearly, she was able to record what she did using her writing. Yeah. She still had not thought about why she wanted to write or with whom she would like to share her story. 
43- S: What [Laughs]? She, um... she had not thought about what...why she wanted to write... [Reads her statements again and mumbles]. 44- T: So, you are saying she should record the event, or just [that] she had not thought about if she wanted to write about the event or with whom she would like to share her writing.

45- S: [Reads and mumbles].

46- T: Here, I would, maybe, kind of like the first sentence of the first paragraph where we were explaining like why this sentence is bad, I might explain why these things are important to her writing or how that is going to make her writing more effective, and I might even link it back to whatever you were saying in this first paragraph. So, you were saying she was kind of going: I do this, I do this, I do this, I do this, etc., without giving any kind of significance or anything. Answering these questions is what is going to make her think of this significance, right? Because you want to leave the two paragraphs together.

47- S: OK.

48- $\mathrm{T}$ : Does that make sense?

49- S: Uh-uh. [Writes] OK.

The next example from session 2 illustrates a moment when the tutor connects a mistake apparently restricted to the use of a possessive adjective to an overall issue of clarity and person in the tutee's paper. Then the tutor immediately connects it to another issue involving the possessive case: 
(21) Session 2:

111- S: No. Actually, I was giving a demonstration in the class now. I am demonstrating one chef.

112- T: OK. So, here we have "their place," so it gets a bit confusing. Put yourself...So, if you're talking...In this case, "put yourself" in whose place? So, we're talking about that one chef?

113- S: Uh-uh.

114- T: OK. Is it a certain gender, or is it gender-neutral, like it doesn't matter if it is he or she?

115- S: Like, when I demonstrated, it was a she.

116- T: OK, um. Also it's not really clear because you haven't really mentioned the chef yet. So, it's not clear who we are talking about here. 117- S: Um... In "their place," "put yourself in their place," it [their] means the customers'.

118- T: Ah, OK. Then you probably want to say that. "Put yourself in the customers' place."

119- S: [Scribbles].

120- T: And it would be possessive, right? Yeah.

121- S: There's no apostrophe?

122- T: It is possessive, so plural: "customers," more than one customer. But it's also possessing place. So we need an apostrophe... That would mean singular possessive [Refers to the 's the student adds to the plural 
noun]. Plural possessive we put outside. Exactly, Put yourself in the customers' place and watch how your workmate...

Another example found in session 3 shows that, in order to respond to the information she read in one of the sentences, the tutor asks a question about the overall content and organization of the tutee's text. A short dialogue about the sentence starts, but the issue expands to the writing strategy used for whole paper:

(22) Session 3:

104- T: Yeah. Based on Frank's conditions, he is having difficulty with several areas of occupation. According to the American Occupational Therapy Association, Frank has difficulty with several areas of occupation which include activities of daily living, instrumental activities of daily living, rest and sleep, work, leisure, and social participation. Even though Frank has difficulty in several areas of occupation, the only area that is discussed in detail is social participation [pauses]. Now, let me ask a question about the last paragraph. This is actually like content. You say that the only area that is discussed... like who discusses it? Is it like that Frank has told the occupational therapist?

105- S: Um, because in the instructions I can either discuss like about all this or I can discuss about social participation. So, I choose to discuss about social participation. 
106- T: So, you are just letting your professor know: this is what I am... Ok, I just wanted to clarify that. No, that's fine, then.

The following chapter will revisit the results from quantitative and qualitative data presented in this chapter 4 and discuss their implications with reference to the research questions proposed earlier. 


\section{Chapter 5 - Discussion}

Based on the data from the previous chapter, I can now address the main issues that came up in the literature review and/or that were proposed by the research questions. These issues are: 1) session ownership and tutee engagement; 2) the validity of addressing grammar issues during the sessions;

and 3) the pedagogical implications of writing center sessions for overall writing development.

\subsection{Session Ownership and Tutee Engagement}

Previous studies on tutor talk and tutee participation in writing conferences have expressed a concern that tutors may easily monopolize, if not dominate, conference sessions (Patthey-Chavez and Ferris, 1997; Ewert, 2009). Some earlier studies (focused on written commentary to L1 students) even advised teachers to refrain from any suggestions to student text in order to avoid intrusion (Brannon and Knoblauch, 1982). Unfortunately, these studies did not target students and teachers in comparable populations, nor did they refer to the same types of conferences: while some investigated conferences students had with their own writing instructors, others focused on tutor-tutee conferences in a writing center setting, such as the ones in this study.

Addressing the issue of ownership requires first stressing an important distinction between teacher-student and tutor-tutee conferences and the role the 
student plays as an interlocutor in each. When a student meets with the teacher to discuss his or her progress throughout a writing task, the student is facing the authority figure in the classroom - the person who designed and determined the guidelines for the assignment. Therefore, during the conference, the teacher is not likely to ask the student to explain what the assignment entails and surely does not need him or her to clarify what the instructor's expectations are. However friendly and approachable the teacher may be during the conference, he or she still has a lot more control and decision-making power than the L2 student, who may be even likely to interpret any suggestion as a mandatory change to the paper in order to improve his or her grade. This is not to say teacher-student conferences are inherently bad experiences to students; however, power relations are strongly unequal in these conferences. This disparity certainly affects the amount of say each interlocutor holds in the context. Such dynamics may be helpful, however, on certain occasions, i.e. when the teacher needs to play a more active or authoritative role.

In tutor-tutee conferences, although tutees still defer to tutors as the authority figures who facilitate the sessions, the decision-making power held by tutors may not be perceived by students to be as strong as their teachers' (Williams and Severino, 2004). Tutees may feel like they have to incorporate feedback obtained in teacher-student conferences because the suggestions are coming directly from their professors. On the other hand, in a writing center session tutees have the role of informing tutors what type of feedback they wish, 
what their assignment is about, and what the guidelines and expectations of their professors are. As a result, they can also be more selective about incorporating the suggestions they receive. In the sessions recorded for this study, no tutor was absolutely certain what the assignment was, which grading guidelines the teacher set for it, or what the main issue to be dealt with was until the session started. Tutors' appointment sheets included what the student had requested they work on, but the important details only came at the start of their appointments, as all session transcripts show (see Appendix 1). Also, throughout the session tutors had to rely on tutees for any information relative to the assignment and its guidelines.

In regards to the relationship between interlocutors' talk time and session ownership, session data ${ }^{7}$ show that tutors indeed talked more during the sessions. However, much of their talk was framed by tutees' requests of what they wanted to revise. In some ways, tutee ownership was expressed more clearly in the role they played in the session than in the amount of talk time they held. Tutees seemed aware that they had a role in framing the appointment, which they also acknowledged during their interviews. However, their views on participation and ownership were not all uniform, and in some cases what they said did not really capture entirely the power they had as the sessions played out. For instance, in tutees' post-session interviews, they were asked to complete sentences written to capture their pedagogical views of the role they

${ }^{7}$ See Passages 6, 7, and 8 in the Results section. 
played in the Writing Center conferences. Two of the prompts they were given, as well as their responses, follow:

\section{Table 9 - Tutee responses to interview prompt}

\begin{tabular}{|l|l|}
\hline \multicolumn{2}{|c|}{ Prompt: DURING A TUTORING SESSION, I LEARN BEST BY... } \\
\hline Tutee 1 & $\ldots$ interacting with my tutor. We talk about each sentence at a time and make sure it \\
& sounds smooth, or if I ask questions I make sure I ask my tutor about it. \\
\hline Tutee2 & $\ldots$ going through my paper with the tutor. \\
\hline Tutee3 & $\ldots$ asking questions. \\
\hline Tutee4 & $\ldots$...example. Basically give me an example and tell me when to use it and not to use it. \\
\hline Tutee5 & ....asking questions and letting my tutor know what I want to focus on. \\
\hline
\end{tabular}

Table 10 - Tutee responses to interview prompt

\begin{tabular}{|l|l|}
\hline \multicolumn{2}{|c|}{ Prompt: DURING A TUTORING SESSION, MY MAIN ROLE AS A STUDENT IS... } \\
\hline Tutee 1 & $\begin{array}{l}\text {...being an active thinker. Not really listening and sitting and asking the tutor to do } \\
\text { everything for you. I just try to think with the tutor and try to focus on how I can make my } \\
\text { writing better. }\end{array}$ \\
\hline Tutee2 & $\begin{array}{l}\text {...to learn more from the tutor on the use of grammar and mechanics and to improve my } \\
\text { writing. }\end{array}$ \\
\hline Tutee3 & $\ldots$ to learn. \\
\hline Tutee4 & $\ldots$ to improve, to become a better writer, and improve my English. \\
\hline Tutee5 & $\ldots$ to ask questions and to provide a background about my paper. \\
\hline
\end{tabular}


Responses from Tables 9 and 10 vary from very unidirectional views of learning (learning from the tutor) to more dialogical or participatory descriptions (being an active thinker and going through the paper with the tutor). Despite these contradictions, session transcripts showed all tutees had a say in framing their session. The comments above also serve to remind tutors that they should not approach all tutees with the same "pedagogical tools," since different tutees will require different strategies to increase their engagement and participation, based on their views about their roles. The strategies tutors use may include choosing the right initiation type for a discussion, selecting prompts that will engage the tutee in explanations, and even using terms that indicate proximal deixis explicitly (see 4.8 in the Results section).

Even though I do not believe that engagement and participation should be measured mostly or only by talk time, for this variable does not explain all elements of power relations, I do believe it provides relevant information. The more equally time is shared, the more likely the dyad is to have productive discussions leading to learning. From a situated learning perspective, discussions play a key (although not unique) role in learning, defined here as the "re -coordination of perception, talk, and other actions" (Clancey, 1985). In other words, if these tutoring sessions can be defined as social interactions mediated through dialogues, then the strategy of encouraging dialogues certainly needs to be on the list of pedagogical approaches used by tutors. In these sessions, since all issues covered emerge from the tutees' texts, then the tutors' roles as readers 
place them in a strategic place to ask questions, demand clarifications, and initiate conversations. Tutors should take advantage of this strategic role to promote more dialogues about the tutees' papers.

Measurements of talk time can offer a distorted view of power dynamics when they are the only variables used to measure participation and ownership. Even though, in more recent studies, researchers have considered other variables, such as turn-taking within the session (Patthey-Chavez and Ferris, 1997), I believe they still have not provided a clear view of the decision-making power tutees have in writing center sessions or the strategies tutors can use to trigger more tutee participation in dialogues. These other variables still do not empower tutors to detect precise elements that they may change to refine their tutoring approach, when necessary. For this reason, I included additional variables, such as what initiation types are used by the interlocutors during their dialogues, which interlocutor follows up on the topic, and how much information about the session and its goals each interlocutor holds. These offer, for instance, more precise insights into the strategies tutors can use to increase tutee engagement because they allow tutors to detect which types of intervention trigger more participation by the tutee. For example, session data in this study showed that tutor pauses and questions were more likely to result in tutee followup than were tutor comments (see Figure 15). This observation can be reframed as a suggestion that tutors should try to verbalize their observations as questions 
rather than comments, or they should use pauses as a way to signal to the tutee that something is not clear in his or her text.

Tutors are also the ones facilitating the session and trained in the pedagogy of tutoring, so they should bear the responsibility to prompt tutees to talk more often when they are not engaged. As for tutees, in the few cases when they initiated issues, the main initiation type they used were questions to which their tutors naturally responded. This behavior may have contributed to the increase in the number of dialogues, but it also contributed to increasing an already high tutor talk time. In these cases, even though tutors could have also reframed tutees' questions as follow-up questions to promote more back-andforth exchanges, it is hard to frame these occasions as tutor appropriation of time because these responses were explicitly requested by the tutees.

\subsection{Addressing Grammar Issues in Tutor-tutee Conferences}

The practice of dismissing grammar issues brought up by L2 students, as is proposed by some scholars (see Review of the Literature), would have directly clashed with the expectations that the L2 students participating in this study held prior to and during the sessions. Appointment logs and the students themselves attested they wanted to work on sentence-level mistakes, and some tutees claimed they brought their papers for a grammar revision, after having already worked on content, format, and organization. This also suggests students were able to prioritize their own issues in the revision process. 
Therefore, for the purpose of analyzing the sessions recorded for this study, the discussion of whether or not grammatical or mechanical issues should be addressed in writing is close to irrelevant, for both parties involved - tutors and tutees - agreed that it was appropriate to address them and that they did not prevent tutors and tutees from discussing other issues. On the contrary, data shows they in fact served as links to other issues. In light of these five sessions, I propose that the question regarding the validity of addressing grammar issues be changed to: At what point in the revision process do we tackle these issues, and how should they be addressed? A possible answer is that they may be addressed concurrently with other global issues because local and global issues do not necessarily occur in isolation. Additionally, from a pedagogical standpoint, it seems logical to respond to a question by first validating the questioner's concern (or description) as genuine. In this case, after being acknowledged and validated, the student's grammar question can be used as a link to its own global repercussions along the text, when that is the case. Talking about tutees' sentence-level concerns may also contribute to creating a positive environment where they feel their needs are being met, and it also allows tutors to give tutees credit for detecting the entry points to other issues. In the post-session interviews, tutees expressed that they value a positive environment where their views and requests are respected and attended to:

I think it's important to find a tutor that you feel comfortable with; someone friendly, down to earth that you can just ask questions to and you wouldn't 
feel like you are asking a stupid question. Sometimes when I ask a question I think, "Oh, it's a stupid question." I feel kind of stupid, but I want to make sure that I know it, so I don't do it [make the same mistake] again. So, it's good to find someone you have a connection, a bond. (Tutee 4, post-session interview)

Additionally, students who ask for sentence-level revisions have their expectations rooted on what is considered acceptable academic writing in their own classes or at the university itself. This means that these expectations are obviously part of the context in which these participants operate. In many cases, particularly at SJSU, their professors require they go to the Writing Center to work on their recurrent sentence-level errors. Based on my personal experience as a former tutor at the SJSU Writing Center and a graduate student, I have seen that many professors take such errors very seriously in assignments or papers. Tutees also report that their instructors tend to pay close attention to sentencelevel issues when grading their papers, which places these errors high in the L2 students' list of topics to be covered during writing center conferences. Therefore, the decision to address errors or not is one that L2 writers, and not tutors, should ultimately make. When tutors address these errors, as requested by their tutees, they show that they understand and respect how L2 writers conceive, experience, and enact academic English writing.

These five tutoring appointments also highlight how tutors can address student errors creatively. Instead of delivering de-contextualized grammar 
lessons, a) they put visible effort in simplifying explanations and making them accessible to students, b) they tried to explore the connection between the issues and their global effect on tutees' papers, and c) they explored the relationship between form, context, and meaning in the students' papers.

\subsection{Overall Implications to L2 Writing Development}

I believe writing center conferences benefit L2 students pedagogically because of their relatively informal nature (when compared to teacher-student conferences), the power it gives tutees to determine the direction of the session, and the connections they allow participants to make between local and global writing issues.

In my interviews with interlocutors, both parties reported that the appointments were helpful. Tutors were able to detect how their tutees writing abilities had progressed, and tutees were aware of the writing or revision skills the sessions helped them develop. Tutees also felt they had enough space to ask questions, accept or decline tutor suggestions, and participate in leading the session toward their goals.

However, the greatest pedagogical gain for tutees is their chance to engage in a revision session that emerges from their own writing, revolves around issues from their text, and connects local to global elements within their own papers. When students claimed, for instance, that after these conferences they have been able to catch more errors than in the past, this may indicate that 
they are indeed learning how to write with fewer errors and to act as better editors of their own texts. From a situated learning standpoint, tutees may be establishing connections between the different contexts in which similar errors occur, thus enabling knowledge transfer and improving their writing accuracy. 


\section{Chapter 6 - Conclusion}

This study by no means claims that tutor-tutee conferences should be placed above all other forms of writing feedback. In a process-based writing framework, it is one of many useful steps, along with written feedback, peer conferences, and teacher-student conferences, to help students, especially international and immigrant students, go through the difficult task of developing their English writing skills. My main goal was to highlight that some writing issues may play out differently when the power dynamics are made more equitable. These same issues may be more difficult to solve in a context where only the student and the teacher are the interlocutors As L2 students have access to an expert peer at a writing center, they gain more control of their own needs and can make sure these needs are brought up in an interaction about their own writing. Based on the premise that writing center conferences particularly benefit L2 students, I present the study conclusions in order of importance. These conclusions are directed mostly to tutors working directly with L2 students in a writing center setting and researchers investigating the topic, but they may also be useful to writing teachers and instructors working in the classroom.

1. Issues of grammar correction can and should be addressed in writing center tutoring sessions involving L2 students, as requested

by the students themselves. I make this claim from the following 
standpoint: as interlocutors in the writing process, students or tutees know their needs, and instructors or tutors should honor and address them as much as they should open the students' eyes to the connections among local mistakes and overall text logic and organization. If the tutees' needs do not match what their tutors think they may need, it is because they have experienced writing through distinct perspectives and carry different descriptions of their own experiences. Now that they share a context and are immersed in the same community, tutor and tutee should negotiate and validate each other's claims, and no interlocutor should dismiss the other's views or needs. While it is true that both interlocutors need to accept the views with which they come to the discussion table, tutors do carry a bigger responsibility for doing so, for they are the ones trained to facilitate these sessions. In the five sessions I recorded, tutors managed to address grammar issues in such a way that empowered tutees to see the repercussions of these errors to overall text logic. Although limited in its scope, this study does not support the view that grammar correction is harmful to students or that it is reflective of pedagogical models of knowledge transfer.

2. Regarding the issue of grammar and mechanics, writing tutors should be open to addressing issues of sentence-level accuracy at any time during the writing process. Sentence-level errors may function like the tip of an iceberg or entry points to global issues in tutees' papers. If 
teachers and tutors decide to address them only at certain parts of the writing process, they may end up dismissing these important entry points. For some students, especially L2 students, expert feedback may be needed to help fix their sentences, regardless of where they are in their writing. Tutors in this study reported that none of the papers contained serious mistakes about organization, content, logic, or format, even though some of these issues emerged as they tackled other errors with tutees in the texts. However, when tutees had problems with global issues, they were often tied to other local issues tutees were not able to detect and/or fix.

\section{As session facilitators, tutors should be trained in strategies to} maximize participation and session ownership by tutees. The dialogues analyzed show that the way tutors respond to a proposed issue has direct implications in tutee talk time and participation. In the four tutoring sessions in which a paper was read aloud, pauses and questions proved to be the most likely way to trigger tutee participation, as opposed to direct comments and/or suggestions from tutors. Refining tutors' pedagogical skills may result in higher tutee participation and more balanced talk times among interlocutors. Although reaching a balance between tutor and tutee talk time may not the only goal toward a more beneficial session for tutees, increased dialogue has been correlated with more thorough revisions (Patthey- Chavez and Ferris, 1997). Moreover, 
tutees' higher engagement is likely to translate into more reflection and learning, especially when it leads to negotiations and problem-solving.

For instance, staff development workshops could train and encourage tutors to record some of their own sessions, with student consent, and code their own topic initiation techniques and the amount of tutee participation they trigger. Further studies, including analyzes of student writing samples, could also be conducted to establish connections between tutee's own reflections during the session and the changes they make to their final drafts.

\section{Session facilitators should be trained in making connections} between narrow and broad issues. By making these explicit connections, they will more easily validate (and not sabotage) tutees' concerns about local issues and highlight the existing tension between form and meaning, an explicit type of knowledge all English writers need. Such training will also translate into an increase ability to differentiate instruction during the sessions.

5. In order to assess session ownership, researchers need to look beyond talk time and use a combination of variables that highlight the power of each interlocutor in the session. The issue of text ownership brought up initially by Sommers (1982) and Brannon and Knoblauch (1982) should be reframed and re-contextualized in a tutortutee interaction because of the shift in power dynamics: the tutor depends 
on the tutee for information about the assignment and about the expectations of the instructor who designed it. Session dialogues also showed that tutees held key information about the sessions, even when they did not necessarily hold higher talk time than their tutors. Additionally, conference transcripts revealed that tutees felt at ease to disagree, even those considered weaker in regards to participation and interaction. These interactions also highlighted the practical nature of these conferences in that they give tutees what they are looking for: an expert reader who helps them highlight and fix inconsistencies, improve their drafts, earn better grades, and develop editing skills they can use to write other papers. In addition, the nature of tutor-tutee conferences may require that researchers consider the text as a separate interlocutor, as I chose to do in this study, since coding reading time as talk time by any participant may contribute to distorting results.

\section{Researchers in the fields of L1 and L2 Composition, Cognitive} Linguistics, Bilingual Education, and Second Language Acquisition should increase collaboration and conduct research to offer tutors and instructors more precise guidelines about the needs of L2 writers. Throughout my investigation and review of the literature, I noticed how disconnected the fields above are. Previous researchers (see Ferris, 2004) have also advocated for more collaboration among these fields. Even though much of the research in these related areas 
relates to language acquisition and development in children and K-12 education, it may still offer valuable contributions to the area of academic writing development, as did the studies on children's cognitive development by Vygotsky. Particularly interesting to the fields of $L 1$ and L2 composition are the studies on language development in bilingual children by Cummins (1999 and 2005) and Krashen (1976), two strong advocates for the development of $L 1$ academic language abilities concurrently with L2 development, a path not yet significantly explored by composition teachers and university writing program developers.

In addition to the recommendations highlighted above, as a closing I present what the tutees themselves reported about how these writing conferences benefit them as writers:

In order to become better writers, we need..." to take the time to think about it and make sure you take the time to go back and revise and edit it with some help. (Tutee 1, post-session interview)

During a tutoring session, I learn best by..." going through my paper with the tutor. (Tutee 2, post-session interview)

I am learning a lot from her when I come here. Sometimes I make the same mistake, but I am able to catch the majority of my mistakes now. I will have less error on the paper. As I am reading along with her, I am 
able to catch it and fix it right away, without her telling me, "Oh, what's this?" If I miss it, she would say, "Oh, what are we missing right here?" Then, I would be able to catch it. The first semester I was here, which was like a year and a half ago [laughs], I was not able to do any of this, and now I am able to pretty much like edit my whole paper. (Tutee 3, post-session interview)

Students who come to the Writing Center mostly get..." hands-on practice. You have a face-to-face session with someone there, and you can just ask. You learn a lot more than when you just look at the computer and just read it and learn it. Because sometimes I read it and interpret [it] a bit differently than most people. When you come to the [writing] center you can read something, you ask right away, and you get the answer. (Tutee 4, post-session interview)

What I like about her [tutor] or other staff members is that sometimes I have a paper, and they say like, "Oh, that's an excellent idea!" "Oh, this is a good sentence!" They always make comments and make me feel good about my paper. (Tutee 5, post-session interview) 


\section{REFERENCES}

Brannon, L. \& Knoblauch, C. H. (1982). On students' rights to their own texts:

A model of teacher response. College composition and communication, 33 (2), 157-166.

Bruce, S. \& Rafoth, Ben (Eds.). (2004) ESL writers: A guide for writing center tutors. Portsmouth, $\mathrm{NH}$ : Boynton/Cook Heinemann.

Clancey, W. J. (1997). Situated cognition: On human knowledge and computer representations. Cambridge, United Kingdom: Cambridge University Press.

Clancey, W.J. (1991). Situated cognition: Stepping out of representational flatland. Al communications - The European Journal on Artificial Intelligence, $4(2 / 3), 109-112$.

Clancey, W.J. (1994). Situated cognition: How representations are created and given meaning. In: R. Lewis and P. Mendelsohn, (eds.). Lessons from learning. Amsterdam: North-Holland. 231-42.

Clancey, W.J. (1995). A tutorial on situated learning. Proceedings of the international Conference on computers and education (Taiwan). Self, J. (Ed.). Charlottesville, VA: AACE. 49-70, 1995.

Cummins, Jim (1999). Alternative paradigms in bilingual education research: Does theory have a place? Educational Researcher, 28 (7), 26-32+41.

Cummins, Jim (2005). A proposal for action: Strategies for recognizing heritage language competence as a learning resource within the mainstream classroom. The Modern language Journal, 89 (4), 585-592.

Cummings, Louise (2005). Pragmatics: A multidisciplinary perspective. Mahwah, NJ: Lawrence Erlbaum Associates, Publishers.

Ewert, D. (2009). L2 writing conferences: Investigation teacher talk. Journal of Second language Writing, 18, 251-269.

Ferris, D. (1999). The case for grammar correction in L2 writing classes: A response to Truscott (1996). Journal of Second Language Learning, 8 (1), $1-11$.

Ferris, D. (2002). Treatment of error in second language student writing. Michigan: The University of Michigan Press. 
Ferris, D. (2003). Response to student writing: Implications for second language students. Mahwah, NJ: Lawrence Erlbaum Associates, Publishers.

Ferris, D. (2004). The "grammar correction" debate in L2 writing: Where are we, and where do we go from here? (And what do we do in the meantime...?). Journal of Second Language Writing, 13, 49-62.

Ferris, D. (2007). Preparing teachers to respond to student writing. Journal of Second Language Writing, 16, 165-193.

Ferris, D. (2009). Teaching college writing to diverse student populations. Michigan: The University of Michigan Press.

Ferris, D. \& Roberts, B. (2001). Error feedback in L2 writing classes: How explicit does it have to be? Journal of Second Language Writing, 10, 161184.

Goldstein, L. \& Conrad, S. (1990). Student input and negotiation of meaning in ESL writing conferences. TESOL Quarterly, 24 (3), 443-460.

Krashen, Stephen (1976). Formal and informal linguistic environments in language acquisition and language learning. TESOL Quarterly, 10 (2), 157168.

Lave, J. \& Wenger, E.. (1991). Situated learning: Legitimate peripheral participation. Cambridge, United Kingdom: Cambridge University Press.

Matsuda, P.K., Cox, M., Jordan, J.,\& Ortomeier-Hooper, C. (Eds.). (2006). Second-language writing in the composition classroom: A critical sourcebook. New York, NY: Bedford/St. Martin's.

Maturana, H.R. \& Varela, F. J. (1987). The tree of knowledge: The biological roots of human understanding. Boston, MA: Shambhala.

Patthey-Chavez, G. \& Ferris, D. (1997). Writing conferences and the weaving of multi-voiced texts in college composition. Research in the Teaching of English, 31 (1), 51-90.

Powers, J. (1993). Rethinking writing center conferencing strategies for the ESL writer. Writing Center Journal, 13, 39-47. 
PowersJ. K. \& Nelson, J.V. (1995). L2 writers and the writing center: A national survey of writing center conferencing at graduate institutions. Journal of Second Language Writing, 4 (2), 113-138.

Rogoff, B. (1990). Cognitive development in social context. New York, NY: Oxford University Press.

Samway, K.D., Karathanos, K., Mena, D., \& Whitenack, D.A. (2009). English learners in higher education: Strategies for supporting students across academic disciplines. San Jose, CA: San José State University.

Silva, T. (1993). Towards an understanding of the distinct nature of $L 2$ writing; The ESL research and its implications. TESOL Quarterly, 27 (4), 657-677.

Silva, T. (1997). On the ethical treatment of ESL writers. TESOL Quarterly, 31 (2), 359-363.

Sommers, N. (1982). Responding to student writing. College Composition and Communication, 33 (2), 148-156.

Straub, R. (1997). Students' reactions to teacher commentary: An Exploratory Study. Research in the Teaching of English, 31 (1), 91-119.

Truscott, John. (1996). The case against grammar correction in L2 writing classes. Language Learning, 46 (2), 327-369.

Truscott, J. (1999). The Case for "the case against grammar correction in L2 writing classes": A response to Ferris. Journal of Second Language Writing, $8(2), 111-122$.

Vygotsky, L. S. (1978). Mind in society. Cambridge, MA: Harvard.

Williams, J. (2004). Tutoring and revision: Second language writers in the writing center. Journal of Second Language Writing, 13, 173-201.

Williams, J. \& Severino, C. (2004). The writing center and second language writers. Journal of Second Language Writing, 13, 165-172. 


\section{APPENDIX A: TRANSCRIPT OF TUTORING SESSION}

\section{Session 1}

\section{Transcript - Session 1}

In the following transcription, numbers refer to turns in conversation, $S$ indicates the tutee is talking, and T indicates the tutor is talking. All italicized text refers to sections read aloud from the tutee's paper.

1- S: This is my writing, and first of all what it needs to do is to assess the student. You know, last week I showed you one of my students' writing about how she had her eye surgery. So, basically this about her assessment prior to the case study and then what I taught her.

2- T: OK.

3- S: And also, I want to work on the tense.

4- $\mathrm{T}$ : The tense?

5- S: Sometimes when talking about the test, I want to use the past tense, but like when I am analyzing what I am doing, I kind of feel like I am going in to present tense, too.

6- T: Valerie's strengths are that she was able to choose topics that are significant to her, and she was able to identify a few things about these events. For example, she chose topics about having eye surgery... and celebrating her birthday. Although in conferences she was able to orally explain the purpose for writing about these topics, she did not include these reasons in her paragraphs. She only wrote down what happened or what she did instead.

7- S: This is like her example [reads], second I open the presents, and she moved on to the next point [reads again]; third, I... do something.

8- T: OK. But she doesn't elaborate on...

9- S: Should I explain that? Like "in her writing, she wrote this... This indicates that she doesn't elaborate on her point."

10- T: You could do that. You could open up instead of putting these in parentheses and explain the example a little bit more. What's the thesis of what you are writing about? Is this supposed to be like an intro with a thesis or kind of like a reflection? 
11- S: Kind of like a reflection.

12- T: OK. I would explain that a little bit more still just to give it an idea...What details do you think you should add in-between these two sentences?

13- S: OK.

14- T: Because I see from the example you gave that she goes "second; says something; third, says something," but you are not indicating what you think she needed to add in-between the ideas.

15- S: Uh-uh.

16- T: OK. When her classroom teacher provided the students with detailed planning sheet ...so, we need an article.

17- S: “... a detailed planning sheet."

18- T: ...she was able to write in a particular genre, such as a personal narrative. However, without planning sheets, she often wrote a paragraph... [Mumbles] does she still do this?

19- S: Yeah, she does.

20- T: So, we would use a verb that...we would use present tense to indicate that she used to do it, but she is still doing it.

21- S: OK.

22- T: "So, currently, even without planning sheets, she often writes a paragraph..."

23- S: I am kind of like analyzing figure 2, like as far as using figure 2, she is still doing that. Right, she is still doing it, but...

24- T: OK. So then, "however, without planning sheets, she writes paragraphs like the one in figure 2."

25- S: OK. The paragraph?

26- T: I would say paragraphs, since she is doing it multiple times. 
27- S: Like the one in...

28- T: Yeah, you can put figure 2 actually in the sentence. ... a green topic sentence, three yellow details, and a red concluding statement. It seemed like the structure of a color-coded paragraph is ingrained in her mind... Is this still true? Because we changed this one [verb] now.

29- S: Yeah.

30- $\mathrm{T}$ : It seems like the structure of a color-coded paragraphs is ingrained in her mind...so we don't need that "and then." So, it will be "when she is writing." When she writes, yeah, she followed the structure... so that seems re...dundant, doesn't it? Because if you say "it seems like she has the structure in her mind, when she writes, she follows the structure."

31- S: Right, right.

32- T: So, either... we've connected the two sentences, it seems like we've made up a compound sentence without dropping the similar information, again. All of this after the comma, we don't even need. In her personal narrative about eye surgery, she wrote a paragraph about having surgery which included the beginning, middle, and end. She concisely told what happened in a single paragraph like a summary, instead of illustrating scenes. As this example shows, without scaffolding such as planning sheets, she chose to condense her writing into a paragraph rather than stretching it and writing multiple paragraphs. She still needed more instruction in the structure of a personal narrative or any genres. Or in other genres?

33- S: Yes.

34- T: ...in order to be able to choose a particular genre herself to convey meaning or fulfill a certain purpose. OK. So, there's a couple... like, "she chose to..."[rereads]. So, this one is fine, cause we're talking about when she is like in the process of writing it in the past. But I think when we are referring to the actual writing, like [reads], the "needed..." She still needs more instruction? Because you are making a point that she still needs it now since we are reflecting on her, even though in the past she has done this, the fact that she still does it, and you are writing a reflection on how she needs to improve these things.

35- S: Right. And this is what I found out, and then the next section is based on this. Like this information... I taught these things. So, partially, she is still doing this. Even if I taught her these skills, she is still... stuck to that... 
36- T: I would just frame it as she is still doing it too because then if you are doing this kind of organization where you have a problem and then a fix, you want to frame the language in that it is still a problem. So, if you put it in past tense, it makes it sound like she's not doing it anymore. And then the next section is going to be like, "and this is how I fix this problem." You want language that shows it's a problem. Does that make sense?

\section{7- S: Yeah.}

38- T: Prior to the case study, she wrote her writing only to herself, not intending to share her piece with anyone else. So, here...the verb [wrote] is fine because we are talking about prior, we gave a time. But she didn't write to herself? Unless she was writing herself letters, like, something directed to her? I think we are looking for something like she was writing things for herself. Does that make sense?

39- S: Just doing her assignment. Not really like writing a letter or writing letters, like Dear me... [Laughs].

40- T: [Laughs] because the "to" kind of means movement, like I am going to send this to myself. She didn't mail herself things or anything; she was just kind of writing to her own enrichment and for her own grade.

41- S: [Laughs].

42- T: She never shared her piece with her classmates or people outside of the class. Clearly, she was able to record what she did using her writing. Yeah. She still had not thought about why she wanted to write or with whom she would like to share her story.

43- S: What? [Laughs]. She, um... she had not thought about what... why she wanted to write... [reads her statements again and mumbles].

44- T: So, you are saying she should record the event, or just [that] she had not thought about if she wanted to write about the event or with whom she would like to share her writing.

45- S: [Reads and mumbles].

46- T: Here, I would, maybe, kind of like the first sentence of the first paragraph where we were explaining like why this sentence is bad, I might explain why these things are important to her writing or how that is going to make her writing more effective, and I might even link it back to whatever you were saying in this first paragraph. So, you were saying she was kind of going: I do this, I do this, I 
do this, I do this, etc., without giving any kind of significance or anything. Answering these questions is what is going to make her think of this significance, right? Because you want to leave the two paragraphs together.

47- S: OK.

48- $\mathrm{T}$ : Does that make sense?

49- S: Uh-uh. [Writes] OK.

50- T: I asked... [Pauses and reads the title of section]: Student Writing Process. I asked her about her writing process during the writing conferences. She shared that if she worked on the formal writing project, then she would use the planning sheets that the teacher would provide to plan the details of her story. If the teacher did not provide a planning sheet, then she would think about what she would say in her head. Then she would start her draft right away. Since this one has kind of an opener, you know the "if the teacher did not provide a planning sheet..." I would maybe get rid of this then and keep the one over here.

51- S: OK.

52- T: She would think about more concrete statements as she would write. In Valerie's class, students do not use a writer's notebook to develop their topics, so she is still not introduced to the idea of using writing tools to rehearse her writing. In class, she had revised her stories [pauses] in class by adding details, cutting unnecessary sentences, and changing the order of sentences.

However, when I asked her what she would so after she finished her draft, she said she would reread her piece to check for capitals and periods. This indicates [pauses] that she understands that she needs to edit her piece and that she would immediately start to edit without revision. I looked at her writing, and it is evident that she takes the time to edit her writing by checking her capitals and punctuations, as she uses these correctly for the most part. However, by looking at her paragraphs, she did not edit or delete any ideas. This again serves as evidence that she omitted revision [pauses]. OK. So, this indicates...Then you have a shift here because you are analyzing what these things mean, right? So, this is fine [rereads and mumbles]. However, by looking at her paragraphs, she did...

53- S: Tense, right?

54- T: Yeah, so we need to make these consistent with the rest of them. [Finishes rereading same part]. OK. When Valerie wrote, she retold what she did in chronological order. She simply listed what she did, instead of explaining 
why each statement was meaningful to her. [Pauses and rereads] ... or focusing on a particular part. For example, in a personal narrative, she wrote "they had to do three surgeries. They said my eye would do much better, and my eyes healed."

55- S: I changed her tense to make it fit. Is it working? She said "they had to do three surgeries. They said my eye will feel better and that my eye will heal." Like that kind of didn't make sense in the context, so I changed it [the verb tense]. Did I fix it correctly?

56- T: Yeah! It works in here. Readers can understand what happens in her story. However, it was not clear what kind of meaning she really wanted to communicate through her story. So, what meaning she wan... the verb here. We have "it is not clear what kind of meaning she really..."

57- S: It was not clear? Because this is like the writing that she completed a long time ago?

58- T: Well, we say when people read it now, readers can understand... I think what's making this confusing is like when you read about literature you have to keep that in present tense, too. So, even though her writing is not like "literature" - Shakespeare or anything like that - it's still a piece of writing, so every time you come and you read it, it's in present tense, so the readers can understand what is happening in the story as they're reading it. And "it is not clear what kind of meaning she wants to communicate through her story..." Because every time you read it, it's going to communicate something.

59- S: Uh-uh.

60- T: Her personal narrative reveals that she knew that a story needed to have a beginning, a middle, and an end [pause]. So, she would still know this.

61- S: Uh-uh.

62- T: That's another thing: when something is knowledge or like a fact, it stays in the present tense too. She picked a significant event in her life, and she established a conflict: there is something wrong with my eye. So, This is good in the past tense because you are talking about her process before writing, so it's something that... in the past she picked that event to write about it. I know it's confusing to go back and forth [laughs].

63- S: [Laughs].

64- T: Although she knew some aspects of a personal narrative, she still needed 
to learn more about the structure of a personal narrative, details, and voice. She needed to think about what she wanted to communicate through her story. Based on the meaning of her story, she needs to learn which part she should develop more and add her feelings and thoughts into her personal... so here we are jumping back and forth.

65- S: [Laughs].

66- T: So, we have, "although she knew..." [Mumbles as she reads]. So, are you making a point that these are the things she should have done beforehand, or are you making the point that these are the things we should work on in the future?

67- S: Yeah, like these are the things she needs to work on, and this is actually what I thought these are things she should have worked on. So, yeah, these are like areas of need.

68- T: So, instead of keeping them in the past and kind of ...because when you keep them in the past tense, you're making it sound as if she, she...like you should have done this! It's something kind of like... these are the bad things you did in the past, instead of looking to correcting these things in the future. So, I think you should try and change those to "although she knows some aspects of a personal narrative, she still needs to learn...She needs to think about what she wants to communicate through her story..." So here we want to put this "which" with this part here. Oh, no! She needs to learn which part... Because we are actually not going from...Even though you are trying to do the "to add" and "to learn," it's not working in the sentence construction.

69- S: Uh-uh.

70- T: I think it's the "which" that kind of throws it off. If we switched them and said she needs to add feelings and thoughts into her personal narrative and to learn which part she would develop more... I don't know, it just sounds...Or, the other thing I was going to say: you can say she needs to learn "which part she should develop more" and "how to add feelings and thoughts into her personal..." So, we go with two question words. Valerie remembered to add periods at the end of each sentence. Most of the time, she was able to check for capitals by herself. However, she was still not ready to catch her own grammatical errors. For example, she needed her teacher to show her how to fix run-on sentences. So, is this like the first thing we are focusing on?

71- S: We are analyzing what she was doing prior to the case study.

72- T: This seems out of place [laughs]. 
73- S: [Laughs]. I think I can take it out because I talked about her conventions earlier, about capitals and... [Laughs].

74- T: You can make the point about catching her own grammatical errors maybe when you introduce the idea of editing before, if it's an important point that you bring up later.

75- S: Not really, because I didn't talk of the conventions. We didn't get to that.

76- T: Because the whole...Up until this point the whole point of your paper seems to be on revision and not editing, and then you end it with a note that she doesn't know how to edit, either, which seems to not be what you want to talk about, right [laughs]?

77- S: We didn't get to editing either during the case study.

78- T: OK. So, based on the assessment, I selected the teaching points for Valerie. She reworked on her personal narrative about having eye surgery. We worked on rehearsal and drafting together, and we were in the middle of revision. And we were in the middle of revision? We are in the middle of revision? She is still working on her personal narrative.

79- S: [Laughs]. "She is still working on this writing?"

80- T: Um... You called it a personal narrative throughout, so at least I read this and knew you were talking about this specific personal narrative.

81- S: And when I speak of "reworked on her personal narrative..." This is the one that she worked on, she worked earlier, like just one paragraph about how she had her surgery. Instead of "reworked," [I should change it to] "working" here because she talked about this topic again, but she didn't really like stretch it out or anything. She kind of started fresh again, but she talked about the same topic.

82- T: OK. I think that word works better than like...so she wasn't doing revision and, like reorganizing some sentences and polishing up, like fragments or things like that.

83- S: She just went back to that topic.

84- T: So, you started like from scratch. OK. It makes sense to me.

85- S: OK. 
86- T: First, I taught her to have a sense of audience. Before the case study, she was writing her story only to herself. I had her think...

87- S: Only for herself?

88- T: Yeah. I had to think with whom she would like to share her story. She took the time to think about these questions and said she wanted to share with her teacher and her mom. I had her expand her audience by asking, who else might be interested in listening to your story? She then decided that she would like to read her story to her classmates and everyone in her school because not many children have had eye surgery, and she would like to tell what it was like to go through it [pauses].

89- S: Do I need a comma?

90- T: [Rereads]. So, when we have a "so," it's one of those FANBOYS. Yes, you got it.

91- S: OK.

92- T: After focusing on who would be her audience, I taught her to think about what she wanted to say about having eye surgery. Prior to the case study, she listed what she experienced, but my teaching point was to have her think why she wanted to share her experience of having surgery with all of the students in her elementary school. She thought for a while and explained that it was really scary to have surgery, and it took a lot of courage to go through it. Based on what I taught, she wrote her first attention-getting signal as "I want to share a story from my life that took a lot of courage." This sentence clearly indicated that knowing who would be her audience and what she wanted to communicate through writing influenced how she wanted to start out her personal narrative. This sentence seems kind of wordy [rereads]. Oh, it was the knowing. It's fine. I was just stressing out. [Reads same sentence again]. That was me. Operator-error [laughs].

93- S: [Laughs]. And also, like right here, so I need to explain it, or is it OK to end a paragraph with quotation marks? Do I need...? I kind of explain it in the next paragraph, but is it OK to end a sentence like that?

94- T: Usually you don't want to end with a quote because you are putting it in to make a specific statement. I would maybe add a sentence about this quote in particular and take these two sentences and add it to the paragraph.

95- S: You mean combining these two paragraphs? 
96- T: Yeah, but I think we need a sentence in-between that specifically says why it is great that she came up with the sentence or why you wanted her to have a reason for writing her narrative.

97- S: OK.

98- T: OK.

[Both laugh before recorder is turned off]. 


\section{Session 2}

\section{Transcript - Session 2}

In the following transcription, numbers refer to turns in conversation, $S$ indicates the tutee is talking, and T indicates the tutor is talking. All italicized text refers to sections read aloud from the tutee's paper, and underlined words were those the interlocutors emphasized in the dialogue.

1- T: OK. What would you like to work on today?

2- S: I have a presentation [inaudible] for which I have to do a write-up, so this is to go through the grammar.

3- T: Yeah.

4- S: So, 15 points was the presentation, the project is 50 points, and 35 points is for the write-up.

5- T: So, you want to work on the grammar for these parts. OK. New Heritage is a casual dining Indian restaurant. The training takes place in the restaurant for employees that handle, prepare, or serve food. This training is aimed at training the food service workers... HAWCP based on standard operating procedures for personal hygiene. So one thing here is it gets a little bit repetitive when you say, "this training is aimed at training...." So far, we've already said "training" once, so we can probably just use "this" as our subject. We can just say, "This is aimed at training the food service workers..." This training will involve a demonstration of procedures on personal hygiene as mentioned in the sample HAWCP-based SOP. The primary agenda of the training is to prevent contamination of food by food-service employees. So this gets a little bit repetitive, as well. What we could do is ... We have already mentioned what kind of employees these are. So we can probably just say "employees," yeah. Number of trainees: 6; age: 18-30 years old; gender: 4 males and 2 females; knowledge level of topic presented: have a general knowledge about personal hygiene and food service operation. OK. So, here it's not really clear what you mean by "food service operation..." um...

6- S: So, should I write "the restaurant?"

7- T: ...personal hygiene. Well, so far I think we have said food service industry. Have we said that [pauses]? Um... We could just say "in the food service organization." Educational background, high school pass...outs. So, what do you exactly mean by "passouts?"

8- S: I mean all of those who have completed high school. 
9- T: OK. Um... We don't usually phrase it as "passouts."

10- S: So, "completed high school."

11- T: Yeah. We could say, "completed high school" or "graduated from high school" or "high school graduate", if you wanted to do that.

12- S: [writes]

13- T: ... Interested in the topic: All the participants have a lot of interest in learning about personal hygiene as memory refresher.

14- S: "a"?

15- T: Yes, exactly. Because here we have "refresher," but it's one kind of refresher out of many different kinds. OK? [Pauses and moves papers on the table] 1 year to 10 years of work experience. OK. Language barrier and multicultural awareness: All of the participants can read and write English fluently. They may come from different cultures, but their first language is English. So, what do you notice about this part here?

16- S: "And"?

17- T: No, well... because "but" and "and" imply different things. But implies contrast...

18- S: It means they speak different languages, but their first language is English.

19- T: Yeah. So, you are contrasting these two ideas. Like, even though they come from different cultures, their first language is English. The "but" is fine. What I was trying to point out is that when we have "but" or "and" or "so" or "or"...When we have these words connecting two different sentences...Sentences as in a subject and a verb... So, here you have "they" and the verb "may come," and then after the verb we have a new subject "their" or "their first language" and the verb "is." So, when we see a new subject and a new verb, it means that we have a new sentence. And when we have "but," "and," "so," or "or", we always need a comma before... Yeah, exactly [pauses]. This training is required as a part of the HAWCP program to rid contamination of food by food service employees. So, it's the same thing here...

20- S: "by employees?"

21- T: Yeah. It is also a great time to reinforce some of the points which are important to follow as part of state and local health departments. OK [pauses].

So, one thing here...

22- S: "Some points."

23- T: Pardon?

24- S: "It is also a great time to reinforce some points which are important..." 
25- T: Yeah, we can do that as well. We can cut out some words. One thing I would say here is that here you capitalize state.

26- S: OK. And local and health departments are not.

27- $\mathrm{T}$ : Yeah. We only capitalize proper nouns, like titles. If, you know, you are naming the actual department, like the title of the actual department or departments, and then we would capitalize it. But here we seem to be just like describing the departments, not giving their actual titles. So, if that's the case we wouldn't capitalize anything. So, you wouldn't capitalize "s" in "state" [pauses as student writes on her paper]. So, in this case we are actually going to have to use "that" instead of "which." When we use "that", what that means, as opposed to "which", is that we're saying this entire; um... clause or group of words is going back in describing points.

28- S: Uh-uh.

29- T: Both "that" and "which" mean "that." What "that" means is that this group of words is telling the reader which points you are talking about or what kinds of points you are talking about. Because the reader so far doesn't know what points you are talking about. If, on the other hand, you have already described the points like earlier, like the reader already knows what points you are talking about, and you just want to give more information about those points, then we use a comma and "which." What "which" means is that it's basically nonessential information. Information that is not essential for understanding what points you are talking about, and you use "that" for what we call essential information. Does that make sense?

30- S: Uh-uh.

31- T: OK. The reinforcement is necessary as two customers complained of upset stomach after consuming food. OK [pauses].

32- S: "This reinforcement?"

33- T: Yeah. It's not just..."the" or "this," but it's just kind of unclear what type of reinforcement you are talking about. It is also a great time to reinforce, um... [Pauses, then reads to himself].

34- S: "They ordered reinforcements on serve procedures?"

35- T: We could also kind of rephrase this. We could say, "it is necessary to reinforce..." and then we can say what we are trying to reinforce. It's necessary to reinforce what?

36- S: "It is necessary [mumbles as she writes] to reinforce the SOP for personal hygiene."

37- $\mathrm{T}$ : And then we can still use the "as" after...

38- S: Is there a comma after this? 
39- T: Ah [pauses], let's see [reads]. That is actually optional. You can add it in, but you don't have to, necessarily, OK? The main objective of this training is to train food servers. So, again, this gets a bit repetitive. We can actually take out this "training" here, and we can say "the main objective..." Because so far all we have talked about is training. So, it's going to be clear to the reader when they see "objective," objective of what? It's going to be clear that the objective is training. The main objective is to train food service employees of the restaurant on using... [Pauses and rereads]. And this is just a difference in prepositions. Usually when we say "train," we say "we train someone in doing something." So here we would use "in" instead of "on." It's just a different preposition.

40- S: [Scribbles].

41- T...train food service employees in the restaurant in using the HAWCP. based SOP for personal hygiene. During the training session, all aspects of personal hygiene the trainees... [Pauses] the trainees are required to follow while handling and preparing food will be discussed.

42- S: It's a comma here...?

43- T: No, the main problem here...it's just an awkward sentence. Nothing you could really fix with just a comma or something. And the main problem is we have passive voice here. What passive voice [does] is it sticks the verb at the end or towards the end of the sentence, or... [Pauses]. Yeah, what it is doing here is sticking the verb at the end of the sentence. We have all this stuff here. And in most sentences the reader is expecting the verb somewhere closer to the beginning of the sentence. So, when it's at the end of all this stuff, the reader is not gonna know where to place all this information in context. So... 44- S: "In the training session..." [Pauses]. No...

45- T: So, who's discussing it? Can we say who's discussing it? Because this is actually not clear either who's...

46- S: I am discussing it.

47- T: You're discussing it. OK. I guess you're forbidden from using "l" here. You think...?

48- S: It's not in APA because in the conclusion I have written "I."

49- T: Well, and you could also...one way to get around it is that you could just say "the author," you know. You are talking about yourself, but you can use "the author."

50- S: Or "the trainer?"

51- T: The trainer? Hmm. Well, I don't know if it is clear that the trainer is the same person as...

52- S: I can use "I." 
53- T: Yeah, either "l" or "the author." And then we can use that as our subject: "I will discuss" or "the author will discuss." Um...

54- S: [Scribbles]. "I will discuss..."

55- T: "I will discuss..." OK. You are discussing during the training session.

56- S: "During this training session, I will discuss...."

57- T: Exactly.

58- S: [Scribbles]. "This" [instead of the]?

59- T: During the training session... No, we don't have to worry about that. The trainees are required to follow... It would probably be better... Actually, it isn't absolutely necessary to have "that" here.

60- S: The comma?

61- T: Actually, "that." What "that" says is that this is a new clause that is working as one big noun here. It isn't always necessary to use it here, but the sentence would be clear if we used "that." [Re-reads]. Good. By the end of this session the trainees should know the important SOPs for personal hygiene while handling food in the food service operation. So, it's the same idea: "food in the food service operation" is a bit repetitive. Um... We can probably leave it at "while handling food." And it's going to be clear to the reader...that we are talking about food service operation. We are only talking about operating procedures, so we are almost already saying operation in the sentence anyways. One other thing [re-reads] is that we are starting the sentences with... Oh, I am sorry. Going back to the previous sentence for a second. When we start a sentence with one of these "-ing..." Usually when we start something with an introductory phrase that's describing the rest of the sentence or introducing the rest of the sentence, we will need a comma after that phrase. Yeah, exactly. And it's the same thing here. Though it's not an "-ing," it's a preposition, and whenever you have a preposition at the beginning of a sentence, we will put a comma after the phrase, you know. Trainees are expected to follow the HAWCP-based SOP for personal hygiene and to adhere to personal hygiene [pauses] procedures during all hours of operation. Good [noise of sheets being moved around]. Introduction? [Starts reading paper introduction] Food poisoning is a serious health problem. It can cause severe illness and even death. As a person who handles food, whether involved in preparing, handling, or serving food... [pauses]

62- S: Um.

63- T: ... have an important responsibility to handle food safely.

64- S: Um... "A person who handles food..." [Long pause]. "The person who handles food..."

65- T: It isn't really a problem with the article here. There are actually two 
problems here. The first is our subject is "person," "a person" singular. You know, it's one person standing for a bunch of people.

66- S: [reads]

67- T: No, you can leave it there. Actually, you could leave it or you could...OK. Let me describe it first. So, our subject here is "a person," singular. And then we have all this stuff, this extra information. We should probably also have a dash at the other end. So, it's almost like a parenthesis, right? We are enclosing this information. We are setting it off. And then we have "have an important responsibility to handle food safely," too. So, here we have "have," which is going back to a singular person. Well, singular needs to have "has," right? [pauses] So, yeah, I think it would be better to take out the "as." So, now this is just working as our subject: "a person." "A person who has..." and then we need to change the verb, right?

68- S: "Had?"

69- T: You want to keep it in present tense, but we are talking singular, in this case.

70- S: "Person who handles food....has?"

71- T: Exactly.

72- S: One last thing here is that... again, it's another repetition issue....when we say "food" here [reads]. Yeah [pauses]. Yeah, so we don't need to say "food" again, we can just end it with the

"-ings." OK. Two: protect other people from getting sick; protect reputation in the food industry. Here you want to say whose reputation you are talking about.

73- S: "The organization's reputation?"

74- T: Um... which organization? Well...

75- S: "The institution?"

76- T: Well, we are talking about a restaurant.

77- S: [Reads].Yeah, the restaurant. In this case, the restaurant.

78- T: Yeah. Because there's a difference between talking....and usually we don't talk about the restaurant as an organization or an institution. Because organization and institution usually mean something bigger. A chain of restaurants.

79- S: So, "protect the restaurant's reputation."

80- T: Yeah, "protect a restaurant's" or "the restaurant's," you can use either one.

81- S: [Scribbles]. 
82- T: Yeah, "Protect the business..." actually, these two, do they mean the same? "Protect the reputation" and "protect the business," or are they two separate actions?

83- S: Reputation, if it spoils then people... [Inaudible] then it spoils the business.

84- T: So, protecting the reputation is protecting the business, right?

85- S: Uh-uh. Should I take this out?

86- T: Yeah. I mean this is just a vaguer way of saying that, yeah. Protect his or her job. An important way to prevent food contamination is to maintain a high standard personal hygiene and cleanliness. Even healthy people carry food poisoning bacteria on their bodies. OK [pauses]. It may be better to rephrase this here, "food poisoning bacteria," as... and put these after bacteria. Maybe something like "bacteria..."

87- S: “...which causes food poisoning?"

88- T: We could use that. Better than the other one. Yeah, "Bacteria that causes..." causes or...yeah.

89- S: [Scribbles]. "Food borne illnesses?"

90- T: Um... Just "food poisoning." It's probably better to just keep it simpler. And one other thing is actually here we have "cause" which means by itself that it will definitely cause by itself at all instances food poisoning. That's not exactly true.

91- S: "That may cause."

92- T: May or can, either one would work.

93- S: So, should I write "even though..."?

94- T: Even healthy people... No, because...

95- S: Oh, yeah. Even healthy people... This is one sentence. Even healthy people carry bacteria that... [Scribbles].

96- T: ...cause food poisoning... exactly... on their bodies. OK. By touching parts of their bodies, such as nose, mouth, hair. So, here we are actually talking about specific parts. Here we can actually use "the," the definite article. ...such as nose, mouth, hair, and including your clothes.

97- S: "and clothes..."

98- T: Yeah, we can't really put "and including." We can just stick it [the noun] in the list. "... and clothes." You can spread bacteria from your hands to the food. OK. Good person hygiene is not only essential to prevent the contamination of food. It also makes good business ads. OK. When we use something like "not only...," it's "not only this... it is also this," we actually can't use a semicolon 
here. Semicolon means these two ideas are closely linked, but they are still completely independent ideas, or independent clauses, we call them. But then "not only," what it's doing is linking these two, so we need to use a comma... Yeah.

99- S: [Scribbles]

100- T: Customers like to see food handling staff who take... hygiene seriously. 101- S: "Personal hygiene?"

102- T: Um... No, I think it's clear now. Customers like to see food handling staff who take hygiene seriously and practice safe food handling. So, this is what we call a nominalization issue. We are using a verb here "practice," "to practice," but then we have another verb here that's turned into a noun:

"handling." Now what we could do is we could just use this [handle] as a verb and not have to use this [practice] at all. So, we say the same thing in fewer words, and we are using a more specific, concrete verb. So, if we just took this "handling" and put it here and use the same tense...

103- S: ... who take hygiene seriously and just practice....

104- T: Well, we would take the "handle" here.

105- S: .... and handle food safely.

106- T: Yes.

107- S: [Scribbles]

108- T: And also because we are saying "handle food safely" here, we wouldn't need to say "food handling staff" here. Because it's clear what kind of staff we are talking about.

109- S: "Staff members?"

110- T: No, we can just say "staff." "Staff members" means the same thing. We are just using more words. Put yourself in their place and watch how your workmate [pauses] handles food. So, it seems... because we have the tense for this one. Or this is...singular tense, right? Actually, no. It's plural tense. People... more than one handle food.

111- S: No. Actually, I was giving a demonstration in the class now. I am demonstrating one chef.

112- T: OK. So, here we have "their place," so it gets a bit confusing. Put yourself...So, if you're talking...In this case, "put yourself" in whose place? So, we're talking about that one chef?

113- S: Uh-uh.

114- T: OK. Is it a certain gender, or is it gender neutral, like it doesn't matter if 
it is he or she?

115- S: Like, when I demonstrated, it was a she.

116- T: OK. Um... Also it's not really clear because you haven't really mentioned the chef yet. So, it's not clear who we are talking about here.

117- S: Um... In "their place," "put yourself in their place," it [their] means the customers.

118- T: Ah, OK. Then you probably want to say that. "Put yourself in the customers' place."

119- S: [Scribbles].

120- T: And it would be possessive, right? Yeah.

121- S: There's no apostrophe?

122- T: It is possessive, so plural: "customers," more than one customer. But it's also possessing place. So we need an apostrophe... That would mean singular possessive. Plural possessive we put outside. Exactly, Put yourself in the customers' place and watch how your workmate...

123- S: ...handles...

124- T: ... handles food, exactly. Would you want to eat at or buy food from their business? Train food service employees on using the procedures in this SOP. Report to work and good health...

125- S: This is like I just copied from the SOP procedures, so I don't think we need to go through this.

126- T: OK.

127- S: OK. Because there is a handout, which I will be attaching to this. It's a standard handout.

128- T: Well, it's standard, but it has grammatical errors [laughs].

129- S: [laughs]. That's OK.

130- $\mathrm{T}$ : Then, conclusion?

131- S: HAWCP-based standard operating procedures...for personal hygiene was introduced to increase...the awareness among the food service personnels. So, "personnel," this is one of these nouns that even though it doesn't have an "-s" at the end, it means more than one. So, it wouldn't need the "-s" at the end. We can just say "personnel," and it would mean more than one. And also, it's not possessing anything; there's nothing after it here that is being possessed, so you wouldn't need the apostrophe either [pauses], yeah. To prevent contamination of food by food service employees. One thing here is that we are talking about procedures. This is our subject, "procedures," plural. 
132- S: We already said SOP at the base, so we don't need to repeat this again. So we can just say...

133- T: S.O.P.S? SOP's? More than one procedure, right? Well, it wouldn't be possessive, though. Well, actually that reminds me. When we have an acronym, something capitalized or in all caps like this, we usually use an "apostrophe + s;" even though it's not possessive, when it's plural, when the acronym is plural, we use "apostrophe + s." Um... But I did not say that before, but it might be once before that. You want to go back and check that?

134- S: OK. I will do that.

135- T: Will you do that? OK, SOP's. So, here we have plural "procedures," and here we have "was," which is singular, right?

136- S: "Were."

137- T: Yeah, exactly. SOP's for personal hygiene were introduced to increase awareness among the food service personnel and to prevent...OK. And it's the same thing here ...food by food service employees. We can just say "the contamination of food. ... to adhere to personal hygiene policies during all hours of operations..." So, we have a list here? But the first item in the list is a complete sentence, the second is just a "to verb," or we call it an infinitive phrase. So, these items are not parallel. Does that make sense?

138- S: Uh-uh.

139- T: And the third is once we train any food service [mumbles] to follow the procedures in this SOP. Actually, all three of these are three different kinds of sentences. We have to have them all agreeing. One thing we can do here is we can take out the "to," and then we have "adhere." Both of these are starting with a verb, or what we call imperative - you are saying to do something. So, you can take out the "to" here, and both of these would be... would work. The first one [pauses] what we could do is... well, the tense it is now is passive voice - this thing was introduced; we don't have to say who. Both of these are phrased like imperative, like "I should do this, we should do this, or you should do this." We could turn this into an imperative as well, which is basically you get the verb at the front of the sentence; [this] is how you do it. So, you can take "introduced," make it present tense, cause these are both present tense, and put it at the front. So, "introduce each SOP." And again, like I said, we want to keep this present tense, because we want it to be like these two, as well.

140- S: [Scribbles and reads]. "Introduce SOP's..."

141- T: ...for personal hygiene to increase...So, basically just take out the verb, move it to the front like that, and the rest will work. OK? So, that's as far as we can get through today. Do you have any questions about anything I said that we can clarify? 
142- S: No.

143- T: No? OK. Thanks for coming in! 


\section{Session 3}

\section{Transcript - Session 3}

In the following transcription, numbers refer to turns in conversation, $S$ indicates the tutee is talking, and T indicates the tutor is talking. All italicized text refers to sections read aloud from the tutee's paper, and underlined words were those the interlocutors emphasized in the dialogue.

1- T: OK, that looks like it [the recorder] is going.

2- S: So, today I am working on my journal again about the two last class meetings. I started on my project for developing recreational activity for one of the client based on a case study.

3- T: So, the journal entry scripts? OK [starts reading student's paper]. Today Suzie and I gave a presentation about the San José Museum of Art. Suzie and I should have presented before Nadia and Caitlin because they did their report on the same site. Since they presented before us, it made our presentation sound... [Pauses].

4- S: sounds?

5- T: Actually, you don't need any modification. Just... [Continues to read] sound repetitive, but... I would say "but" is not so much an introductory word, so I would take out the comma there. But I was glad we had plenty of photographs that made our presentation more insightful. Hmmm, I would just generally kind of avoid saying "more insightful" because this is going to your professor, right? And it is kind of saying, "our presentation was more insightful than Nadia and Caitlin's" [both laugh].

6- S: Better than [laughs].

7- T: So, you could just say, "that made our presentation insightful." I do like their presentation. They had a lot of information that... And then, information, that's non-count, right?

8- S: Yeah, that was...

9- T: So, that was relevant to their topic because they chose to use a wheelchair to maneuver in the facility. We interviewed the staff to get our information, so we had to walk around to take photographs of the place to give us a closer look at the types of accessibility. I enjoyed today's lecture about airlines accommodations...Hmmm. So this would be possessive, right, because they have the accommodations?

10- S: Airlines... 
11- T: U-hum. ...for persons with disabilities. I also had a fun time researching... researching actually doesn't need to take a preposition.

12- S: The same like discuss...

13- T: Same like with discussing and... There was one more today, but I can't remember [laughs].

14- S: I will ask you next time [laughs].

15- T: Researching the different accommodations and how our client would travel to Ethiopia. This topic on how people with disabilities are able to travel to and from other countries has entered a question in my mind. Now here we can actually make it pretty concise. Do we actually need the first part of the sentence? Do we really need this part of the sentence here, or can we just start...?

16- S: Yeah, we can just start right here: how people...

17- T: Ok. Today lecture... Oh, that looks like it should be a possessive, right?

18- S: $\underline{\text { Today's }}$

20- T: lecture answered a lot of the questions that I had. OK. And this one [referring to another piece of writing] is a final project?

21- S: Yeah. I kind of have to introduce a case study first and then I have to talk about some... um... Basic... Because he has two diagnoses, so I have to kind of explain the symptoms first before I transfer to making like a plan.

22- T: Ok. So Frank, a 42 year old male... an then... "42-year-old" would actually be hyphenated because it all comes before the noun, right?

23- S: Before the noun... [Repeats as he writes it down]

24- T: ... who has been diagnosed with depression and alcoholism, was referred to occupational therapy. Currently he is seeing a psychologist and taking Prozac to help with his depression. In addition, he attends Alcohol Anonymous... I think it is actually Alcohol...ics Anonymous...

25- S: Al-co-ho-lic Anonymous.

26- T: Yeah, I think it is plural, too ...meetings every week. They saw Frank's diagnosis. Um... diagnoses, right?

27- S: Actually, I have a question...

28- T: Actually, we should...

29- S: Yeah, I keep on thinking because -es is plural and -is is singular.

30- T: That is the plural and singular, right. Yeah.

31- S: This is the... 
32- $\mathrm{T}$ : This one is the singular and this is the plural [writes them down]. I would say we may actually probably do want to keep it plural because he was diagnosed with depression and alcoholism. So, he has two diagnoses. OK. He is anticipated to encounter problems dealing with symptoms of depression and alcoholism and side effects of Fluoxetine. Probably and the side effects just because it is a pretty specific drug we are talking about here, specific side effects of this.

33- S: Oh.

34- T: According to the National Institute of Mental Health, people who are depressed have persistent feelings of sadness, helplessness, guiltiness, worthlessness, and restlessness. These native feelings can cause one to have suicide thoughts...

35- S: suicidal...

36- T: Exactly.

37- S: Su-i-ci-dal [spells as he writes].

38- T: And here exactly, when we talk about suicide, it is rarely used as a verb because generally one says like, "committed suicide", so "committed" is the main verb and it [suicide] is generally a noun. So we can just say "attempt suicide."

39- S: Attempt to suicide.

40- T: So, here, instead of using...

41- S: Attempt suicide.

42- $\mathrm{T}$ : Yeah, because if we put in the "to," it is the infinitive, right? But if we take it out, it just becomes the noun. And I don't think this is so much like a grammar rule, it's just common usage.

43- S: Because I used "suicidal thought" and then "attempt suicide".

44- T: Yeah. But there are psychological problems that the person can have such as difficulties concentrating, remembering details, making decisions, and maintaining interest in hobbies. The NIMH also explains that the person can have persistent aches, headaches, and digestion problems that do not ease with treatment. The person also gets fatigued easily, has decreased energy, and losses of appetite. OK. Actually... [Pauses]. Um. You used a verb here, "gets fatigued"," has decreased..." I think we probably want to make this parallel and put in a verb [pauses]. You could say...

45- S: "gets fatigued, has decreased..." This is a verb phrase, right?

46- T: Actually, just has, right. Even though "decreased" is often a verb, here it is the adjective for "energy", right? If you want to have some suggestions which could work, we could repeat "has" and say, "has losses of appetite," and we 
could say, "and loses appetite..." and then it would be present tense, right? And we wouldn't need that preposition.

47- S: Without the "s" right here, this is the past tense, right?

48- T: Actually present because...

49- S: Oh yeah! That's right.

50- T: It is "to lose."

51- S: "Lost" is the past tense.

52- T: Yeah, "Iost". So, the University of Maryland Medical Center (UMMC) explains that people who are alcoholics drink by themselves or in secret crave... um... You could say "crave for," but you also could take it out and have a direct object.

53- S: "Crave alcohol?"

54- T: Yeah, "crave alcohol." And then when we say "most of the time," it's actually "time" singular.

55- S: Singular because even though [we may say] "many times," actually when you talk about most of the time you...

56- T: Yeah, generally when you have "times" with the " $s$ " at the end, it's the more idiomatic phrase. It's either very literal like "I am free at these times" or "the times are changing". But then most of the time is used without the " $\mathrm{s}$ " because it is more thought of as a non-count noun.

57- S: Oh, OK. Unless you talk about... like you gave me in your examples like, "how many times...?"

58- $\mathrm{T}$ : Yeah. Because time as we measure it is non-count, whereas time as in terms of when something happens, like exact time, that's count.

59- S: Oh.

60- T: Become irritated if he does not get a drink at the regular time... maybe "at a regular time"?

61- S: "a regular time."

62- T: Um. Now we need a verb for this one, right? Drink by themselves, crave alcohol, become irritated...um

63- S: "cannot control."

64- T: Yeah. Cannot control the amount of alcohol... The amount of alcohol...

65- S: "Consumed?"

66- T: "Consumed." Yeah, exactly... And drink more alcohol to feed or feel [laughs]? 
67- S: To feel [laughs].

68- T: They tend to have problems with legal issues and cannot maintain a relationship or a job. The more severe problem that drinkers are at risk for is risk... is risk... Actually, we just said...

69- S: "is liver disease"?

70- T: Actually, that works. ... is liver disease due to long-term alcohol consumption. Actually, here...

71- S: We don't need the "s"...

72- $\mathrm{T}$ : Yeah, we don't need the "s" because it's actually a non-count.

73- S: Oh, "consumption" is a non-count.

74- T: Yeah. The UMMC also says that people who stop drinking may experience alcohol withdrawal symptoms such as nausea, sweating, shakiness, and anxiety. In addition to withdrawal symptoms, the American Academy of Family Physicians says that the person can experience severe withdrawal symptoms, such as fever, convulsion, and delirium tremors. One thing I notice in this page is you say, "... may experience withdrawal symptoms (...) in addition to withdrawal symptoms." We might want to say like, "in addition to these withdrawal symptoms?"

75- S: "These."

76- T: Or you could even say, "in addition," comma, "the American Academy of Physicians..., if you wanted to make it a bit more concise.

77- S: Oh, OK. So, I can use either...

78- T: Yeah, either works. The National Alliance of Mental Illness says that people who are taking Fluoxetine to help with depression reported experiencing some common side effects which include nausea, vomiting, diarrhea, headaches, insomnia, nervousness, restlessness, and tremors. Oh, I don't want to take that [tutor and tutee laugh].Other side effects of the medication may include sweating, sleepiness, fatigue, weight loss or gain, or dizziness. The person may also have problems. Um, that would generally be...

79- T and S: "Problems."

80- T: Yeah, plural, problems with orgasm and ejaculatory delay. Besides...Um, "besides" and "from" are the same here, right? So,

81- S: Besides these common...

82- T: ...common side effects the person can encounter the various side effects...

83- S: [laughs]. 
84- T: Now, you say here "the various", we could actually take out "the" because we are about to say "which include," right?

85- S: Yeah [mumbles sentence as and writes].

86- T: ... low sodium blood levels, acute abdominal pain, high or low blood pressure, abnormal heart rate, increased frequency or urination, increased bleeding, blurred vision, seizure, muscle stiffness, and teeth grinding [both laugh]. The INMI also mentions that people who take Prozac usually experience the side effects during the first few weeks. The side effects will diminish over time as the person continues to take the medication.

87- S: I have a question about the content. Like, I know a lot of the symptoms are kind of repetitive, even though each, I mean like "depression" and "alcoholism," each has like...

88- T: The same symptoms?

89- S: The same symptoms. Is it correct for me...? I mean, I have different paragraphs about like each topics, right.

90- T: Context-wise, I would say that you should include them because it might be important because this is a report that you are writing as an occupational therapist maybe for another occupational therapist, right? So, like in your profession it is probably really important to know that both these things can cause these side effects as opposed to just one. I would say it is really important, but if you are at all worried you might want to check with your professor and just say like, "I feel this is redundant, but this is the information for each." But I would say, don't worry about it.

91- S: Ok, because when I was writing this sounded kind of repetitive, like the symptoms for each diagnosis.

92- T: Yeah, they tend to overlap.

93- S: Yeah, overlap.

94- T: I would say it's important to list each of them because it also shows awareness of the problem and... You know, a paper is always so that you can show what you know, basically. So, ... Furthermore, the World College of Psychiatrists points that people who take antidepressants for depression make switch from being depressed to manic. Symptoms of mania may include higher irritable mood, very high self-esteem, decreased need for sleep, pressure... ah; do we need the " $d$ "?

95- S: "pressure."

96- T: ... to keep talking, racing thoughts easily distracted...um. This almost seems like non-parallel. And I know I have seen it in this form in papers before. 97- S: Maybe if I switch it around, "distracted easily?" 
98- T: All the others are nouns.

99- S: "Can [it] be distracted easily?"

100- T: But that's still non-parallel. I think we can just leave it. I know I have seen it in other papers before, so I think it is actually a standard symptom that people list.

101- S: You say this is not parallel.

102- $\mathrm{T}$ : It almost seems non-parallel because we end up with an adverb, then the adjective, whereas the rest are...well, this is actually an adjective but then a noun. But we can't really say distraction because easily distracted is the symptom. I think we just need to...we could... And increased involvement in activities with a large risk for... Probably a large risk of something

103- S: "Of."

104- T: Yeah. Based on Frank's conditions, he is having difficulty with several areas of occupation. According to the American Occupational Therapy Association, Frank has difficulty with several areas of occupation which include activities of daily living, instrumental activities of daily living, rest and sleep, work, leisure, and social participation. Even though Frank has difficulty in several areas of occupation, the only area that is discussed in detail is social participation [pauses]. Now, let me ask a question about the last paragraph. This is actually like content. You say that the only area that is discussed... like who discusses it? Is it like that Frank has told the occupational therapist?

105- S: Um, because in the instructions I can either discuss like about all this or I can discuss about social participation. So, I choose to discuss about social participation.

106- T: So, you are just letting your professor know: this is what I am... Ok, I just wanted to clarify that. No, that's fine, then. The problems that Frank encounters interfere with his ability to be fully engage... That's going to be an adjective, right [pause]? ... with his community because he is felling sad, helpless, hopeless, and restless. Frank might not want to go anywhere or interact with anyone. He is feeling guilty and worthless, so he might think that his friends do not what to spend time with him because he might think that he does not want to do anything besides... besides

107- T and S: "drinking".

108- T: Oh, and just for usage, you can say "aside from", or you can say "besides". "Aside" always comes... ....actually not "asides" but always "aside from."

109- S: "Aside from" together, right?

110- T: A space in-between both. 
111- S: Oh, "aside"

112- T: "Aside from". "Aside" always carries "from" with it; "besides" doesn't take a preposition. So, he might think... Can we change one of these to maybe "believe," just to avoid repetition? Actually, do we know if he believes it, though? 113- S: "He might believe..."

114- T: We probably want to keep the "might", so "he might believe."

115- S: [mumbles sentences as he makes corrections]. I have a lot of "believe" here.

116- T: Actually, you could keep "think" for this one, I would say. Yeah... um... because he is felling sad... Did you get this from the case study itself, like you know he feels these things, or...?

117- S: I am anticipating some of the problems he [pauses] has.

118- T: Oh, because of his...

119- S: Yeah, because of his diagnosis.

120- T: In that case, I might actually put this in the subjunctive [conditional], and say, you know, "if he feels these, Frank might not want to go anywhere or interact with anybody," because we don't know.

121- S: So, I am concluding that he is feeling this...

122- T: Yeah, if he didn't tell you, you don't know for sure... Generally we don't want to assume. And then here you could say, "If he is feeling guilty...." OK. They might also think he is irresponsible when he drink.... $\mathrm{s}$ too much. Even if they want to spend time with him, he will not be able to join them in a simple catching up conversation at a Starbuck...Probably Starbucks... I think it has the "s"...coffee because he cannot concentrate....Probably...

123- S: Um, "he is unable to concentrate."

124- T: "He may or he..."

125- T and S: "He might not be able..."

126- T: Yeah. It's always hard framing language in possibilities [both laugh].

Oh, I think we need "be able" here, right?

127- S: be ...able... to... concentrate [writes].

128- T: And then here we probably want to say: or stay focused just because... if you say... and it means kind of simultaneously, but we mean one or the other at any given time. And then, this is an adjective.

129- S: to stay focused, umm, "d".

130- T: to have a normal conversation with them. Since he gets tired easily and 
has low energy [pause]. Then the same... "He might..."

131- S: "He might..."

132- T: Or "if he gets", yeah. He cannot walk around for too long [pause].

133- S: I was trying to rewrite this point. I think we can stop right here because I will try to correct this myself.

134- T: So, if you want to go through that, and then maybe...

135- S: I have some questions... about this.

136- T: Sure.

137- S: I wrote this earlier: "symptom of mania are, symptom are." Like are [emphasizes verb "are" multiple times]. If I use "are" right here, instead of "may include", "are high or irritable mood..." would I be able to keep this, or do I have to use "decreasing", "are decreasing...?"

138- T: Actually, you would not need to change anything in your list. The main difference between "are" and "may include" is basically like... if you say "are", it might imply to a reader that to be manic one has to have all these symptoms, whereas [with] "may include" we are dealing with the realm of possibility, so like... maybe if you have one of these symptoms, it could still be mania. So this [verb "are"] is more absolute as for this is kind of like... think of ...

139- S: Is it more specific, or like a...

140- T: [Reads]. If you were to use "are," you would not need to change any of these because they are still adjectives. It's almost like... I think...Did we ever discuss like subject and subject complement before?

141- S: Subject complement?

142- T: Yeah. It's kind of like... if I say "you are smart", "you" is the subject, "are" is the verb, and "smart" is the subject complement, which is going to be an adjective.

143- S: Oh, no. Not yet. So, if you say...

144- T: It's one of the most basic constructions where it's like, "you are..." let me start with subject [pause], verb [pause], and then whatever comes after is the subject complement.

145- S: Which is describing "you."

146- T: Yeah. So, "you are an occupational therapist." "Occupational therapist" is your subject complement. "You are a writer;" that would be it. Generally this is going to be an adjective, and it can also be a noun. And here these are all functioning as subject complements: Symptoms of mania are...so they can be nouns, which means we would not need "decreasing" because that would... 
147- S: Would not describe...

148- T: Yeah, that would be the present participle to modify need for sleep, whereas "decreased need" is more of a noun phrase in itself.

149- S: When I was rewriting this, I did not know how to use it, so I just changed it back to...

150- T: I would actually go with "may include" because I think "are," I mean, it would not necessarily [apply] to all readers, but to some it might mean all of this very literally, whereas like maybe someone who is manic only has high mood something.

151- S: Yes, I understand. I have a question right here. When using "pressure to keep talking," I know we have a lot of increase, decrease. How come it's not pressure to keep talking and just pressure?

152- T: If you think about this. It's just not "need for sleep," which is our main noun phrase, it's "decreased need". So, even though this is an adjective modifying "need," it is essential to the noun itself, so we can kind of view it as part of the noun phrase. Here, "pressured", this implies a verb in some ways because one could be pressured, so even though if functions as an adjective like in "I am pressured to do this," that's an adjective, but it's a verb too.

Form/function kind of...

153- S: Yeah.

154- T: So like, here we just need the noun, basically.

155- S: Ah, OK, OK. So, "pressure to" because...I have this to...

156- T: So the noun and then "to do something". So, infinitive: "to keep talking." 157- S: So, I would not use a verb, say "to"?

158- T: Because all of these, except for "easily distracted", are nouns. I think we should just keep it. We should be fine.

159- S: I will look it up. Thank you so much!

160- T: You're welcome. Did you have any other questions?

161- S: No, but I will be back next week [laughs].

162- T: OK. I will see you then. 


\section{Session 4}

\section{Transcript - Session 4}

In the following transcription, numbers refer to turns in conversation, $\mathrm{S}$ indicates the tutee is talking, and T indicates the tutor is talking. The student did not bring a paper to this session. Instead, tutor and student used handouts available at the Writing Center. Emphasized words, phrases, sentences, and examples appear underlined, whereas sentences read aloud from the handouts appear italicized.

1- S: I actually have a question for you.

2- T: Yeah.

3- S: When should I use the "be" verb compared to or versus the main verb or whatever, like "get" or "want?" When is it a good idea to use that [verb "be"]? It is kind of confusing. You know that I tend to use "be" like "I am," "he is," a lot compared to like "he get." I am using... like "if he get hungry," I would say like "if he is hungry." I tend to use that way more. Is there a reason? Would you recommend a situation when I should use the "be" verb?

4- T: Well, that's a big question, I mean, the "to be" form or the "to be" verb sometimes is a little bit unnecessary. You know, you would say like "he is becoming hungry." Why not just say, "he became hungry" or, you know, "he gets hungry?" I don't know, but it's just a matter of what you are trying to achieve. I would not say you could never use the "to be" verb or anything like that, but I think that it gets overused sometimes, especially with ESL students. You know it's a common thing to see "he is going to go" instead of "he will go." That's kind of a recurring thing that I would see. But I can't really say when it's better to use it. If you have examples, maybe it's easier...

5- S: I am thinking, maybe, when you want to focus on the adjective, then you want to use it, right? You want to maybe like stress.

6- T: You want to stress the adjective, you are saying?

7- S: Yeah.

8- T: "He is ravenously hungry" or something like that?

9- S: Yeah. I don't know, but I have been thinking I am using a lot of the "be" verb... a lot. Sometimes that does not look really good.

10- T: Do you have any examples?

11- S: I don't think so. But like, when you said "he is hungry" or "he get 
hungry"... interesting. It's the same meaning when you use "get?" But I would say "he is hungry."

12- $\mathrm{T}$ : You know, it might have just been the word that popped in my head the first time when we were revising, but you've done some work with passive voice. You know about the passive voice, and you know when you are in the passive voice...it's not that you're guaranteed to turn in to passive voice if you are using the "to be" form, but a lot of times using the "to be" form creates a gerund out of the noun, or pardon me, out of the verb, and it becomes a passive sentence. So, you know, I guess [you should try] writing it down when you feel like it works appropriately and then rewriting your work and revising your work and saying, "Here I am using the 'to be' form. Here it is three times in the first paragraph. Well maybe I can find a better way to construct the sentence." But once you have it down on paper and you have the idea out, I find it is a lot easier to try and... I mean even in writing that I would do [it] if I see the passive voice over and over and over, and it's not on purpose. Then I usually try to re-finagle my words and try to take at least some of it out of passive voice if I can.

13- S: The passive voice is not easy to identify, right?

14- T: Well, you've seen our handout, right?

15- S: Probably not.

16- $\mathrm{T}$ : [stands up, picks up a copy of handout, and starts going over it.] You don't necessarily have to look over this right now, but if are going to work on it over spring break, it might be helpful. It doesn't constitute grammatical error; use of to be in any form does not constitute the passive voice. Not by itself, anyway

17- S: So, let me see... so the "be" and the past participle. That's when you get the passive voice.

18- T: It's when you make the object of an action into the subject of a sentence.

19- S: Sometimes you do not see the "by," so it does not have the subject, right? [Student is referring to the agent of the passive voice which is obtained from the subject of the active voice.]

20- T: Yeah, I mean, you know, "why did the chicken cross the road?" Why did the chicken cross [pauses] the road [repeats sentence for emphasis]? Right, "why was the road crossed by the chicken?" You know what I mean?

21- S: Yeah, in this way, in this context, yeah I know because [of the presence of ] "by..."Because sometimes you don't see it [the agent of the passive]. You don't know who the actor... Sometimes you don't see the actor in the sentence. 22- T: Yeah.

23- S: So, how do you distinguish? They told me as long as you have the "be" 
verb and then the past participle...

24- T: Say that one more time?

25- S: So you need to have the "be" verb and then the past participle.

26- T: Participle, yeah. Let's see...Yeah, here we go [starts reading from handout], look for a form of to be followed by a past participle. The participle is a form of that verb that typically but not always ends in "-ed." Some of the exceptions to the rule are "paid" and not "payed", "driven" and not "drived" [Tutor keeps on reading]. So, form of "to be" plus past participle equals passive voice. The metropolis has been scorched by the dragon's fiery breath. When her house was invaded, Penelope had to think... So, like the actor in this sentence when her house was invaded. Well, who invaded her house? You know what I mean? If we said it like, "when thieves invaded Penelope's home..." We don't know who the actor is. We don't know...In this case, the metropolis had been scorched... we never see the dragon; we see the dragon's fiery breath. So, instead you might be able to say, you know, "with his fiery breath, the dragon scorched the metropolis." You know what I mean?

27- S: [laughs]

28- T: [laughs]. You know what I mean? Does it make sense [laughs]?

29- S: Yeah, yeah.

30- T: You should hang on to this. Because actually, you know, some students who come here say. I get it now, and I realize what I am doing. But you know, just try to identify. Maybe whatever material you brought in and we can try to work and see if we see it.

31- S: Um [sound of student going through his papers]. We can just go over this [handout on passive voice].

32- T: Sure, we can just keep reading about passive voice. Do you feel like for you it's something that you have a handle on and then you could identify? I mean, if you could read over your own paper, you could say, "Oh, there's passive voice."

33- S: Yeah, now I feel comfortable identifying it. Yeah, I think so [pauses]. Yeah, but sometimes you just write it, you can't help it.

34- T: Hey, but that's kind of my mantra. That if you do that: just think, and write, and give, you know, a day or a few hours or however long you have to give it, and then just go back and look at it, look at it like a critic. Try to look at it like, "well, if I was reading somebody else's work, what would I have to say about this?" Trying to distance yourself enough to, you know... of course it's your work, but you are trying to look at it from a more critical perspective. "Am I identifying pertinent examples in this section? Look at how much passive voice I can see". You know, one of the things to remember about the passive voice is 
that it is not always wrong. The use of a passive voice is not a grammatical error. It is a stylistic issue that pertains to clarity. But there are times when using the passive voice can prevent a reader from understanding what you mean. Like if you were to say, "the metropolis was scorched by the dragon's fiery breath," we never see the dragon. Maybe the dragon is really important in this essay or in this story, whatever, but to identify that it has been scorched by the dragon's fiery breath. OK, yeah. It has been, but you can do that in a much more concise manner if you are able to show us the dragon, you know, scorching the metropolis with his fiery breath. I think you can rewrite it by saying, "the dragon scorched the metropolis with his fiery breath."

35- S: Then you turn it from passive to active...

36- T: Right, here you have the actor. In the other case, you did not have the dragon. He is kind of off screen [laughs] somewhere. We don't know where he is. But in this case he is not, I mean, in the active form, it's the "dragon" scorching the metropolis with his fiery breath. When her house was invaded, Penelope had to think of ways to... After suitors invaded her house, Penelope had to.... So, who is doing the acting? Was invaded by whom? And you know, if you can look at some of the sentences and say, "is the actor present here? Is the person or thing that is committing the action, is it something that I can put into the sentence?" You know, maybe it is, and maybe it's a good idea to think about reworking the language a bit to make the actor present in the sentence, I mean, probably more in academic writing. In creative writing you may be trying to achieve different things by sometimes using the passive voice, like you [may] find a whole novel written in the passive voice, just because that is a different thing to do. When you are writing essays or writing academic papers, it's probably better to write in the active voice as much as you can.

37- S: Yeah, they recommend.

38- T: Yeah. So, this [the handout] will talk more about clarity in meaning. They often have to guess what you mean. The metropolis was scorched by the dragon's fiery breath. Ok. That makes sense, but when her house was invaded... well, if you read that, you go, "well, wait a second. Who invaded her house? I don't get it." And a lot of times a student might think that this covers... "Well, I told you that her house was invaded," and the comment in the margin from the professor might be like, "well, who is committing this action? Who did that? You need to tell me that." When you leave things like that out, the clarity suffers a little bit.

39- S: Huh.

40- T: That's what they say. Sometimes the confusion is minor.

41- S: Yeah, but sometimes it makes a difference.

42- T: Right. It lacks explicit reference to the actor. If there is one thing you can 
take away... This is how you can identify the passive voice [by asking]: "does it lack explicit reference to the actor?" We don't know exactly what the acting force is, who what is invading her house. Let me see... What other questions do you think you have regarding...?

43- S: Passive voice?

44- T: The passive voice, the use of to be. I mean you kind of came in and had that on your mind...

45- S: The reason I ask is because you kind have a tendency... I guess I had a problem with it about a year ago. Sometimes you use the "be" verb, and you have an adjective or sometimes a verb in it with an "-ed," and it becomes an adjective. And it can also be a passive voice, too. How do you know that? But now I think I have a better grasp.

46- $\mathrm{T}$ : Well, you will be able to identify the passive voice now and see when it's the passive voice. Well, but sometimes you can't avoid it [verb to be], you know. $\mathrm{He}$ is hungry. He is hungry. What else can I say? It's not always that cut and dry that you use the "be" form and you have passive voice. Sometimes you just have to use the "to be" form. It's a pretty popular verb, and there is a reason for that. It gets used a lot. But like anything else, if overused, it gets boring, and you start to lose clarity. Everything can't just "be" something. You can't just... "The metropolis has been scorched by the..." The dragon had to do something to scorch the metropolis, so let's try and use it that way and see, and maybe we have better meaning and the clarity is much more present. I don't know... because the passive voice is something you see a lot or quite frequently, and students who come in here, you know, after looking at something like this [the handout] go, "ok, I get it."

47- S: I know, but we tend to use the verb "be" a lot. Maybe use a lot of passive voice instead of active voice

48- T: Yeah?

49- S: Well, I was talking to one of my friends and he said, "Yeah." He said he tends to use a lot of the "be" verb, too. So, you would consider "be" to be a "happening" verb, right?

50- T: What?

51- S: Wouldn't you consider it a "happening" verb?

52- $\mathrm{T}$ : I mean. It can be. I mean often times it is. But sometimes it is not exactly.

53- S: Yeah, sometimes you don't exactly need it to be like "he were afraid" or something.

54- T: He was afraid? 
55- S: Yeah, yeah.

56- T: Right, but how could you like fear it's something you are inherently... so you can't avoid it

57- S: There is no other way to describe...

58- $\mathrm{T}$ : [There is no other way] of getting around it, like [when you talk about] hunger. It's funny because different languages assemble things differently. In French, you would say not "I am hungry," but the way that the verbs are used it's I have hunger. So, the "être" verb is to be and "avoir" is to have, so [for] hunger and thirst you would say, "I have hunger or thirst." You don't say "I am hungry" or "I am thirsty." So, if French people would say it [in English, one would respond:] "What do you mean I am hunger? How have you transcended human skin and become hunger or the embodiment of?" Well, it's just the different constructions of things. I mean, the message gets across, [but] I guess just not as effectively as "I am hungry."

59- S: There is something I want to kind of understand too while I am here. When you change it [be] to "have." "Have" tends to be followed by a noun. It can be a noun or a verb, right? But to describe something, a noun, right?

60- T: I have?

61- S: I don't know. I was trying to... I don't want to confuse myself. So I try to look for a pattern. "Have" tends to be followed by a verb or a noun, not an adjective.

62- T: Well, you could say like "I have white teeth." White is an adjective describing teeth. Yeah, you are going to have a noun or a verb...

63- S: and the adjective to describe the noun...

64- $\mathrm{T}$ : Yeah, the adjective would describe the noun...

65- S: But you would not have just the adjective: "I have white..."

66- T: No.

67- S: At least the object has to be a noun...

67- T: Yeah, I mean this [the example that follows] is a bad example, but you could say, "I have stupid friends," you know, "my friends are silly," or "I have silly friends." It's [This last example is] better than the other one [laughs]. But you would not just say "I have silly" and period.

68- S: Yeah, yeah.

69- T: That does not work. Because "to have..." inherently in the form of the verb if you have something, you have to tell us what that something is, and a noun is a person, a place, or a thing. So, if it is falling under that heading, it's probably going to be a noun. [In] "I have to go," it is followed by an infinitive. 
[provides another example] "I have to find my silly friends." But a lot of times you have "I have" and the infinitive form. That might be a helpful pattern to think about. It might not always work that way, but off the top of my head, anyway, you could almost say it is partially a rule. What else? Just having some basic understanding of French, it is so strange to see how different languages assemble their different concepts. I mean, in French you would say "I am a man" or "I am a person," like... some verbs are conjugated... Well, I am not getting to the point here. [restates idea:] The past tense of many verbs in French is conjugated with either "have" or the "to be" form. So, to say like "I went to the store," you would say, "Je suis a le magazine." So, "Je suis a le" is written like this [tutor writes it down], right? But it literally means "I am went." Yeah, this is the way.

70- S: "I am went?"

71- $\mathrm{T}$ : Yeah, there is an acronym like FANBOYS for all the [French] verbs that require the "to be" form and not the "have" form.

72- S: What do you mean the FANBOYS require?

73- T: Well, I am just saying like the thing [the acronym] in French is written like DOCTOR, MRS, etc., so you remember the verbs. Like the verb to become, "Devoir..."

74- S: Oh, OK. I thought you were talking about the conjunctions.

75- T: No, no, no. I wasn't talking about conjunctions. I was just trying to say like, "Je suis doir," well, it's been a while since I have had to go through all this stuff. You know, the point I am making is that the "to be" form and the "have" form are kind of the two verbs that are able to unify everything, in English as well. You know, how many times would you say, "I am going to go to the store," like, you are stating your own existence as well as saying that in the future you are going to go the store. I kind of feel like I have derailed here [laughs]. I am not exactly sure where I was going with that. Well, when you think about how to use it, maybe a way to address it a little more... I don't know if you are trying to do some work during spring break. I know you will kind of come and go from here, but if you are proofreading your papers, pour out sentences. Start with a list of those that are funny to you, like you are going through your paper that you are writing for whatever class and go, "Am I using the passive voice here? Should I use have as opposed to get, or whatever?" But cut the sentence out and paste it into another document and then maybe... and then you will have a list of what confuses you, and then you can take it in here and we can talk about like... because you usually bring really good questions to the table. You understand the construction of the English language. You understand the structure, you are getting a much better hail on that, but for really specific examples like this, it gets hard without being able to look at some real examples. 
76- S: The context, yeah.

77- T: Yeah! We are not really sure of the context. But like I said, if you came up with a number of different examples or, you know, even two or three of them... Because you might feel like the sentence sounds wrong, but it's grammatically correct, or you think it sounds correct, but it is actually grammatically wrong, and then we have something to work with, and we can get all the books on the table.

78- S: [laughs] Yeah, definitely.

79- T: So, yeah. That's about it. So we have...five minutes left?

80- S: Five minutes. I have another question for you.

81- T: Sure.

82- S: I have a tendency to...I don't know when sometimes should I use plural or singular. Sometimes I don't know because I am just talking about things in general, so I put "s" or no "s?" I don't really know.

83- $\mathrm{T}$ : Uhuh.

84- S: Like yesterday I was talking about employee. Let's say I am talking about a homeowner. Sometimes I try not to put the "s" there. Like when addressing more than one homeowner, I don't know why, but I guess I cannot keep it consistent for some reason.

85- T: So, you are saying when using the example of the homeowner, you would say, "homeowners..."

86- S: Yeah maybe, "Homeowners should be more cautious of their...er..." I don't know, I am just saying, "Homeowners should not pay way more than they can afford." It's like when you address a number or people and not one specific group.

87- T: Well, it depends on what you are trying to...You know, we were looking at a memo yesterday, right? And you were like, "employees who don't work at the university are still able to come and get the flu shot provided they take the appropriate time off." And do you remember we were saying you can achieve singularity by speaking to a plural, or you can do the reverse and achieve plurality by speaking to a singular? A good example is the word one instead of using "I" in a paper. Like, "I should think about brushing my teeth..." When you can say, "one should brush one's teeth every morning." [laughs.]

88- S: That should be OK, right? You can say "one..." [laughs]

89- T: Yeah, it's kind of awkward [tutor laughs], but I am not good at examples off the top of my head. But when you say "one", one can apply to anybody; it's generic; it's universal in the sense that you can pick it up and say that "one" can apply directly to you, but you are also thinking to yourself of "one" being any 
other person who would pick it up, and it would pertain to them. Just the same as [in the case of the paper the student had brought to the previous session], an employee who does not work on the SJSU campus is still eligible for the flu shot; however, that employee must come and take time off. I think you said "an employee," and I guess we said, "no you don't need 'an;' you can just say, "employees who dont work at SJSU are eligible..." And by saying "employees," it implies that [you are referring to] employees who work in the SJSU system, who do not work here but are still eligible. So you are talking to a specific demographic of employees. I think you have the sheet [handout used on the previous session] here, right? So we're talking [reads from handout], all of them everywhere, one of many, or this one exactly. Well, this one exactly [the first case] is either no article or "the;" one of many is either "a or an;" and all of them everywhere is "nothing, a, or the." All of them everywhere is who you are talking to in that case, so you're going to go with "no article" because you are going to say, "Employees who do not work at SJSU...." All employees everywhere who do not work at SJSU but work within the system..., so you don't need anything. Remember we tried to take it down to a specific example, "the employee...," and then you would need "the" because it is specific: "The Employees who work at the SJSU Health Center...;" then you are talking about the specific employees who work in a specific department, whereas when you say "any and all employees who work in any and all departments...," and I know it is kind of confusing because articles... Honestly, I could not tell you what the best way to teach articles is because so much of it is just ingrained. Getting a hang of this is helpful, but sometimes it does not necessarily apply; or sometimes you think it applies, like you want to talk about this one exactly, but it does not. You do it a different way.

90- S: Article is the same thing as determiner?

91- T: What?

92- S: Determiner. Article and determiner are different, right?

93- T: Determinant? Well, kind of. An article... we can probably read the handout definition [reads]. Here are certain situations when you always use "a" or "an." The example they give is my lab is planning to purchase 'a' new microscope. It's one of a number, but it's also one specific kind of, I guess.

94- S: I can say "the," right? I can say "the" microscope.

95- T: I was planning to purchase "the" new microscope? What new microscope then are you talking about?

96- S: I just thought of a proper name.

97- T: Exactly, "trying to purchase the new pulsar 9000 microscope." Then you are specifically narrowing down which microscope, but if you are just talking about just a generic microscope from the catalogue or whatever, it could be one 
microscope, referring to one of a number of possible things. Maybe the new microscope is the new Pulsar 9000, but we just don't know it yet.

98- S: The thing we are talking about proper noun and then take the article. The proper noun does not take the article, right?

99- $\mathrm{T}$ : The proper noun would take an article because it's this one exactly, so that's why you say "the pulsar 9000 microscope" because it's the specific type of microscope you are going to buy; it's not just any microscope. It's not just a possible microscope. It is one specific. I think we are out of time. I am sorry. But like I said, if you are going to be doing any writing over the break, try to get like two examples, and when you come in we can look at it and like... when you confuse me [both laugh], and I will hand you over to whoever will know exactly [both laugh]. But these [the handouts] are helpful. Check out the passive voice. I guess you got the passive voice down. But the article thing, it's just too idiosyncratic. It's really through repetition and practice that you get better and asking questions, and making mistakes, and realizing how you correct your mistakes.

100- S: The problem with me is that I do not make the mistake once, I make it a couple of times, and I turn in the paper and don't have time to type it.

101- T: And you turn it in, yeah. All right. 


\section{Session 5}

\section{Transcript - Session 5}

In the following transcription, numbers refer to turns in conversation, $S$ indicates the tutee is talking, and T indicates the tutor is talking. All italicized text refers to sections read aloud from the tutee's paper, and underlined words were those the interlocutors emphasized in the dialogue.

1- T: Ok. So, what are we working on today?

2- S: I have to write a paper about...well, I am doing my internship, and I have to like find out a problem that my community has, and I have to like provide some ways to solve it.

3- T: OK.

4- S: And I would like to focus on grammar.

5- T: [Scribbles] OK. So, mostly grammar...

6- S: Yeah.

7- T: OK. Canoas Elementary School is a school located at the Westside of San José, um... "on the Westside of San José."

8- S: Uh-uh.

9- T: ... and it is one of the 29 elementary schools in the San José Unified School District. Compared to other schools, Canoas is considered a small school. Currently, it serves approximately 465 students in grades K-5. Canoas reopened ... un-capitalize that, ok? ... in 2001 after being...

10- S: "Closed?"

11- T: Exactly, because that'll be an adjective, right?

12- S: Uh-uh.

13- T: ...closed for about 10 years due to budget cuts. And then ten...

14- S: Uh-uh.

15- T: Did we go over that before, about when to write it out and when to use the numbers? 
16- S: Yes.

17- T: OK. According to the Canoas Elementary School website, the school...good comma, well done! ...the school is committed to... committed to crea... [Pauses] ...ting, I would say.

18- S: Here?

19- T: Uh-uh. And the reason is that if you put it in this form [rereads], the whole rest of the sentence basically becomes one big noun. Then you can say "is committed to" [plus] the one big noun.

20- S: Oh, OK.

21- T: ...to creating a well-balanced learning...good use if a hyphen, too... learning environment to ensure its students' academic success by working with parents and the community. Some of the programs that the school offers include student volunteer programs, student conflict managing, parent tutoring, after-school homework center, um... let's see, "an after-school homework center?"... after-school childcare, and optional after-school enrichment classes. Regarding the diversity of the school, most of the students come from Hispanic origin. Others include Caucasian, Asian, and African-American backgrounds. Almost $50 \%$ of the students are English learners. A great number of students at Canoas Elementary School come from very low-income households, and the majority of the students are participating in the free or reduced price lunch program. For the 2008-2009 Canoas academic year, exact percentages can be found in the following table [pauses]. Exact percentages...let's see...

22- S: "Backgrounds?"

23- T: Yeah. Maybe "ethnic background and..." [pauses]. "...ethnic background and other... and ... resource information?" I don't know. Something like that?

24- S: Uh-uh.

25- T: About the school and the city demographics, the school is composed...

26- S: Of?

27- T: Exactly. The school is composed of 22 rooms with one two-story building. The school has large grass areas, two quads, a big playground, and several parking spaces. For the purpose of this paper, I went around the school and the neighborhood to take a look...

28- S: At?

29- T: Exactly ...the community surrounding the school.

30- S: [Scribbles].

31- T: Cause the school is actually surrounded by the community, right? So, "the community surrounding the school." Canoas is surrounded by mostly 
community houses. On the right side of...um, maybe "the campus?" ...there is a very nice new-home neighborhood. A block away from the school, up in a little mountain, there is a Christian Church on the left side and back of the school more houses...comma "...on the left side and maybe behind the school?"

32- S: Uh-uh [scribbles].

33- T: “...and behind the school” ... are more houses and a small city park. It seems... "it seems like?" ... a really safe and...

34- S: "Quiet?"

35- T: Exactly. That one happens all the time, and of course, your computer is not going to tell you that it's wrong. There are not a lot of cars in the streets. So, you just have a little section, you're going to put anymore in there? 36- S: Yes.

37- T: OK. [Reads title] Anti-bull "...bullying policy." Schools can help discourage bullying by enforcing a simple, clear anti-bullying policy to ensure that students are aware that bullying is unacceptable and that they should not bully others and how they can help those around them being bullied. So, here you are listing things, right?

38- S: Uh-uh.

39- T: ... that the anti-bullying policy will do. But there are three things. And when there are three or more we need...

40- S: A comma?

41- T: Exactly. So ...to ensure that students are aware that bullying is unacceptable, that they should not bully others, and how they can help those who are being bullied. Good. This policy needs to be clearly communicated to staff, students, and parents, and writing rules about bullying and tips on preventing bullying should be posted in every classroom and other important parts of the school. The end. "And written rules." And "everyone" can be one word in this sentence.

42- S: OK [scribbles].

43- T: Everyone in school should be worded...

44- S: Aware?

45- T: Aware. ...that bullying is unacceptable and appropriate consequences must be developed. Putting an end to one child bullying does not only protects...you actually have a couple of options. You could say "does not only protect the student, but it also..." or "... bullying not only protects the student, but also..." I think that also sounds better, so we can take this one out, and it's just the " $s$ " in the end. Because to say "does not only protects...," you actually now have two verbs: "does not" and then "protects." So, "putting an end to one child 
bullying not only protects the student, but it also sends a message to other students that bullying is not tolerated." Oh, good! I didn't even see that [laughs].

46- S: [Laughs].

47- T: Proper discipline to students who bully. Now this... Do these need to be capitalized, in the heading?

48- S: Ah, yes.

49- T: OK.

50- S: Thank you.

51- T: Bullying should be effectively disciplined. However, the purpose should be to deter the bully's aggressive behavior rather than to humiliate or embarrass him. According to...

52- S: "Embarrass them?"

53- T: No, you actually have it correct here, and the reason is because we are using one bully as an example. You could say... "him or her."

54- S: Him or her. OK.

55- T: And that would be OK. According to Kids' Health

Organization...hmmm... most kids bully because they are looking for attention so they can feel more important and powerful. Many of them come from families where bullying is common [pauses] commonly and they have been bullied themselves [pauses], um...

56- S: "Common?"

57- T: Uh-uh. So, many of them come from families where bullying is common... because with the "-ly," it's an adverb, right? ... and they have been bullied themselves. Now we are talking about the kids specifically, right?

58- S: Uh-uh.

59- T: OK. Therefore, disciplinary approaches should... should included, in the past?

60- S: include?

61- T: Exactly. Good job! ... should include interventions...that include strategies that will help...students [pauses].

62- S: Um, how do you say that word?

63- T: "Cope?"

64- S: "Cope" [laughs].

65- T: Exactly. I knew it was in there [laughs] ...to cope with their stress.

Recess detention and suspension have been used at the school as the most 
common form of punishment; however...excellent use of a semicolon! Good job! 66- S: Do I need a comma?

67- T: But you do need the comma. ...however, they seem to be ineffective due to the fact the issue keeps growing [pauses].

68- S: "Students?"

69- T: Exactly. Students who bully should be referred to individual counseling and or group counseling where they can get the support needed to stop the bullying. I would say "the support they need to stop the bullying." Bullying prevention and intervention treatment staff: All school staff members need to understand the nature of bullying and its effects, how to respond [pauses]. There you go .... and how to work with others at the school to help prevent bullying. Staff members need to take bullying reports seriously and should act as quickly as possible. If staff members ignored children's reports of being bullied, these children will not look for their help anymore, and the cycle of abuse will continue. So, this one, both verbs in the sentence, I am going to take the "d's" off. Because we are talking... it's hypothetical, right? We are talking kind of in the future: if this happens... if that's the case, we keep it in the present tense. So, "if staff members ignore....these children will not..." So, this one is perfect: "will not look for their help anymore, and the cycle of abuse will continue." Staff members need to be consistent with their interventions and expectations. If we are expecting children to be respectful, staff members need [pauses]. "We" can't really be in there; we can't really be a part of the issue. So, let's take this guy out, and let's say.... we could put "staff members" in there. "If staff members" [reads].

70- S: "They?"

71- T: Uh-uh. ...they need to be respectful toward students as well. They should not yell or use any type of abuse when trying to solve the problem.

72- S: Is it "or" or "nor?"

73- T: Let's say "or." Now you could say, "They should neither yell nor use any type of abuse," but that sounds almost too formal. So, I think it is better the way that you have it.

74- S: OK.

75- T: ... better supervision before recess or lunch time. Because it has been shown that bullying tends to thrive in locations where adults are not present or are not watchful, more adult supervision is needed to prevent kids from being exposed to bullying. Is that smaller [asks about sudden change in font size]?

76- S: Yeah [laughs].

77- T: Ok [laughs]. I was like: OK, wait a second! I am going crazy, but...OK. If the kids know that someone is going to be around making sure that everything 
is going well and/or available to help solve their problems immediately, children will be less likely to bother other kids and will be more likely to report if they are being bullied, um... Let's see [rereads sentence]. I am going to take that comma out because we are kind of listing things again, but there are only two at this time, really. We are talking about "making sure everything is going well" and "being valuable to help solve their problems. Both those who bully or have been bullied should receive help. Good! Groups should empower students to be their own advocates. Um, let's go ahead and say "support groups."

78- S: Uh-uh.

79- T: You have it in the heading, and I think it's just clearer to have it that way too. So, support groups should empower students to be their own advocates. Those who are being bullied should be provided with a safe space where they can show their frustrations and their emotions as a result of being bullied by other students. The focus of the group should be to teach children tips on how to defend themselves when they are [pause] exposed to situations. Um... because basically that becomes an adjective, right?

80- S: Uh-uh.

81- T: ... where bullying is involved. On the other hand, those who are bullies also learn to learn strategies to control their behaviors. Anger management techniques can help them to respond to their frustrations. Maybe like, "respond to their frustrations appropriately?"

82- S: Uh-uh.

83- T: Language should not be a barrier... bilingual, bicultural...let's see

84- S: I should capitalize that one, right [referring to the title]?

85- T: Yeah, you would need to. Language should not be a barrier to access services or look [rereads]. I think I am confused by the "look" there.

86- S: "Look for help?"

87- T: OK. OK. Language should not be a barrier to access services or look for help ...for the students...um, let's see, or "from their parents?" So, "language should not be a barrier to access services or look for help for the students or their parents?"

88- S: Uh-uh.

89- T: As was...

90- S: "mentioned?"

91- T: Exactly ... before, more than half the students at Canoas [pauses and rereads]... have primary languages other than English. For example, more than half of the students have Spanish as their first language. Yeah. The school principal and the school counselor do not speak Spanish. Really? That's 
amazing.

92- S: Uh-uh.

93- T: The school principal is Asian, and the school counselor is Caucasian. A counselor and a principal that speak Spanish are crucial if the population is the majority [rereads] are crucial if that population is the majority groups in the school [pauses]. So, you say "that population." What population, "Spanishspeaking?"

94- S: "Spanish-speaking" [scribbles].

95- T: So, a counselor and a principal that speak Spanish are crucial if...or you could say "crucial if the majority...of students are..."

96- S: "Spanish-speaking?"

97- T: Uh-uh, or "Spanish speakers?" It's fine. If a child or a parent has an issue, they should be able to communicate... "with?" No, I am sorry. Silly, I didn't read ahead ...to communicate their concerns in their own language with the principal and/or counselor. Good. Recreation activities during morning recess and lunch recess: Many times the problem of bullying arises when students are struggling... or having few...or no friends at all. In my time at Canoas, I have seen a lot of kids who... this is a really common issue, and most people don't even know. But it's always "things that" or "people who." So, kids who do not have anyone to play with or anything to do during morning and lunch recess. Therefore, I and other SJSU social work interns... Let's switch "you" to the end. So, another SJSU social work intern and I opened a jump rope club on Tuesdays and Fridays, and it has worked well. Oh, that's cool! At jump rope club, kids are kept busy playing with the ropes and learning or practicing their rope skills. In collaboration...and, maybe...so, in collaboration and with our supervision, children are able to make friends and spend a good time... and "have a good time."

98- S: OK.

99- T: Therefore, more extra-curricular activities are needed to give students a space where they can learn or practice their social skills to make new friends working collectively with others following the rules and learning to use their time productively while they are having fun. So, there is an issue in this sentence with parallelism. So, "practice their social skills to make new friends..."

100- S: "To work?"

101- T: Exactly, so "to work" and "to learn." Yeah. Good. The following is a schedule of some fun learning...I think we can just say, "...fun leaning activities that can be implemented in the school." These activities can be used at different areas, for example, students participating in the dance club can perform... or "can dance" or "perform dances", maybe [pauses while students scribbles]? 
...can perform dances for the monthly assemblies or end of the year graduation. The arts and crafts created an arts and crafts club...

102- S: "to be used?"

103- T: Exactly, in the library displays [reads list fast]. Parents can play one of the most important roles in a child's behavior. There is considerable evidence that parent involvement leads to improved student achievement, better school attendance, and reduced drop-out rates, and that these improvements occur regardless of the economic, racial, or cultural background of the family. Good sentence! Therefore, parents need to be...

104- S: Included?

105- T: Yes, excellent ... in these interventions. Parents should be supportive to their children, and they should advocate for "...their child's well-being," right?

106- S: Uh-uh.

107- T: Well, we should say: "their children's"...and the reason I say that is that since it is multiple parents, they're going to have multiple children. If children communicate that they are being harassed by other students or even staff members, they should "...be taken seriously?"

108- S: Uh-uh.

109- T: ... be taken seriously, and parents must report to the school. Cool, is that it? Do you have questions about what we went over? [ls there] anything that didn't make sense?

110- S: Yes, when I use like, "I should," the next verb... like how do I know if it is present or past? Is it always present, always past?

111- T: If you are saying "I should," and it is sort of in general like: "in the future I will do this," then it will be in the present. "I should go running every Tuesday, but I don't." And of course, if it is going to be past, then it is going to switch to "I should have... I should have gone running every Tuesday" or whatever the case may be.

112- S: [Scribbles]. And when do I use I could?

113- T: Same thing, pretty much. "I could do this, I could do that, I could have done this, I could have done that." Yeah, because these ones [verbs in the student's paper] are both conditional, they'll be in the present tense. Yes?

114- S: Yes.

115- T: OK.

116- S: Thank you.

117- T: Yeah. Good. Good job! You are welcome. 


\section{APPENDIX B: TRANSCRIPT OF TUTEE INTERVIEWS}

\section{Tutee 1's Interview}

I came to the United States when I was 14 years old, so I was a freshman in High School. First of all I learned how to write a paragraph because I was not really used to writing a paragraph in English. So, learning the structure, that was the first thing that I did. And then really expanding it, and expanding it. Yeah. (First language is Japanese).

\section{1- Topics covered during session}

a. When you scheduled your session online, what did you want/expect it to focus on?

I mainly wanted to focus on grammar because that is something that I can't fix by myself because I am an EL. I can think about content and organize things and ideas and things like that, but when I think of grammar [pauses], I need someone to specifically point out, like this is something you specifically need to focus on, because I would not be able to fix them by myself. So, this is why I come to the Writing Center a lot, just to focus on grammar. But at the same time, when I work with [tutor], she, in addition to grammar, she thinks about the content and argument, as well. So, every time I come here I get to learn something new.

c. What issues were not covered? Why?

Basically none. Because every time when I have questions I use bold letters or I type it in different colors so I can ask [tutor].

d. What additional ones were covered? Why?

In addition to grammar... sometimes I feel like, I don't know how to say this, or is there something that I need in between these two sentences? And [tutor] would say like, maybe you could add this kind of sentence here, and maybe you can combine these two sentences or make it so that things would flow better. It's not just grammar, but it's about content as well, making sure that things are smooth and easy to understand.

\section{2-Writing assignment}

a. What assignment did you bring to the Writing Center? Please, describe it. I was working on a case study, so basically I was supposed to show how my student was at the beginning of the case study, what I did, and how the student made growth at the end, so I was kind of reporting what happened, yeah. 
b. Did you learn anything else about this assignment during the session? If so, what and how did it come up?

I think it was clear to me.

\section{3- Tutoring session as apprenticeship}

a. Think about the tutoring session you just had, your tutor's coaching, and your learning. What three words would you use to describe your interaction with your tutor?

Being proactive - A tutoring session is not just a tutor sitting next to you and telling you everything that you need to fix. Of course I can ask my tutor to look at a few things, but at the same time, I think a tutor and a student need to be thinking at the same time. So, if I had some questions that I was not sure, I would always ask. If the tutor said something, and I did not understand it, then I would have to ask her to clarify it. So, making sure I am on the same page, understanding what is going on. Or, you know, this is something that I have some issues with: I need to be always asking questions and make sure that...I am saying what I want to say. Because this is my writing, this is the way to convey my thought, so I just want to make sure how best to.... to... explain. In order to do that, I need to be proactive by really participating and thinking. You can't ask the tutor to think for you.

Being open to new ideas - you know, sometimes a tutor would say something that I have never thought of, and then I would say, "No, I am going to stick to this one." So, it's really important that, "maybe I can think of it." You know, it's being open to new ideas.

\section{4- Socio-cultural roles of tutors/Writing Center}

a. Read the following statements. Then say whether or not they apply to the session you just had. Please, state what and/or why:

1. "My tutor helped me understand what the assignment was." Basically I knew what my assignment was, so no.

2. "I felt encouraged by my tutor during the session."

All the time, because they really make me feel great, and the thing t hat I love about the Writing Center is that the tutors never put you down. They give you a lot of encouragement, or maybe, even though it's something that I am doing, for example, like I said I use bold letters or type in a different color when I have some questions, and they say that they really like the strategy that I am using because that helps them too. So, it's really encouraging, and they give me a lot of feedback on my writing, so they just make me feel better, like I am in the right track. 
3. "My tutor shared some of difficulties he/she faces when writing." Yes, they have. They too are writers themselves, so when they write they share about their experiences, you know, making sure that your argument is clear and really strong.

4. "My tutor shared some of the strategies he/she uses when writing." Not all the time, but sometimes yeah. Sometimes, not really trying to share their strategy, "when I write, I do this." Yeah, that kind of thing.

5. "My tutor covered useful information I can use for future writing assignments." Yes, definitely. Every time I come to the Writing Center, I learn something new. Whether it is a grammatical thing or making sure that your argument is really strong and cohesive. So, every time I learn something new, I get to use that and apply to other writing assignments. For example, because I am an EL, sometimes I am not really sure about prepositions, and the tutor would say, "With this word, you need this kind of preposition." Then, if I learned that, I would not make the same mistake again. That's something they shared. Again, sometimes I don't come up with the right expression, and my tutor would say, "Well, maybe you can combine these two sentences, and say like, indicating..." So, every time I learn something like that, you know, new expressions, yeah.

6. "I could have used another service at SJSU to get the help I needed during this session."

I only come to the Writing Center, and I love it. I never considered going to other places for help.

\section{5- Writing Center and Pedagogy}

Think about the learning benefits of a Writing Center session to you and students in general. Read the statements below and complete them as you wish:

a. During a tutoring session, my main roles as a student are... being an active thinker. Not really listening and sitting and asking the tutor to do everything for you. I just try to think with the tutor and try to focus on how I can make my writing better.

b. During a tutoring session, I learn best by... interacting with my tutor. We talk about each sentence at a time and make sure it sounds smooth, or if I ask questions I make sure I ask my tutor about it.

c. Some of the things I have learned in my Writing Center sessions are... how to write a paragraph with a strong argument, how to connect ideas and make it smooth, and also how to fix my grammar. 
d. In order to become better writers, we need... to take the time to think about it and make sure you take the time to go back and revise and edit it with some help.

e. Students who come to the Writing Center mostly get... the support that they need to be successful to do well at school. 


\section{Tutee 2's Interview}

I did my education in my country [partly in English]. I came here for graduate school.

\section{1- Topics covered during session}

a. When you scheduled your session online, what did you want/expect it to focus on?

Grammar and mechanics.

b. Were these issues covered during the session?

Yes.

c. What issues were not covered? Why?

None.

\section{2-Writing assignment}

a. What assignment did you bring to the Writing Center? Please, describe it.

That's a training assignment. I had given training in my class, and I have to do a write-up.

b. Did you learn anything else about this assignment during the session? If so, what and how did it come up?

It was already clear to me, and I had already given a presentation in the class. After presenting in the class, I did my write-up.

\section{3- Tutoring session as apprenticeship}

a. Think about the tutoring session you just had, your tutor's coaching, and your learning. What three words would you use to describe your interaction with your tutor?

Good learning experience - a few things like the use of "the," and "a," so I try to write again. Similarly with the commas, punctuation, when I am writing again, so I know how to use it. So I find the sessions quite useful, and it is very informative, and I learn a lot from the session. When I came from my country, the kind of English used over there and the kind of English used over here is very different. So, through the tutor sessions I learn a lot instead of taking any other English classes over here: The grammar, the punctuation, everything.

\section{4- Socio-cultural roles of tutors/Writing Center}

a. Read the following quotes. Then state whether or not they apply to the session you just had. Please, state what and/or why: 
1. "My tutor helped me understand what the assignment was." No.

2. "I felt encouraged by my tutor during the session."

Yes. It's not only mechanics and grammar. We paraphrased a few sentences; we changed a few sentences to make it more understandable, to make it more clear.

3. "My tutor shared some of difficulties he/she faces when writing." No.

4. "My tutor shared some of the strategies he/she uses when writing." No.

5. "My tutor covered useful information I can use for future writing assignments." Yes. Not the information as such, but the use of grammar and mechanics. Like the proper use of the and placing comma before using "but" and all this. And then, like when it was a complete sentence, and then the other two sentences, and all three of them were different, so just to make it proper language.

6. "I could have used another service at SJSU to get the help I needed during this session."

Yes, I could have, but I prefer to come to the Writing Center because I learn a lot more from here. Whatever I am working on, I feel if the tutors have been appointed by the Writing Center, it must be something very good.

\section{5- Writing Center and Pedagogy}

Think about the learning benefits of a Writing Center session to you and students in general. Read the statements below and complete them as you wish:

a. During a tutoring session, my main roles as a student are... to learn more from the tutor on the use of grammar and mechanics and to improve my writing.

b. During a tutoring session, I learn best by... going through my paper with the tutor.

c. Some of the things I have learned in my Writing Center sessions are... the use of grammar and mechanics, which I am still trying to improve on prepositions, balancing nouns and verbs, paraphrasing, reducing the word content, avoiding repetitions.

d. In order to become better writers, we need... good tutors 
e. Students who come to the Writing Center mostly get... good advice. 


\section{Tutee 3's Interview}

Tutee came to the United States when he was 8. He started first grade in Vietnam where he had classes only in Vietnamese but then transferred to a US school after he came here. He says he always struggled with English, especially writing. He said he thinks he struggles with writing because he needs to practice a lot, and he claims it to be his fault that he did not develop it well enough.

\section{1- Topics covered during session}

a. When you scheduled your session online, what did you want/expect it to focus on?

Mainly grammar and sentence structure because I tend to make mistakes, like right now I got better, but before I usually had problems with run-on sentences, and sometimes I do not remember that this is a dependent clause or an independent clause. So, I forget like a comma, I forget to put "an," so it becomes like a run-on sentence.

b. Were these issues covered during the session?

For this session, it was mainly verbs like past and present tense and adjectives.

c. What issues were not covered? Why?

Content. Like I am also doing a research on depression and alcoholism, and I am paraphrasing a lot of the contents. For example, the symptoms for depression can be like difficulty concentrating... If there's a symptom for alcoholism, should I keep it in, is it repetitive? So, I didn't know like, "should I keep it in the paragraph or just take it out? Or just put it together?" So, I asked for that.

d. What additional ones were covered? Why?

$\mathrm{N} / \mathrm{A}$

\section{2-Writing assignment}

a. What assignment did you bring to the Writing Center? Please, describe it. I am developing a recreational and leisure plan for a client in a case study, and I have to list the problems that the client might encounter because he has depression and alcoholism, and he is taking Prozac for depression. So, list all the problems he has first and transition to developing this leisure plan that will help him become like... participate in the community, basically change his lifestyle through activity.

b. Did you learn anything else about this assignment during the session? If so, what and how did it come up? 
I already knew about it. I had the instructions and everything.

\section{3- Tutoring session as apprenticeship}

a. Think about the tutoring session you just had, your tutor's coaching, and your learning. What three words would you use to describe your interaction with your tutor?

Educational - to me it's very meaningful.

Motivated - so far, I have been trying to keep the same tutor. I know I can switch it around, but if you keep the same tutor, she will know how you write, and she will be able to teach you better next time. So, if I switch around a lot, so every time I have a new tutor it will be difficult for the person because the person might not be familiar with it [the way I write] and give me different opinions.

Enjoy — I enjoy it a lot.

\section{4- Socio-cultural roles of tutors/Writing Center}

a. Read the following quotes. Then state whether or not they apply to the session you just had. Please, state what and/or why:

1. "My tutor helped me understand what the assignment was." No, because I already understood what the assignment was.

2. "I felt encouraged by my tutor during the session."

Yes. She was very encouraging. Usually while she is correcting my paper, she will read it out loud, and she will kind of explain it to me. Some people would just laugh, laugh in a way that you would feel kind of bad and ask yourself, "Why are you making this silly mistake?", and for her, it's more like...she tells you the mistake and explains you why. She does not make you feel like, "Oh, you are making that same grammar mistake." And it's kind of encouraging. You can learn more from her.

3. "My tutor shared some of difficulties he/she faces when writing." No, not on this session.

4. "My tutor shared some of the strategies he/she uses when writing." Yes, she would tell me how to use a word, or what I should have in this paragraph, or how to make a transition. She would help me to improve my content and my writing skills.

5. "My tutor covered useful information I can use for future writing assignments." Yes. Actually, I am learning a lot from her when I come here. Sometimes I make the same mistake, but I am able to catch the majority of my mistakes now. I will have less error on the paper. As I am reading along with her, I am able to catch 
it and fix it right away, without her telling me, "Oh, what's this?" If I miss it, she would say, "Oh, what are we missing right here?" Then, I would be able to catch it. The first semester I was here, which was like a year and a half ago [laughs], I was not able to do any of this, and now I am able to pretty much like edit my whole paper. The first meeting actually took like half an hour to spend like on two pages. Now I can go through four or five pages with her without asking questions. Sometimes I ask questions because I want to know like why this is an "s" or something like that.

6. "I could have used another service at SJSU to get the help I needed during this session."

Yes. I know there is [names another service], but it seems I do not learn as much. I have been there three times, and when I go over there I feel kind of disappointed. I was able to stay there for an hour, but that one hour is like helpful, but it does not compare to half an hour that I get here.

\section{5- Writing Center and Pedagogy}

Think about the learning benefits of a Writing Center session to you and students in general. Read the statements below and complete them as you wish:

a. During a tutoring session, my main roles as a student are... to learn.

b. During a tutoring session, I learn best by... asking questions.

c. Some of the things I have learned in my Writing Center sessions are... sentence structure, past and present tense, verbs, nouns. Actually, there is a lot more. Since a year and a half ago, I have had questions every time I got here. The things you need to be able to develop a paper, I ask at least once.

d. In order to become better writers, we need... to keep on reading and writing.

e. Students who come to the Writing Center mostly get... something different every time [they] come here. 


\section{Tutee 4's Interview}

I came here about 15 years ago. I came here during my high school years. I did all my high school here, and then I went to college here [speaks Vietnamese]. But the problem with me is that I talk to a lot of foreigners who have been here for a year, and their English is so good compared to my English. I have been here longer. I don't know. I think they had better foundations when they came here. When my family came here, we did not have a good foundation in English, of structure in English. Then [later throughout his education] no one points out. When I go to college, and I turn in a paper, there is no corrections and just a letter [grade]. Then, I am taking take English $1 \mathrm{~A}$ and $1 \mathrm{~B}$, and they mark so many words. I get the paper back and I get so many mark downs.

\section{1- Topics covered during session}

a. When you scheduled your session online, what did you want/expect it to focus on?

I brought up the idea of using the 'be' verb. Like, active, main verb, passive voice, then we talked about singular and plural. I didn't bring a paper this time. I just wanted to talk about these issues.

b. Were these issues covered during the session?

Yes, definitely.

c. What additional ones were covered? Why?

Not today, because we went off topic a lot [laughs]. I don't think so.

\section{2-Writing assignment}

a. What assignment did you bring to the Writing Center? Please, describe it. $\mathrm{N} / \mathrm{A}$

b. Did you learn anything else about the topics during the session that you didn't know before?

I am aware of them, but not to the point where I would become an excellent ESL. Sometimes I just get lost and confused.

\section{3- Tutoring session as apprenticeship}

a. Think about the tutoring session you just had, your tutor's coaching, and your learning. What three words would you use to describe your interaction with your tutor?

1- I think it's important to find a tutor that you feel comfortable with; someone friendly, down to earth that you can just ask questions to, and you wouldn't feel 
like you are asking a stupid question. Sometime when I ask a question I think, "Oh, it's a stupid question." I feel kind of stupid, but I want to make sure that I know it, so I don't do it again. So, it's good to find someone you have a connection, a bond.

2- The thing with second language. Sometimes you don't know a word, and you look for help, and you don't have a friend. It's nice to have a friend native here [in the United States] that you can just ask, but everybody is busy. It's really nice to have a center here you can come by and ask them to check your paper and proofread it. It's really nice. This is kind of free to us. You learn new things, and you don't pay anything, so it's kind of nice.

3- With [tutor], it's kind of nice because I can ask him a question or something I do not know, and he will go into further detail and give you more examples. I learn best by examples, something you can relate to, you can grasp.

\section{4- Socio-cultural roles of tutors/Writing Center}

a. Read the following quotes. Then state whether or not they apply to the session you just had. Please, state what and/or why:

1. "My tutor helped me understand what we talked about." Yes, because he gave me examples and told me when and where to use it.

2. "I felt encouraged by my tutor during the session."

Yes, definitely. I realized that the more I know about English, the less I know, so I feel encouraged to go and learn new things.

3. "My tutor shared some of difficulties he/she faces when writing." I don't think so. Sometimes he will do it, like ask a co-worker if he does not know, but most of the stuff I asked him he fully knew.

4. "My tutor shared some of the strategies he/she uses when writing." $\mathrm{N} / \mathrm{A}$.

5. "My tutor covered useful information I can use for future writing assignments." I think so. When you have a paper, and there is something you don't know, and you ask, it [appears] later on your paper and you have the knowledge.

6. "I could have used another service at SJSU to get the help I needed during this session."

I don't think so. Maybe we do, but I don't know. I did not know about this until my English professor told me. If they don't advertize, no student will know.

\section{5- Writing Center and Pedagogy}


Think about the learning benefits of a Writing Center session to you and students in general. Read the statements below and complete them as you wish:

a. During a tutoring session, my main roles as a student are... to improve, to become a better writer, and improve my English.

How do you do that?

By learning, coming prepared. Basically, when I come to [tutor], I prepare. When I have a paper, usually my paper is returned to me. My professor marks it down.

b. During a tutoring session, I learn best by... example. Basically give me an example and tell me when not to use it and when to use it.

c. Some of the things I have learned in my Writing Center sessions are... I learned when to use passive and when not to, I leaned about articles, I learned about plural and singular. I learned a lot of things. One day, one semester would not be enough.

d. In order to become better writers, we need... practice, to keep practicing, read more.

e. Students who come to the Writing Center mostly get... hands-on practice. You have a face to face session with someone there, and you can just ask. You learn a lot more than when you just look at the computer and just read it and learn it; because sometimes I read it and interpret [it] a bit differently than most people. When you come to the center you can read something, you ask right away, and you get the answer. 


\section{Tutee 5's Interview}

I came here six years ago, so I did school most of the time in Mexico, my home country. I did two years of high school, college, and university in the United States.

\section{1- Topics covered during session}

a. When you scheduled your session online, what did you want/expect it to focus on?

Most of the times when I come here, I focus on grammar and spelling because I am always done with my paper; like, I don't need help with structure or anything. So, I like just want to make sure the spelling is correct, so I don't get grammar errors.

a. When you say grammar, what exactly do you mean? Just to make sure the subject agrees with the verb, I have complete sentences, I don't have run-ons.

b. Were these issues covered during the session?

Yes, all of them.

c. What issues were not covered? Why?

I brought only half of the paper, so I was able to finish the grammar, and at the end I had time to ask some other questions.

d. What additional ones were covered? Why?

Yes, like sometimes, my tutor corrects one thing like the verb and I understand, but then at the end I asked, so "how do I know when to use like -ing or -ed?"

\section{2-Writing assignment}

a. What assignment did you bring to the Writing Center? Please, describe it. I am doing an internship, and I have to write an assessment about my community, like, mention some of the needs and some of the solutions that I can create.

b. Did you learn anything else about this assignment during the session? If so, what and how did it come up?

I knew what it was.

\section{3- Tutoring session as apprenticeship}


a. Think about the tutoring session you just had, your tutor's coaching, and your learning. What three words would you use to describe your interaction with your tutor?

Productive - even though we had only thirty minutes, we were able to cover the, to go over the paper.

Helpful - because she was great, and I got help with my paper. Learning - because every time I come I learn something about grammar and about English.

\section{4- Socio-cultural roles of tutors/Writing Center}

a. Read the following quotes. Then state whether or not they apply to the session you just had. Please, state what and/or why:

1. "My tutor helped me understand what the assignment was." No. I already knew.

2. "I felt encouraged by my tutor during the session."

Yes. Many times what I like about her or other staff members is that sometimes I have a paper, and they say like, "oh, that's an excellent idea!", "Oh, this is a good sentence!" They always make comments and make me feel good about my paper.

3. "My tutor shared some of difficulties he/she faces when writing."

Yes. I think I wrote a word or something and she said like, "oh, it is a really common error that people make."

4. "My tutor shared some of the strategies he/she uses when writing." Yes. [She mentioned that] sometimes the computer will not tell that a word is incorrect, so I just have to read the paper before and make sure it is correct.

5. "My tutor covered useful information I can use for future writing assignments." Yes, like to go over my paper or just read it, read it out loud.

6. "I could have used another service at SJSU to get the help I needed during this session."

This is the only place I know.

\section{5- Writing Center and Pedagogy}

Think about the learning benefits of a Writing Center session to you and students in general. Read the statements below and complete them as you wish: 
a. During a tutoring session, my main roles as a student are... to ask questions and to provide a background about my paper.

b. During a tutoring session, I learn best by... asking questions and letting my tutor know what I want to focus on.

c. Some of the things I have learned in my Writing Center sessions are... rules about grammar, some tips about how I can improve my proofreading skills.

d. In order to become better writers, we need... to come to the Writing Center and get help and to keep writing and writing.

e. Students who come to the Writing Center mostly get... help. 


\section{APPENDIX C: TRANSCRIPT OF TUTOR INTERVIEWS}

\section{Tutor 1's Interview}

\section{1- Topics covered during session}

a. What issues did the student want to focus on during the session?

We had had a session earlier where she brought a piece of her student's writing - I think she helps out with a first and second grade classes - and it was a personal narrative of the student about an experience with eye surgery. And we had talked about how to improve that student's writing at that grade level because she was unsure if what she was requesting was too high of a standard. I said what I would think, not knowing much about first or second grade education, and she came back with a reflection on what she had actually gone and taught the student to improve her writing, so we focused on... I think we only read the first couple of pages of her reflection where she set out the goal she wanted to improve, and that was having the student think about audience and voice, and not just a personal narrative as "let me describe an event to you," but a personal narrative as representing something like: you have an audience, you have a voice, you are trying to portray something in the event, which is probably higher grade level than I assume second grade does, but it sounded like it went well.

b. Did you and the student cover these issues?

She started the session saying she wanted to focus primarily on verb tenses because she said it was hard to talk about the student's writing, to talk about what the student did when she wrote a certain assignment and then to reflect upon what the student needed to fix in the future. So, she thought her response... She analyzed that her response needed like all three kinds of verbs - present, past, and future - but she was not sure if she was using them correctly. She does not have a lot of grammar errors, but I could tell that she was really struggling with the verb tenses to a point where she starts worrying about something, and she will make it worse sometimes. So we went through looking at, "so what's the content of this sentence we are talking about and what are we going to use?"

\section{d. What additional ones were covered? Why?}

There were a couple of missing articles and commas with FANBOYS, but at this point she has such a strong knowledge of grammar that I can say, "Oh, I think you are missing an article," and she can put in a proper one, or I can say, "it looks like this is a FANBOY," and she can put the comma without much prompting besides that. 


\section{2- Writing assignment}

a. In your opinion, did the student understand his/her assignment? How could you tell?

I think so because I asked her a lot of questions about the assignment. I was not sure if it was supposed to be an academic kind of reflection on what she did or a more journal-style reflection; you have this kind of this opening introduction that was more personal-sounding than a step-by-step break down of what things you looked at, as opposed to an academic paper, which probably would have been more fine-tuned, more formal, and more tightly organized, and she could explain, "no, it's supposed to be more informal."

b. Did the student's understanding of the assignment change during the session? If so, in what way did it change? How did you know that there had been a change? Can you remember what happened that might have caused the change?

As we talked about how the introduction part of it was organized, I think she began to see that even in the less formal assignment, it would still have some kind of coherence between all the paragraphs and some organization. So, there were a couple of times when I suggested maybe linking two things back and forth, but I don't think it changed her overall understanding of what the assignment was supposed to do.

\section{3- Tutoring session as apprenticeship}

a. Think about this writing session you have just had with (student) in terms of your coaching and his/her learning. What three words would you use to describe this interaction?

Synergy/Discussion - we have worked together to the point that we "work together... I don't really like the whole "I have the authority" or "listen to me" kind of situation. So, there's that, and it is more like a discussion. She will come in and out with questions while we are reading, instead of... I know a lot of students are too afraid to speak up, so you have to keep stopping and going, "did you want to say something?", whereas she is participating in the discussion. She will go, "Wait! What about this? Or "Shouldn't this be...?" which makes me a lot happier. It seems like she's learning.

Fun - I think it's fun, but I am a huge dork. I think she thinks it's fun too.

\section{4- Socio-cultural roles of tutors/Writing Center}

a. Think about your role as a Writing Specialist as you read the following statements. Then state whether or not they apply to you and the session you just facilitated. When applicable, state what and/or why:

1. "I helped the student understand what the professor expected from him/her." 
This wasn't really applicable to the session that we just had, but I think at least 60 or $70 \%$ of the time what you are doing is to help the student understand what the teacher wants. They don't always come and verbally sit down and say, "I don't know what I am supposed to do," "I don't know what they want." There are a small percentage of people that actually fully admit they don't have any idea what is going on. There are more people that will come with a specific question about the prompt. You know, "I am fine until here, but I don't understand this one question." l've had students come in, and if they have to look at assumptions and limitations, they don't know what assumptions and limitations are, so a lot of the time there is comprehension of prompt, comprehension of vocabulary, explaining those types of things. When we help a lot of the 1A and 1B students, it's even past understanding the question; it's understanding the passage they have to read, too, which I find a lot of the times when I have students here from $1 \mathrm{~A}$ and $1 \mathrm{~B}$, it's to help them understand what the passage was saying, not just what they are supposed to be writing about or organizing their ideas. It's that they are interpreting the passage incorrectly.

\section{2. "I helped the student by encouraging her/him to do better."}

I think that's true for every tutoring session [laughs]. I think that we're... As a tutor, you are the go-between between the teacher and the student. I think a lot of them [students] are so afraid of their professors... They don't want to look stupid; they don't want to admit they don't understand what is going on. So, a lot of the times you have to... I try to be really reassuring and give them support. I've had a couple of people come in and cry. [And I say] like, "it's OK, we can do it." And I try to make them laugh because you don't know what else to do. I think a lot of what we do here is a mini therapy session. "You can do it!"

\section{3. "I shared some of my own difficulties as a writer with the student."}

I don't think I did it in this session. I do that a lot, though, especially because in English we have to take a foreign language to get a degree, so like especially when there are things like articles, I understand that they are arbitrary. It happens when I am trying to do Italian. I go like, "why is it that way?" No one can give you an answer. So, I try to empathize with how frustrated they get about certain situations or how question words upset the structure of a sentence. I try to relate.... a lot of people have problems with commas. They go like, "They just told us to put them where there's a pause," but then you find that it's wrong. So, I try to relate with them. I guess it's more that I don't like being an authority; I want them to understand writing is a process, and everyone has problems, and you just work on them and they get better. I think it makes it easier for them.

\section{4. "I gave the student useful information she/he can use for writing university} assignments in general."

When we were talking in this session about verb tenses, we kind of went over generally when you would use different types of verb tenses, like when she was 
talking about the student's writing, I related it to how you write about literature, even if the student's writing isn't literature, like a formal sentence, it's the same concept, so you are writing in the future. Because every time you read the student's story, it happens again. And I related, like, talking about what the student did before she wrote it in the past, it's like when you have to link literature with history and things like that in a paragraph, somehow. Sometimes verbs get really confusing, and they'll sound wrong, but you are doing it correctly because there are different time periods going on. And try to give students ideas to carry with them through all of their writing like, "explain the quote, it's the favorite thing about a teacher. They love it when you explain the quote or why it's important."

5. "The kind of help this student could get from this session is different from the help he/she can get elsewhere at the university."

It might be a little biased [laughs], but I think that because we are led by an English teacher, and we are led under kind of an English infrastructure or Linguistics, or Humanities kind of format, a lot of us want to be educators, that our tutoring is different than some of the other places that I think are much more like peer-tutoring. That's why I think we are a little bit between. I mean, you have full professors and kind of peer workshops. I think we fall in the middle. I think that we...I don't want to say that I am as smart as a professor, but I think we have a firmer grasp of a lot of concepts, but then we are not as scary as a professor. So, we kind of fall in this middle ground that I think makes us unique, granted I don't have a lot of firsthand knowledge of other places on campus, just to be "peacy" about it. But I think things like peer mentor they have a different sort of appeal. That seems like it would be really good with someone in the same class, and if you don't have really severe grammar errors, and it's a content thing, and you don't understand it, I think it's a different place to go to.

\section{5- Writing Center and Pedagogy}

Think about the pedagogical benefits of a Writing Center session to students in general. Read the statements below and complete them as you wish:

a. During a tutoring session, I help students mostly by... Listening and being understanding. I think most of them feel like they get lost in the shuffle, especially if they have a hard time articulating what they think. A lot of students are appreciative when you, "Oh, so you are saying..." "Yes, that's exactly what I am saying!" I think they just want to be listened to.

b. During a tutoring session, my main roles are... Listening and figuring out what they want, helping them achieve it, and giving them something to go away with, hopefully something different every time and something that they remember [laughs]. 
c. When I tutor English Language Learners, some of the things I do are... I use visual aids. I think that helps a lot. I've tried to become more aware of the errors associated with different languages. Spanish students may have problems with articles, Asian students may have problems with plurals, so I try to be aware beforehand of what their issues are going to be, and I try to be understanding. And I make sure [laughs] that when they just keep saying "yes," I corner them, and I make sure that they actually know what I am talking about. Because I think a lot of them have been taught just to agree, even when they don't. So, I surprise them, "so you agree, what do you agree with? ", and they get all like "Ahhh!" "Do you really get what I said?", and they say "No!"

d. In order to become better writers, English Language Learners need... To immerse themselves in English. I feel like a lot of them... I know I read a lot of LLD papers in the Writing Center, and I know for a lot of people there's the cultural issue, so you don't want to just read English magazines because of cultural issues, but they have to do some of it. To really understand English idiom and speech and be able to articulate ideas at the college level, you have to do some of that, even if you don't want to. And a lot of them ask what they should do, and I tell them to watch something like the news and put on English subtitles, and they go like "that sounds boring", and I go "well, it's the only way you are going to learn."

e. Students who come to the Writing Center benefit mostly because... I think because we have structure and we all have that desire... We are all, I think, educators in our hearts. So, I think the format of the Writing Center, even if we come out a little rigid sometimes, is really helpful because they know what they are going to expect every time they come back. And I think that is reassuring. So, once you come and do it once, it's not like, "Who am I going to be paired with?" Like, if you walk into other places, and it's not this format, that can be a scary situation. So, I think that helps after the first time you get over that. And then that we are all educators, we build relationships with a lot of them. They come back and then, again, get over the scary idea, and they know that we care, and we write reports about them, and we think about them later [laughs]. 


\section{Tutor 2's Interview}

\section{1- Topics covered during session}

a. What issues did the student want to focus on during the session?

She wanted to focus on grammatical errors. That's the case with most tutees, I think. Some will come and say, "I want to learn about..." I have a tutee who will come every week and say, "I want to learn about 'that' and 'which' clauses. For most cases, it's just, you know, a compromise. They want their papers corrected to get a good grade. In order for us to correct their papers, they are going to have to learn first, you know. "We are going to teach you, and you're going to get a good grade." So, it's the case in most tutoring sessions.

\section{d. What additional issues were covered? Why?}

There were a few things that were not strictly grammar. It might be hard to figure out when you are listening to them, but they were more clarity, you know, they were more based on the clarity of the content or clarity of the ideas than strictly grammatical. In most cases it was something that I noticed. Most of the issues I noticed. At points, she will pick up something, and she may not know exactly what is wrong with the sentence at first, so she kind of goes fishing, "what's wrong with this sentence?", and I give her a little bit of time to see if she can figure it out, but if she is kind of off track, l'll try to focus more on the problems, "there's a problem with this part right here," "you are focusing more on this article in the beginning of the sentence, but the problem is more the passive voice in the sentence."

\section{2- Writing assignment}

a. In your opinion, did the student understand his/her assignment? How could you tell?

I think so. She came in and said, "This is worth so many points, this is worth so many points. I need to do this, this, and this." So, yeah she seemed to have a good idea, and I was like, "can you use 'I' in this one, can you use 'the author'?", and she gave a pretty detailed response, even though she did not seem completely sure what she could use, "well, this isn't necessarily APA format, and I think I can use ' $I$ ', because there are some passive voice issues that arose from not being able to have an active subject.

\section{3- Tutoring session as apprenticeship}

a. Think about this writing session you have just had with (student) in terms of your coaching and his/her learning. What three words would you use to describe this interaction? 
Leading - in most sessions, I, as the writing specialist, lead the session. In most cases, when I give them the option of, you know, "do you want to read it out loud, or do you want me to read it out loud?" They'll be like, "you read" because maybe they think I'll pick up more errors that way. Clearly most tutees defer to me as the expert. Sometimes you are going to have tutees that will argue like, "why is that?, Why do we need this article here?" You know, those sessions seem to be a lot more productive than when they just nod their head, and you don't know if they are getting it or not. When you get a good back and forth with questioning, that is kind of rare, and I don't really know how to get students to ask more questions because a lot of them are clearly focused on getting corrections as much as they can.

Haste or Rushed - Not too rushed, Not too rushed. I have had some tutees that are just clearly trying to push you along. She does not push you along, but she does not really stop for you to explain anything. You get that idea.

Engaged - she was engaged. I would ask her, "what would be the best way to rewrite this?", and she would give a suggestion. And often times it is the right suggestion. You don't necessarily have to tell her.

\section{4- Socio-cultural roles of tutors/Writing Center}

a. Think about your role as a Writing Specialist as you read the following statements. Then state whether or not they apply to you and the session you just facilitated. When applicable, state what and/or why:

1. "I helped the student understand what the professor expected from him/her." No, because we did not really go over the assignment requirements.

2. "I helped the student by encouraging her/him to do better." I guess I am not very good at that. I know some tutors are very much like...I will be like, "yes," if she suggests her own right answer, I will give her positive reinforcement.

3. "I shared some of my own difficulties as a writer with the student." Not explicitly, but I think in almost every session. This session is not one where I shared my own difficulties because I am trying to unravel the sentences just like they are, right. I don't read a sentence, and just like that I know exactly what is wrong with it. I have to figure it out myself. I can do it a lot faster and maybe more accurately than the tutee, but I think I go through the same process. I just have more experience.

4. "The kind of help this student could get from this session is different from the help he/she can get elsewhere at the university." 
I think it is different than the help the tutee can get anywhere else including other tutoring centers, especially on grammar. These writing specialists are the only people out of the whole university qualified to do grammar. There's just no one else. It's very strange. I think that we do...just in terms of that specialty. In terms of tutoring, I have never been to other tutoring services, so I can't really say, but when it comes to tutoring as opposed to teaching, I think we do something unique. Last semester I was in a composition theory class, and I read an article that talked about writing centers and the kind of back and forth you can have. You know, in a classroom information is going one-way, usually, in most cases, but there is a very conversational aspect to a tutoring session. You are getting instant feedback from your tutee, whether they are getting it or not, whether they are engaged or not. And I think that really helps them learn, and it helps us to focus our tutoring or pedagogical style to them, and I think it is something you can't do in a classroom.

\section{5- Writing Center and Pedagogy}

Think about the pedagogical benefits of a Writing Center session to students in general. Read the statements below and complete them as you wish:

a. During a tutoring session, I help students mostly by... making complex ideas, whether they be grammatical, organizational, thesis statements, by making complex ideas easier to understand or explain, which I guess is the job of most teachers, you know. That goes in terms of complex grammatical rules, but that's also trying to get them to explain their own writing, to simplify their own ideas. Or maybe not simplify them, but to make them more understandable for the reader, which I think is a similar process, you know, what I am doing in terms of the complex grammatical organizational ideas and what they're doing, or what they want to do with their own writing.

b. During a tutoring session, my main roles are... to point out the problems, what is wrong, with the exception of those sessions where the students are already coming with the problems they want to work on. There are a few tutees like that. But in most cases, first of all, pointing out what is wrong and guiding towards how you might fix it, hopefully not telling them. Something like prepositions, I just have to tell them because I can't really lead them along a logical path that will show how it is. But a lot of times you can kind of lead them, like you can get them to look at certain parts of their sentences or something like that will help them correct it on their own, hopefully.

c. When I tutor English Language Learners, some of the things I do are... I try to explain things in the terms... I try to build a bridge between someone who speaks English from birth, like me, and someone who has learned it along the way. It seems like a lot of times English Language Learners will be discouraged. 
They will see, "Ok, there are a lot of people that are just fluent in English. They can just spell articles correctly without even thinking about it, and I have an article problem in every single sentence. What is going on here?" And they get discouraged by that. And one of the things that I try to do is say, "Most English as a first language people, they just say it because it sounds right, and the challenge for you as an ELL student is that you are going to have to go through a logical process, whereas for most English as a first language students, it's just a natural process. So, for now at least it's going to be an unnatural process for you," and I try to explain that and also bring in my experience because I have also taken classes in Spanish and Japanese, as well, and I can bring in those, especially with tutees from east Asia. I can say, "You know, I have the same problems going from my language to that language. I understand that your language does not have these articles, and that's why it's so difficult. You've lived your entire life not having to think about it, and now you do." I try to build bridges, I guess it's the one big thing I try to do.

d. In order to become better writers, English Language Learners need... constant tutoring. One big thing aside from help from tutors and teachers is just to try to immerse yourself in the language, basically read a whole lot. Not so much just watch the news, but read, read, and read. It's the only way you can really pick up, especially as a writer, pick up all those little things that you have to do when writing, like avoiding repetition, redundancy, and all these things, and all these conventions that are in written language that are not in spoken language.

e. Students who come to the Writing Center benefit mostly because... because it's a conversation. It's a back and forth. We get instant feedback, and they get instant feedback as well. They can tell us immediately if they are having trouble understanding what we are saying. And it might help as well that we are not $\mathrm{PhDs}$, and that we are not professors, that we don't ...Again, going back to that composition class that I took last semester, it was talking a lot about the political dimension or the power dynamics of what happens when someone is named a professor or a teacher. There's this certain sense that you can't approach them with certain questions, that they are infallible in certain ways, and that they are distant. You know, they are up there at the front of the class, and you and thirty other students are facing that way, and there's this one person facing this way. But if it's one on one, and you are just facing each other, I think they might be more willing to explain the problems they are having because they are less afraid to sound stupid. 


\section{Tutor 3's Interview}

\section{1- Topics covered during session}

a. What issues did the student want to focus on during the session? It's actually kind of funny because he is one of the first students I started working with, so with him I don't even ask anymore, like generally it's always going to be grammar. Traditionally with him I go over article use, prepositions and idioms, that's really...and actually verb tense. He used to have problems with verb tense, but I think he has really fixed that. So, we just sit down and he tells me what it is that we are looking at, and if he has anything special like, "this one actually I am really worried about content," he will let me know. But otherwise we just sit down and read through it. In most of our sessions we focus on grammar.

b. Did you and the student cover these issues?

Mostly grammar. At this point it is a lot of... you know like, verbs that are used with prepositions, for instance, is something that we have been focusing on more recently. And sometimes they are just grammar questions. This one specifically it was grammar and idiom, a lot of idiom.

c. What issues were not covered? Why?

$\mathrm{N} / \mathrm{A}$

d. What additional ones were covered? Why?

$\mathrm{N} / \mathrm{A}$

\section{2- Writing assignment}

a. In your opinion, did the student understand his/her assignment? How could you tell?

Definitely, he actually had two things. The first one is the in-class journal that he has been working on. We have looked at other entries from it in the past. It's more like an informal.... You know, anytime he has an assignment for the first time, he explains to me exactly what it is. Usually he will show me the prompt, so... Just knowing him and having worked with him in the past, I know that if there is a problem in the prompt for him, he will come to me and just say it. He is such an easy person to work with because he has all his stuff set up already. Like, he knows what he wants to work on. I trust that he reads the prompt and knows what [it is].

b. Did the student's understanding of the assignment change during the session? If so, in what way did it change? How did you know that there had 
been a change? Can you remember what happened that might have caused the change?

$\mathrm{N} / \mathrm{A}$

\section{3- Tutoring session as apprenticeship}

a. Think about this writing session you have just had with (student) in terms of your coaching and his/her learning. What three words would you use to describe this interaction?

Preparedness

Inquisitiveness

\section{4- Socio-cultural roles of tutors/Writing Center}

a. Think about your role as a Writing Specialist as you read the following statements. Then state whether or not they apply to you and the session you just facilitated. When applicable, state what and/or why:

1. "I helped the student understand what the professor expected from him/her." Not this session.

2. "I helped the student by encouraging her/him she/he can do better." l'd say so. l'd like to think so.

3. "I shared some of my own difficulties as a writer with the student." Not this one particularly, but that does happen in our sessions. He and I have been working together since my very first day here. He is one of my regulars. He usually comes once and twice a week to see me. He's gotten really good about sitting down first, going through and self-correcting and bringing me his corrected paper. And sometimes he'd do that, and we'd still find a lot of errors, and he would be discouraged. And you know, some of it is just idiom, and I would go like, "Yeah, I have the same problem too." I always tell students, "You know, you read something so many times that you stop seeing the errors because you need another eye on it." You know, I just think it's good to let them know like, "look, you are not a bad writer. Just because you have errors, it does not make you different in any way. It happens to people who even write professionally."

4. "I gave the student useful information she/he can use for writing university assignments in general."

Yeah. Working with Aaron is really nice because he always has questions prepared. You know, we, for instance, went over, "what's the difference between time and times? Which one is count or non-count?" I think it's just kinda like idiom and grammar, things like that. You can apply that to any academic writing. 
5. "The kind of help this student could get from this session is different from the help he/she can get elsewhere at the university."

I'd like to think so because most of us are English majors and Linguistics, of course. I think we have had very good grammar training. These are not classes that people tend to take for fun [laughs], so we don't get too many people with that experience. Just the fact that we write all the time for ourselves academically gives a new breach of perspective for other people's writing and writing across the curriculum.

\section{5- Writing Center and Pedagogy}

Think about the pedagogical benefits of a Writing Center session to students in general. Read the statements below and complete them as you wish:

a. During a tutoring session, I help students mostly by... asking the questions about their writing.

b. During a tutoring session, my main roles are... moral support, definitely, and in a lot of ways grammar and organizational coach. We don't always know the content, especially some topics, like engineering, are way over my head, but every essay has its basic organization which an outside reader should be able to figure out. And, of course, grammar. That's part of what we specialize in.

c. When I tutor English Language Learners, some of the things I do are... I try to pinpoint repeated errors really quickly because people, for instance, who are English learners from Asian countries often have problems with article usage. You know, if you keep that in mind and then you look and see, you know, "oh, you are missing these articles." If you see the error a few times and keep an eye out for it to see if you catch it more. And I think it also makes it easier to teach it. So, just kind of look out for repeated errors and focus on those instead of look for a broad range of everything that we can deal with.

d. Students who come to the Writing Center benefit mostly because... because we offer real help with writing and encouragement. I've had so many tutees who say that either they are scared to talk to their professors because they are not good writers, or they don't like sharing their writing with other people because they are insecure about it. You know, everyone writes and has errors, no matter who you are, no matter how many books you sold, you will still need improvement on your writing because it is a process, so I think one of the most important things we do here as people who write and as people who put themselves out as professional writers is to say, "you are also a writer, and we like reading your work." 


\section{Tutor 4's Interview}

Tutor: In this case [session prior to the interview], the student did not have anything [a paper] to look at, he just wanted to look at handouts. He started coming to see me every week or two weeks. He didn't always have a paper to bring in. Sometime he would just be like, "Well, I just want to talk about this sentence, why is this the case in this sentence?" So, we would just get the book out and ask [names co-workers he goes to for help].

\section{1- Topics covered during session}

a. What issues did the student want to focus on during the session?

Passive voice and articles. We just went from the handouts. He actually brought up [the topic of] articles to the session. He brought the articles handout with him. But we had a meeting yesterday, and he wanted to know close to the end of the session [the day before], I was saying, "you can probably rephrase this sentence as he gets hungry," and he was like, "why is it gets and why is it no is?" So, he came in today [and said], "you know, I have a lot of problems with the 'to be' form. I feel like I am using it all the time, sometimes I feel like it is passive voice or whatever." So we kind of went and looked at the passive voice sheet and said, "Well, here's passive voice. So, it's not just cause you are using 'to be' you are in the passive voice. Here are the rules of passive voice." And he said, "yeah, it makes more sense." And then we just started talking about 'to be' and 'to have', sort of kind of these two really big complicated verbs and the way you sort of navigate the grammar of such a thing.

\section{b. Did you and the student cover these issues?}

Yes and no, because sometimes his issues are broad, like at one point he said, "how can I get better at not using the 'to be' form?", and I am kind of like, "you can get better at not using passive voice, but sometimes you have to use, like, he is hungry. Sometimes you just have to use it." Sometimes I just get frustrated with myself because some of those to be and to have... the rules behind them I am not like well versed enough in the pedagogy of teaching someone how to really, well, "here's the best way to get a handle on to be, here's the best way to get a handle on to have, here are the seven rules that you can just remember." So, to me, it becomes a bit frustrating. One thing I suggested him during the session was... because he will say, "sometimes in a paper I do this," but he won't have the paper in front of him, then we get stuck, and it takes a little while to craft an example in your head like, "so, is this what you mean, he is going to go to the store?, or he is tired after having left the store," or something, you know. I said, "you know, maybe if you are going to be doing writing over the break, and you come to sentences that you either are confused about or you feel like, this is weird, I don't feel like I am doing what I really want to do here." I said, "just cut and paste them, and put them into a document, and bring that document the next 
time you come and we can talk about specifically," like "oh, this sentence here... here's what you have going on: this is the passive voice..." But we don't know if he's going to do it. The nature of our sessions is quite different than other students'; I feel like 'if we get in a situation like this, I think I will be able to assist you more if we had some specific examples, so we are not spending two minutes every time you ask a question with me coming up with an example."

\section{d. Did you cover any additional issues? Which ones and why?}

We did. At one point we started talking about the French language because it is my foreign language, and I was just saying that the difference between have and be in French, like, we don't say "I am hungry," you would say, "I have hunger [says it in French]." [In French], you can't be hunger, and I was just kind of showing him how past tense verbs are conjugated. Sometimes it's either, "I have" and the past participle or "I am" and the past participle, and there's like fifteen verbs in the "to be" form that go along with the "to be" infinitive... that you use their past participle with "to be" instead of "to have." You know, there's fifteen weird French verbs that are like, you know [gives example in French]. So, we kind of talked about that a bit and just like... talked about how different the two verbs are and how difficult it can be to articulate when to use one and why.

\section{2- Writing assignment}

a. In your opinion, did the student understand his/her assignment? How could you tell?

$\mathrm{N} / \mathrm{A}$

b. Did the student's understanding of the topic change during the session? If so, in what way did it change? How did you know that there had been a change? Can you remember what happened that might have caused the change? I think with passive voice it did. With articles, I stressed with him to try and read the handout I gave him yesterday, and I don't think he had time because he didn't seem to have any questions that were different than yesterday's session when we talked about articles. But I feel like he is the kind of student who will come back, and there will be some stars on his handout, and he will say like, "I get everything up to here" [goes over topics in the handout]. He's done that in the past with other... I think it was the thesis statement handout we worked through last semester.

The passive voice, being that we were kind of using the handout as texts to go from, the passive voice is much more easily defined than how to use articles. I read the introduction to each thing, and it's like "the passive voice constitutes this." And you can look at a sentence [says a sentence from handout]. So, he could look at that and say, "Oh, I see why this is better. This is active and this is passive," whereas with articles you can think like you have a great understanding 
of articles, but then all of a sudden you are not saying, "the bags on the shelf," you are saying "bags on a shelf," you know, "bags on the shelf are blue." You know which bags are those? They are "the bags on the shelf." And he is not necessarily making that connection. For me, it's difficult because you try to articulate what is on the handout, but still there is a level of grayness to it that you can't just pick it up, whereas with passive voice you can say, "form of to be plus past participle of a verb, that's going to constitute the passive voice, you know $99.9 \%$ of the time." And that's something he can say. "Oh, that I know," but the article thing is still like [details of handout]. Sometimes being a native English speaker, it's just something that I can't tell you why I know it or how I know it [mentions two other examples]. They kind of look at you and ask "can you define it for me?" And you show them a handout, and even the handout has some...the definition is there, but it is not concrete enough that if you are an ESL student, and you've learned a certain way in your own native language, then you can just, "Oh, English is easy, that makes perfect sense!", because it doesn't.

\section{3- Tutoring session as apprenticeship}

a. Think about this writing session you have just had with (student) in terms of your coaching and his/her learning. What three words would you use to describe this interaction?

Engaging - because we were able to converse. He is not afraid to state a question he may have.

Fun - it's a fun session for me when the student is not just sitting there looking for answers, but they are challenging you as much as you are trying to answer their questions, but also challenge them to answer their own questions because you feel they might be able to do that.

Enlightening - it's interesting to me in sessions that challenge me like that, it sheds light on what I don't know and need to work on, and he is one the students I work with when that happens quite a lot. After the session I go like, "Man, I feel like I need to go out and understand the pedagogy behind how to teach something like 'to be' or 'to have'." I feel like that's good because it sheds light on your own weaknesses, and you see your strengths as a tutor, and you feel good about that, but you also try to see where you have your shortcomings. I feel like just because I was not able to fully explain the idea about articles, I should have done a little bit more.

\section{4- Socio-cultural roles of tutors/Writing Center}

a. Think about your role as a Writing Specialist as you read the following statements. Then state whether or not they apply to you and the session you just facilitated. When applicable, state what and/or why:

1. "I helped the student understand what the topic was about."

One of the topics, definitely. 
2. "I helped the student by encouraging her/him she/he can do better." In a way, I didn't necessarily say he could do better because there wasn't like a specific example that we had, but I think I maybe offered an idea for him to, instead of being confused when he is writing a paper, to take the sentence that confuses him and put it into a separate document and bring that separate document at a later date to the Writing Center or to someone who will be working with him as a specialist to try and, yes, on that front, I think I encouraged him.. That he could do more, could get more out of a session like this just because it's hard when you don't have a specific example in front of you. It's much easier to have a paper and say, "here's what you are doing here, do you understand why, because two sentences earlier you didn't specify, so now we are really lost." You have a text to sort of refer to, whereas when you don't, it can be a little more difficult to explain things or explain concepts.

\section{3. "I shared some of my own difficulties as a writer with the student."}

Yeah. I think so. I definitely shared some of my difficulties articulating the whys in the session. I think there was a time when I said, "Sometimes you want to write something the way that you do, but it just sounds better that way. I mean, you have to go back later on and say, I need to be a critical or myself and just..." I think I said to him, "sometimes I will just sit down and have an idea on my head and just try to write it out, and then you look at it twelve hours later and you are all in passive voice, or your verb tenses don't mix or whatever, and that's kind of like you have the ability to go back and rework it." Sometimes the ideas are coming so fast that you just want to get them out, but then that is also your responsibility to make sure that the "i's" and the "t's" are taken care of on a second reading.

4. "I gave the student useful information she/he can use for writing university assignments in general."

Yep. I think that just the information about the passive voice will help this student in particular because he does it often enough, and I don't know if he's ever had the handout from here. We've definitely never talked about the handout in a session before. To have somebody else be able to sit there and explain it and talk him through it a little bit will help him in future papers.

5. "The kind of help this student could get from this session is different from the help he/she can get elsewhere at the university."

Definitely. You are talking one on one versus in a classroom setting. I think that when you are in a class, people are less inclined to, you know, you don't want to feel stupid, you know, everybody else is getting this, and I don't want to be the one to raise my hand and be that person. In a one-on-one session, anything and everything can be a fair game because nobody is judging you. At least that wall has come down in a one-on-one tutoring session at the Writing Center. I 
definitely heard people say, "You know, I really didn't get it in class, I was having a hard time telling the teacher that. The prompt does not really make sense to me. Could you explain it to me?" Part of me thinks you [the student] should talk to the professor, but part of me understands the difficulties that happen when you feel like you are the only person who does not get it, and you don't want to feel stupid or be the outcast who does not understand. So, in an environment like this, you can definitely connect more on a personal level with the students and address problems in their writing because you have developed a comfort zone or you've kind of found each other's comfort zones.

\section{5- Writing Center and Pedagogy}

Think about the pedagogical benefits of a Writing Center session to students in general. Read the statements below and complete them as you wish:

a. During a tutoring session, I help students mostly by... trying to articulate the issues or problems that they are having with a positive spin. It's not like, "you don't get it," it's more like, "well, you are making the connection right here, but you are not making it down here, so let's talk about the differences between these two."

b. During a tutoring session, my main roles are... is to be someone to bounce ideas off of. Every session is different, but sometimes it's like, "here's my idea for a thesis statement, and this is what the paper's got to be about. Is this stupid? Does this sound stupid?" "No, that does not sound like a stupid thesis statement at all. You have something good there, but you just have to flush it out a little bit more. This can't be your thesis statement. You have to work on making your thesis better."

c. When I tutor English Language Learners, some of the things I do are... I try to use concrete examples. I try not to speak in abstractions or, like I said, I am big on concrete examples just because I feel like you can identify specifics about them a lot more than you can with high concepts.

d. In order to become better writers, English Language Learners need... to practice.

e. Students who come to the Writing Center benefit mostly because... you leave here thinking that you made some progress. I don't think I have ever had a session with a student who didn't leave and say...maybe they did not learn everything they wanted to learn, but they walked away with something that can help them in their writing in the future. If you come to the Writing Center and you have an open mind, and you have some questions, you are going to learn something. 


\section{Tutor 5's Interview}

\section{1- Topics covered during session}

a. What issues did the student want to focus on during the session?

She was mostly concerned with grammar and mechanics and that sort of thing.

b. Did you and the student cover these issues?

Yes. She had a pretty good understanding. Organization was not an issue.

c. What additional ones were covered? Why?

Not really. Of the bilingual students I tutor, she is the one who has a pretty good hold of her language skills. I feel like she had very good understanding.

\section{2- Writing assignment}

a. In your opinion, did the student understand his/her assignment? How could you tell?

She had her paper organized in a fashion such that she answered questions pretty directly. She knew what she had to do. She told me she seemed pretty confident about her content. She didn't want to focus on content, so we didn't. If anything did come up with her, I would address it.

b. Did the student's understanding of the assignment change during the session? If so, in what way did it change? How did you know that there had been a change? Can you remember what happened that might have caused the change?

$\mathrm{N} / \mathrm{A}$

\section{3- Tutoring session as apprenticeship}

a. Think about this writing session you have just had with (student) in terms of your coaching and his/her learning. What three words would you use to describe this interaction?

Engaged - she did ask questions. As we followed along, she was able to notice some of her own mistakes, so definitely it was a two-way interaction.

Interactive - because sometimes they [the students] don't talk. You know, sometimes they dont't say anything, they just sit back and watch you do what you do. But I feel like she was more engaged than some students. She was engaged, she was interactive.

Concentrated - I feel like she knew what she wanted to work on, and we worked on that.

\section{4- Socio-cultural roles of tutors/Writing Center}


a. Think about your role as a Writing Specialist as you read the following statements. Then state whether or not they apply to you and the session you just facilitated. When applicable, state what and/or why:

1. "I helped the student understand what the professor expected from him/her." No. Because she told me she didn't have a problem with it.

2. "I helped the student by encouraging her/him she/he can do better." Yes. I don't remember a specific moment, but in every session regardless of who the student is, I try to point out things that they did well also, and she had quite a few things that she did well.

3. "I shared some of my own difficulties as a writer with the student." I don't recall it. I try to because it shows them I don't think I am some great English master. But I don't recall if I did it or not.

4. "I gave the student useful information she/he can use for writing university assignments in general."

I think so. Since we were going over mostly grammar and mechanics, anyway, it was stuff that is going to be useful in any area of writing.

5. "The kind of help this student could get from this session is different from the help he/she can get elsewhere at the university."

I think so. I think it's more specific and tailored to her needs than just either an English class or... I think even if she had made a specific appointment with a teacher, I think she would have gotten more on content, which is not something she was having a problem with, anyway.

\section{5- Writing Center and Pedagogy}

Think about the pedagogical benefits of a Writing Center session to students in general. Read the statements below and complete them as you wish:

a. During a tutoring session, I help students mostly by... helping them with specific areas in which they need help.

b. During a tutoring session, my main roles are... to make sure the student leaves knowing more than they did when they came in.

c. When I tutor English Language Learners, some of the things I do are... try to point out that it's not just them, that all English Language Learners have a hard time. English is difficult, and I try to sort of universalize to show them that everyone has a hard time with it and to come to a level where they don't feel like I am condescending in any way...hopefully to make the process more comfortable. 
d. In order to become better writers, English Language Learners need... individual help. They need more help than even LLD classes give on an individual basis.

e. Students who come to the Writing Center benefit mostly because... we are able to work with them on their own terms. Because we can work with them specifically on issues that they have and other students may not have, and we can also work with them, as in my case with this tutee, I could work on areas where she felt she needed help with the most, but at the same time address problems that we notice as we go. 


\section{APPENDIX D: IRB APPROVAL LETTER}

\section{2 \\ SAN JOSÉ STATE UNIVERSITY \\ Division of Academic Affairs Associate Vice President Graduate Studies \& Research www.sjsu.edu/gradstudies \\ One Washington Square San José, California 95192-0025 Voice: $408-924-2427$ \\ wwwsisuedu}

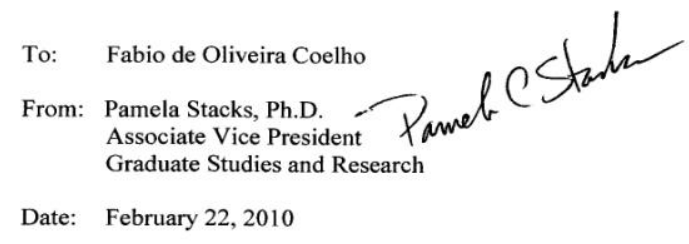

The Human Subjects-Institutional Review Board has approved your request to use human subjects in the study entitled:

"Academic writing development through dialogues between writing tutors and second-language learners"

This approval is contingent upon the subjects participating in your research project being appropriately protected from risk. This includes the protection of the confidentiality of the subjects' identity when they participate in your research project, and with regard to all data that may be collected from the subjects. The approval includes continued monitoring of your research by the Board to assure that the subjects are being adequately and properly protected from such risks. If at any time a subject becomes injured or complains of injury, you must notify Dr. Pamela Stacks, Ph.D. immediately. Injury includes but is not limited to bodily harm, psychological trauma, and release of potentially damaging personal information. This approval for the human subject's portion of your project is in effect for one year, and data collection beyond February 22, 2011 requires an extension request.

Please also be advised that all subjects need to be fully informed and aware that their participation in your research project is voluntary, and that he or she may withdraw from the project at any time. Further, a subject's participation, refusal to participate, or withdrawal will not affect any services that the subject is receiving or will receive at the institution in which the research is being conducted.

If you have any questions, please contact me at (408) 924-2427.

Protocol \#S1002046

cc. Rosemary Henze 0093 